Biomed.

$$
\begin{aligned}
& \mathrm{QH} \\
& 390
\end{aligned}
$$

$\mathrm{G} 223 \mathrm{~m}$

1921

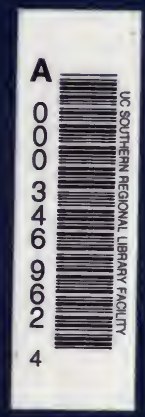

lifornia onal ity 


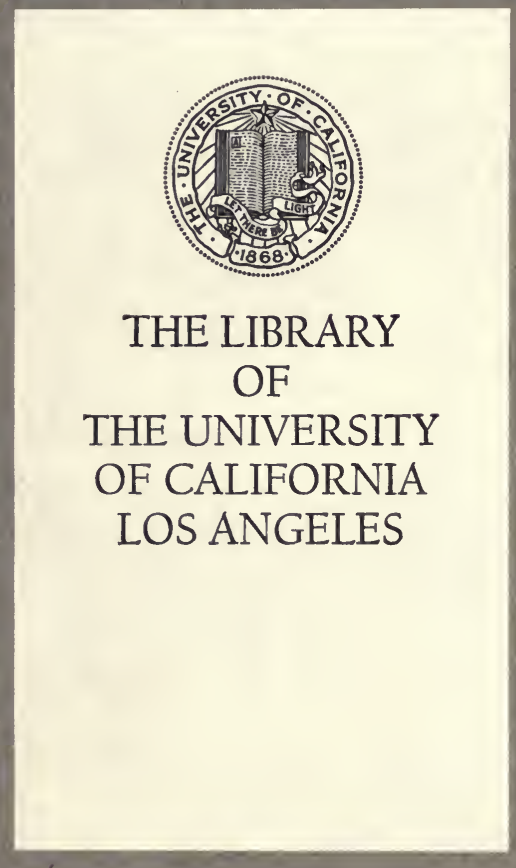




\section{MUTATIONS AND EVOLUTION}

BY

R. RUGGLES GATES.

Ph.D., F.L.S., Reader in Botany at the University of London, King's College.

Neiv Phytologist Reprint,

No. 12.

PRICE - SIX SHILLINGS. POSTAGE - 4D

WILLIAM WESLEY \& SON,

2K ESSEX STREET, STRAND IV.C.2, LONDON 1921. 



\section{MUTATIONS AND EVOLUTION}

BY

R. RUGGLES GATES.

New Phytologist Reprint,

No. I2

WILLIAM WESLEY \& SON,

28 ESSEX STREET, STRAND, W.C.2, LONDON

1921. 
c 
390

G223m

1921

MUTATIONS AND EVOLUTION.

225244 
ALL RIGHTS RESERVED. 


\section{CONTENTS.}

CHAPTER I.

Page.

$\begin{array}{llllllll}\text { INTRODUCTION... } & \ldots & \ldots & \ldots & \ldots & \ldots & 1\end{array}$

CHAPTER II.

Foundations of The Mutation Concept ... 6

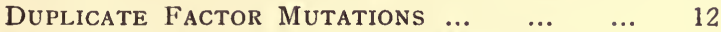

Recessive Mendelian Factor Mutations ... 15

Mutations Arising at or AFter Fertilization 17

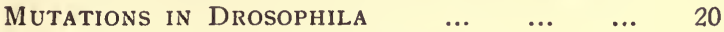

CHAPTER III.

Forms Having an Extra Chromosome $\quad . . .24$

CHAPTER IV.

Non-Disjunction in Drosophila $\quad \ldots \quad \ldots \quad \ldots \quad 35$

CHAPTER V.

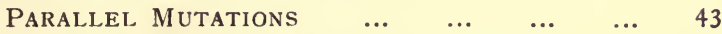

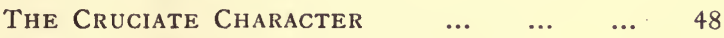

Parallel Mutations in Drosophila ... $\quad . . . \quad 52$

CHAP'TER VI.

Presumptive Mutations in Wild and Culti-

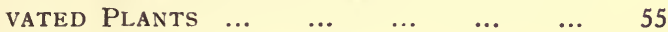

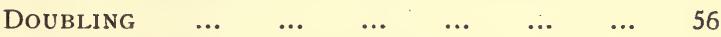

$\begin{array}{llllllll}\text { PELORIA } & \ldots & \ldots & \ldots & \ldots & \ldots & \ldots & 64\end{array}$

OTher Mutations in Wild and Cultivated

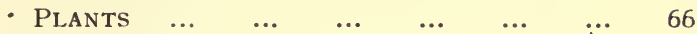

CHAPTER VII.

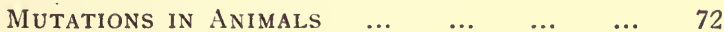

CHAPTER VIII.

Limitations of the Cell Theory $\quad \ldots \quad \ldots \quad \ldots \quad 76$

CHAPTER IX.

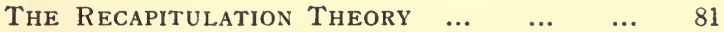

Recapitulation Phenomena in Gametophytes 83

RECAPITUlation IN THE SPOROPHYTE $\ldots . \quad \ldots \quad 86$

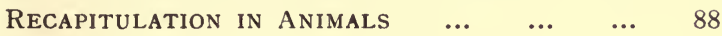

CHAPTER X.

INHERITANCE OF ACQUIRED CHARACTERS $\quad . .94$

CHAPTER XI.

GENERAL COMPARISON OF RECAPITULATORY AND

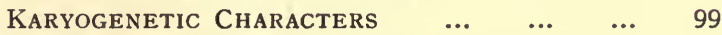

The Biogenetic LaW $\quad \ldots \quad$...

Relation to Geographic Distribution $\quad \ldots \quad 100$

The Neo-Lamarckian Principle $\quad \ldots \quad \ldots \quad 101$

CHAPTER XII.

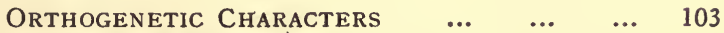

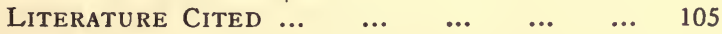

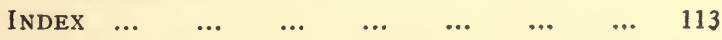


Reprinted from Тне New Pнутоlogist, Vol. XIX, 1920. 


\section{PREFACE.}

THE aim in producing these Chapters was to make them a contribution to current problems of genetics and evolution. The earlier Chapters deal with some of the more recent contributions to genetics, both in plants and ánimals, particularly as regards questions relating to mutation. This involved comparisons of the mutation phenomena in Enothera, Drosophila and various other forms. The importance and significance of parallel mutations has also been emphasized. Owing to circumstances for which the writer is in no way responsible it has been necessary largely to curtall the treatment and to omit almost entirely a discussion of the important cytological results concerning mutation in plants and animals which have been attained since my Mutation Factor in Evolution was published in 1915.

In Chapters VI and VII are cited from the recent literature numerous cases of mutations in plants and animals, and also a selection from the great number of presumptive mutations described as new varieties or species in the systematic journals. The history and geographic distribution of these is often of the greatest interest from the point of view of their probable origin, and the mutation theory has undoubtedly been of great value in interpreting such variations both in wild and cultivated forms.

In the last five Chapters more general evolutionary problems have been considered. Some of the corollaries of the mutation theory as regards organic structure, and some of its limitations, have been pointed out. In particular, the contrasts between mutational and organismal characters as regards the structure and distribution of organisms, their relation to recapitulation and such problems as those of adaptation, alternation of generations and inheritance of acquired characters, have been considered in so far as space permitted. The aim has been to show that despite the importance of mutations or germinal changes in evolution, they have definite limitations; and that large fields of organic phenomena will require the neo-Lamarckian factor for their adequate explanation. This is really applying the point of view of Darwin to the modern advances in our knowledge of variation and of the structure, ontogeny, inheritance, distribution, and relationships of organisms. 



\section{CHAPTER 1.}

\section{INTRODUCTION.}

THE adoption of experimental methods of evolutionary study 1 early in the present century was accompanied by sanguine hopes that a general and universally applicable method of evolution might thus be discovered. But two decades of intensive experimental work with plants and animals has led to a greater diversity of opinion concerning evolutionary factors than ever before. Wherever a particular species or group of forms has been intensively studied, the results have illuminated a particular field of inquiry concerning evolution. But other results, dealing with organisms having different bionomic relations, have answered other questions and at the same time propounded new series of problems. While there has therefore been a great accumulation of data concerning the variations of organisms, the inheritance of characters new and old, and the relations and reactions of these organisms to their varied environments; yet this has led to no unitary result which can be universally applied. These experiments have rather served to emphasize the manifold character of the evolutionary process.

Not only have various groups of organisms contributed their quota to this multifarious result, but different methods of experiment and different fields of observation have no less clearly tended to emphasize particular evolutionary factors. Individual bias has also of course played a part in the interpretation of many results.

Important and valuable as these experimental studies have been in opening a new era of evolutionary investigation, and leading to very definite conceptions concerning heredity and many aspects of variation and distribution, yet I believe they have been perhaps most generally useful in a direction which has not as yet been recognized. For their very variety, apart from interpretations put upon them, is sufficient to show that in the search for one allexplanatory evolutionary principle, man is following an ignis fatuus. Darwin recognized this even in his day, for while he laid chief stress upon natural selection, he also relied upon the Lamarckian factor, 
and to some extent on the direct effect of environment. But Darwin's followers at the end of the nineteenth century, having eliminated other factors, were endeavouring to show that natural selection was sufficient to account for all the then known phenomena of variation and adaptation. In the meantime palæontologists and anatomists, particularly the American School of Neo-Lamarckians, had kept alive the Lamarckian factor. Following that period, the striking discoveries in connection with mutations and Mendelian inheritance opened up a new outlook.

Darwin made no clear distinction between continuity and discontinuity in variation or inheritance, although his language sometimes clearly implies that he had observed one thing or the other. In some cases infinitesimal variations were apparently in his mind in writing, but when he refers to "individual differences" it is usually clear that he is citing what we should now call small or parvigrade (Poulton) mutations. In one aspect then, mutation as an evolutionary factor represents a refinement and an increased precision in the application off Darwin's theory of natural selection. That he recognized the occurrence of variations which were not necessarily subject to natural selection is clear from such passages as the following in the "Origin": "I am inclined to suspect that we see, at least in some of these polymorphic genera (such as Rubus, Rosa, Hieracium and fossil Brachiopods), variations which are of no service or disservice to the species, and which consequently have not been seized on and rendered definite by natural selection" (p. 33).

If we go but a step further, and assume that these variations are followed by others in the same population with elimination of some steps by selection; or if we assume the immediate origin of new specific types through single mutations, and their gradual spread from the centre of origin, then we are using the mutation theory of de Vries as it is widely applied at the present time. Darwin's objections to "sudden and considerable deviations of structure" as material for evolution, were based largely upon his observations of wide saltations and monstrosities. They included the well-known argument of swamping through crossing, which has since been negatived by the Mendelian discoveries.

It cannot then be said that the present Mendelian-mutationist attitude in its general aspects represents more than a refinement of Darwin's main thesis, based upon greatly increased knowledge of variation, inheritance, and cell structure; and a restriction of 
the incidence of natural selection. Nevertheless this increased precision is of vast importance, because it is based upon a multitude of actual breeding experiments and accurate observations.

But while mutationist conceptions have been coming in as a refinement of Darwinism, other elements of the problem have not been left without attention. Much has been written concerning isolation, the adaptation of geographic races, and orthogenesis; while even crossing has been raised by some to the importance of an evolutionary factor. While these pages are primarily a discussion of mutation as an evolutionary factor, an incidental consideration of some of the other factors will be necessary, in order to give mutation its proper setting in the picture.

As mentioned above it appears probable that the era of the vain search for a single evolutionary principle is now at an end. That end has been chiefly brought about by the experimental researches in genetics on the one hand and the work of animal palæontologists on the other. While palæobotanists have been actively accumulating valuable historical data, it does not appear that palæobotany has yet much direct evidence to offer concerning the causes or methods of evolution in plants. The reason for this probably lies in the greater difficulties of method involved in palæobotanical research. The animal palæontologist may be able to determine or identify an animal from the mere outline of a single bone or a few portions of the skeleton. The fossil botanist must rely largely upon sections of material which is so preserved as to show the details of histological structure.

All the known evolutionary factors have in turn had their advocates, who usually attempted to make their application universal. We have had the Lamarckian factor of use and disuse, natural selection, isolation, direct adaptation (" epharmosis"), orthogenesis, mutation, the unpacking of Mendelian factors, and crossing, as explanatory principles. Their failure in universality has been apparent enough in every case. On the other hand, many of these factors and perhaps all, may be reasonably claimed to have had some share in the evolutionary result. Each advocate may be expected to press his claim as far as possible, but there are obvious limiting factors with regard to every one of these principles the moment we begin to examine them; and it is only by limiting the field of vision or deliberately closing our eyes to other facts, that a belief in the universal application of any one of them can be retained. 
Any future evolutionary principle which aspires to universality must consist in a synthesis or integration of these factors, or such of them as can be proved to be sound in the fields of their application. The time for unlimited advocacy of single exclusive factors is past. Puture advance in the understanding of evolution must then consist in the determination of the limitations of each factor, and the weaving together of such elements as are sound, into a connected whole.

The recent attempt of Osborn (1918) to deal with organic evolution from the energy standpoint, while not as yet markedly successful, may perhaps represent a line of appruach through which a synthesis of evolutionary factors, may ultimately be reached: Whitman's (1919) elaborate studies of evolution in pigeons are grounded upon energy conceptions. The great accumulation of palæontological material which has taken place in recent years, gives vertebrate palæontologists a solid substratum of fact on which to construct hypotheses, which experimentalists can no longer afford to ignore. Gaps in mammalian phylogenies, for example, have been filled up to a remarkable extent, so that many of the older arguments drawn from the imperfection of the geological record are no longer applicable. The wonder is rather at the completeness, variety, and abundance of the skeletons preserved in deposits and unearthed by man.

A re-reading of the Origin of Species-an exercise which any biologist could profitably indulge in, at least once in every five years-serves on the one hand to emphasize the greatness of Darwin's vision, and on the other to encourage the present scientific man by showing the immense accumulation of accurate knowledge concerning organisms which has taken place since Darwin's time. The problem of to-day, just as it was in 1859 , is to bring all these facts to bear upon the explanation of the diversity of organic species. In connection with this task not one of the modern biological sciences can be safely ignored, and such physical sciences as astronomy, geo-morphology, physiography, chemistry and many aspects of physics must be pressed into service. Darwin dealt with variation in wild and domesticated animals and plants; heredity; the relations of organisms to each other and to their inorganic environment, hybridization and sterility; the geological record : geographical distribution; and embryology; in so far as the knowledge of his time permitted. In every one of these flelds, except perhaps the broader principles of plant distribution, the 
subsequent advances have been enormous. Many new sciences, such as cytology, bio-chemistry and ecology, have come into existence, and have made possible an insight into organic structure, constitution and relationship which was undreamed of even half a century ago.

Just as it is rash to attempt to interpret heredity and variation without a knowledge of the microscopic details of cell and nuclear structure or the physiology of hormones, chalones and enzymes; so it is equally unsafe to explain many questions of distribution without an intimate knowledge of the ecology and physiology of the organisms concerned. The burden of knowledge laid upon the modern evolutionist is thus so great that no one measures up to the possibilities, and it becomes necessary for the worker in one field to obtain second-hand his knowledge of the results in other fields. But it is none the less incumbent upon him to utilize these results intelligently if evolutionary science is to advance.

This is particularly true of such disciplines as the experimental study of heredity and the investigation of cell and nuclear structure, which had their historical origin in complete independence of each other and have since converged so closely that their results are mutually interwoven. Rarely in the history of science has such a remarkable convergence taken place. Modern genetics represents a synthesis of these two sciences into one. Many genera of plants and animals have now been attacked from both aspects, that of breeding experiments and that of cell structure, with mutually beneficial results; and it is too obvious to need pointing out that the present position of genetics, both in our knowledge of heredity and of variation, could not possibly have been attained without such combined studies. Enothera and Drosophila are conspicuous examples but there are many others in the recent literature. In future these two sciences cannot afford to stand alone, but must derive mutual support from each other. Interpretations of breeding results, especially those introducing new complications, which ignore or run counter to well known cytological facts, will have little chance of acceptance. Cytology in its turn will greatly benefit by more comparative studies of related races and species, such as are now being made in a number of plant and animal forms. In such way it is to be expected that a synthetic understanding of genetic phenomena from the combined structural and functional or physiological aspects may be attained. 


\section{CHAPIER 11.}

Foundations of the Mutation Concbpt.

In later chapters we shall deal with the occurrence of mutations in a wide range of wild plants and animals. The writer's book on mutation', dealt particularly with the mutations of Enothera and the conclusions to be drawn from them. A cell theory of mutations was formulated, based on the cytological and breeding work with Ginothera and incidently a wide range of other forms; and concepts were developed which proved applicable to many other plants and animals. This has involved certain departures from the theory of mutations as originally propounced by de Vries. Instead of the purely hypothetical and conceptual pangens, whose alterations were the putative cause of mutations, it has been possible to link up many of the changes in Enothera with visible structural changes in the chromatin of the cell.

Let us consider for a moment the simplest case of this kind. It is already well-known, but requires restatement because some writers have endeavoured to deny the significance of the facts. The lata mutation is now known to occur in $E$. lamarckiana, $\mathscr{E}$. biennis and $E$. suaveolens. The peculiarities are the same in every case-obtuse-tipped, deeply crinkled leaves, a somewhat weak or irregular habit of growth, stout rounded buds, almost completely sterile anthers, and 15 chromosomes in the nuclei. This constellation of characters is super-imposed on, or rather substituted for, the characters of the species in each case, and the same mutation has also been observed from some of the mutants of E. lamarckiana and also in various hybrids. Thus $\mathscr{E}$. biennis mut. lata has small flowers while $E$. lumarckiana mut. lata has large flowers, but the lata forms otherwise agree. $E$. lata rubricaly $x$, two of which occurred in the $\mathrm{F}_{2}$ of rubricaly $x \times$ grandiflora had lata peculiarities combined with the red pigmentation of rubricalyx. ${ }^{2}$ It is also significant that lata mutants sometimes occur in pairs.

Only one hypothesis based on observation has been suggested to account for the origin of lata with its $\mathbf{1 5}$ chromosomes. In 1908 occasional irregular reduction divisions in the pollen mother cells were observed in $E$. mut. rubrinervis whereby an 8-6 separation of chromosomes took place in the heterotypic mitosis. This would lead to the formation of two pollen grains with 8

- Gates, 1915. "Gates, 1914; Gates and Thomas, 1914. 
chromosomes and two with only 6. The same irregularity has since been seen in various other types. There can be no reasonable doubt that lata originates in this way, through the union of a germ cell having 8 with one having 7 chromosomes, unless we deny some of the best established facts in cytology. Stomps, however (1916), goes so far as to deny the probability of this hypothesis, although he does not venture to offer anything in its place. His denial is based on the fact that several mutant types are known to have $\mathbf{1 5}$ chromosomes. But, as has been pointed out, ${ }^{1}$ if the 7 gametophyte chromosomes are unlike, as is probable from many general cytological considerations, then $\mathbf{7}$ distinct types with $\mathbf{1 5}$ chromosomes are to be anticipated. Up to the present, no such number of forms having $\mathbf{1 5}$ chromosomes has been described from any strain of Enothera, nor have seven such forms been authenticated altogether, although there is no obvious reason why they should not ultimately be found.

The evidence, then, is clear and definite that lata originated through a chromosome entering the wrong nucleus in the reduction division. In this way two, pollen grains, or one megaspore will be produced, each having 8 chromosomes in its nucleus. The presence of the extra chromosome, as a duplicate of one, will no doubt immediately have its effect on the cytoplasm of the pollen grain or megaspore containing it. So that the mutation must quickly become a property of the cell as a whole, and, theoretically, at least, this will alter the character of the whole male or female gametophyte derived from a spore with $\mathbf{8}$ chromosomes, though the differences may not always be demonstrable by the microscope. Renner (1919) has shown that visible differences exist between the pollen grains and male gametophytes of various species, and that segregation of these characters takes place in the pollen of the $F_{1}$ hybrids. If an egg from a mutated megaspore has 8 chromosomes, it is already different both in nucleus and cytoplasm from an ordinary egg of the type, since the extra chromosome has been producing its effect thoughout all stages of the embryo-sac formation. Nevertheless, the only original change which it is necessary to assume, to account for the appearance of lata, is a chance irregularity in which both members of a pair of chromosomes enter the same nucleus in the reduction division. To endeavour to explain the origin of $E$. lata through an alteration in a hypothetical pangen when the visible facts of the chromosome structure are so clear, is to desert science for obscurantism.

Gates, 1915, p. 181. 
The same irregularity has been observed in animal spermatogenesis and found to produce individuals with one or more extra chromosomes, e.g., in Metapodius (Wilson 1909), where the $\mathrm{Y}$ chromosome may be represented as many as 6 times in the cells of certain individuals. The most striking case in animals is known as non-disjunction in Drosophila melanogaster, where it has been studied by Bridges (1916) in great detail. This consists in duplication of the $\mathrm{X}$ or $\mathrm{Y}$ chromosomes through both passing to one cell in spermatogenesis, and it leads to the production of individuals whose heredity behaviour, as in $E$. lata, is peculiar owing to the presence of these extra chromosomes. It also results in the formation of certain non-viable and sterile types. The whole situation, though very intricate, is perfectly clear, and the chromosome behaviour corresponds with that previously described in $G$. lata. Any sceptic cannot do better than study conscientiously this excellent paper of Bridges. No one who studies this subject with any attempt at an impartial frame of mind can fail to agree that the chromosome content of the various individuals determines the differences in their hereditary behaviour. Indeed, it is not too much to say that most of the arguments against a chromosome basis of heredity are based on sheer unfamiliarity with the enormous advances in this subject which have taken place in recent years.

It must not be inferred from the preceding remark that the whole mystery of heredity is believed to have been solved. Such a conclusion would he contrary to the history of every branch of science. It is recognized that no "explanation" is final, but that each discovery represents a further step in analysis, whether it be in the processes of inheritance or in the structure of an atom. The evidence for the independent identity of chromosomes is at the very least equal to that for the existence of electrons, emanations and other particles constituting the atom. Fortunately, physicists are not worried by the argument that until the exact nature of electrons and corpuscles is known it is unsafe to recognize their existence in formulating a hypothesis of atomic structure. But this is the type of argument with which the cytologist is frequently confronted, coming from biologists whose knowledge often does not extend to the chromosomes. The chromosomes are structural facts whose existence can no longer be ignored in any fundamental analysis or interpretation of the structure, development, inheritance or other properties of organisms. 
Just as the cell theory of organic structure has long since passed into the realm of fact, so in a sense has the chromosome theory of inheritance. We need mention only three of the most striking cases where a definite relationship has been established between a particular chromosome complex and a certain set of external characters. These are $(a)$ the sex chromosomes, now known to show dimorphism in a wide range of animals, and recently discovered in a liverwort (Allen 1919); (b) the aberrant chromosome conditions in the Enothera lata series of forms; and $(c)$ the non. disjunction phenomena in Drosophila. In all these cases, without obscuring the issues by introducing the concept of "causality," it is definitely known that a certain set of external features of the organism is associated with a certain structural complex of its nuclei, and this complex has been passed on by mitotic division from its inception in the fertilized egg. This is not hypothesis but fact. Enothera lata whenever it is examined (some $\mathbf{5 0}$ individuals have had their chromosomes counted) invariably shows the extra chromosome in its mitotic figures. The spermatocytes or the embryonic tissue of the males in various groups of insects show the characteristic male constellation of chromosomes, i.e., with an $\mathrm{X}$ or an $\mathrm{XY}$ group in addition to the autosomes, while the females show a corresponding $\mathrm{XX}$ group.

While we must therefore regard the "chromosome theory," like the cell theory, as an established fact up to a certain point, so, again like the cell theory, must we also regard it as subject to qualifications and limitations.

Since we are not here discussing the general arguments for a more minute and detailed relationship between the chromatin and the complex of inherited characters, this aspect of the subject may be left for the present, with the remark that in the three classes of cases cited a definite relationship which may be classed as hereditary has been clearly established between particular external features and particular chromosome complexes of the nuclei.

From the standpoint of the mutation concept, Enothera lata, while a critical case in demonstrating the occurrence of germinal changes, differs in several respects from the most frequent and widespread type of mutation, i.e., the type which results in a new Mendelian character. The latter type of change will be considered in greater detail in connection with the origin of dominant and recessive Mendelian characters, mass mutations and parallel 
mutations. The type of mutation involving an extra chromosome differs from this in the following points. (1) There are present three representatives of the extra chromosome instead of a pair. A Mendelian mutation, on the other hand, will first appear usually as a heterozygous individual if the new character is dominant, or as an individual homozygous for the new character if it is recessive : that is, a pair of chromosomes only will be involved, one or both of which carry the new factor. (2) As we shall see later, the presence of the extra chromosome determines, at least in large measure, the hereditary behaviour of the form possessing it. (3) Chromosome duplication, viewed as a germinal change, arises through, or at least in connection with, a rearrangement of the chromatic material, resulting from an irregular distribution or non-disjunction of a pair of chromosomes in the heterotype mitosis, while when a Mendelian character arises one must assume it is by alteration in one element of a chromosome.

Thus while the bearing of the extra chromosome in Enothera lata upon the mutation concept is clear in that, as we have already pointed out, there is a constant relation between the lata characters and the additional chromosome, yet the relation of this type to the numerous other forms now known to have 15 chromosomes is by no means so clear, and raises a number of intricate problems. These forms and the problems connected with them will be discussed later. For the moment we are concerned in pointing out some of the other bases of present concepts regarding mutations.

The gigas and semigigas series of forms, having respectively 28 and 21 chromosomes, again clearly justify the concept of a mutation as a cell change involving a new nuclear structure perpetuated by mitosis. This type of change is now known, through parallel mutations, in several species of Enothera: but tetraploidy exists in a wide range of wild species, and a doubling of the chromosome series is also known to occur under various experimental conditions which will be referred to later. The forms, such as lata and semigigas, with an unbalanced chromosome number, will seldom if ever breed true, and such forms can only occupy a somewhat temporary and aberrant place in evolutionary descent. But tetraploidy is a condition of evolutionary significance, as the cytological study of many genera and families already shows. It gave the first hints towards the construction of a phylogeny of the chromosomes, and ultimately it is quite certain that such a phylogeny must be constructed. 


\section{Foundations of the Mutation Concept.}

While the 15-chromosome mutants produce two types of gametes, and hence are at least dimorphic in their offspring when crossed back with the parent type, the tetraploid forms are also peculiar in their inheritance, giving triploid intermediate hybrids when crossed back with the parent (diploid) type. Such forms are for the most part unstable, and although they occur in nature (e.g. the well known natural hybrid between Drosera rotundifolia and D. longifolia) yet their instability and partial sterility prevent their giving rise to permanent intermediate links between the original diploid species and its tetraploid derivative. Meiotic irregularities in these hybrids may lead to the production of a series of plants with new chromosome numbers, as is well known in the Enotheras. But seldom will a stable form arise having a balanced chromosome equipment. With the exception of tetraploidy, therefore, none of the types of visible chromosome change so far demonstrated in the Oenotheras are likely to have played a very large rôle in any phylogeny. They are chiefly valuable as a means of furnishing a visible demonstration of the occurrence of germinal nuclear changes.

All the evidence indicates that the great mass of mutations originate as new Mendelian characters. Among such changes in the Enotheras are E.rubricalyx, a. dominant, and $E$. gigas nanella, which in crosses with its parent form gigas hehaves as a Mendelian recessive. We may consider these two forms as types of Mendelian mutants. On the basis of their inheritance as such, we must assume that they originate through an alteration in a particular locus of one chromosome, a view set forth elsewhere ${ }^{1}$ and now generally accepted. The history of $E$. rubricaly $x$ has been given in the work cited, ${ }^{2}$ but the salient points may be referred to here.

One plant in a large culture of $\sigma$. rubrinervis ${ }^{3}$ appeared with an extreme increase in anthocyanin pigment, this red being especially conspicuous on the sepals, flower stalk, stem, and the under surface of the leaves, although histological examination shows it to be present in increased quantity in all parts of the plant. The original individual was heterozygous, originating therefore through the union of a mutated with a non-mutated germ cell. The premutation must then be considered to consist in a change,

1 The Mutation Factor, p. 300.

2 'The Mutation Factor, p. 102.

I It now appears (Lutz 1917b) that the form which other investigators, at least MacDougal, Miss Lutz and myself, regarded as rubrinervis, differs from theAmsterdam rubrinervis, which is a less robust form. liurther study by de Vries has revealed several types closely related to rubrinervis, which will be referred to later. 
probably chemical, in a locus of one chromosome, and this change probably occurred during some stage of meiosis. : Farther than this the matter cannot be analysed at present. The altered chromosome, present in the nucleus of every cell through mitosis, increases the capacity of every cell for producing anthocyanin, as is shown for instance by comparing cells of the chalaza in the two forms.

Through an unfortunate accident, only a few offspring of the original novum survived. They were 9 rubricalyx, 1 rubrinervis, and 2 rosettes classed as "doubtful." The next generation gave three families, with ratios $10: 5,14: 6$ and $33: 11$ respectively, all clearly representing $3: 1$ families. This leaves no reasonable doubt that the original rubricalyx mutant was heterozygous for one factor for red. For by no possibility can any of the three ratios $10: 5,14: 6$ or $33: 11$ be considered to represent a $15: 1$ ratio, while their total, $57: 22$, is clearly close to the $3: 1$ expectation. Also the ratio in the previous generation (which may be taken as probably $11: 1$ ), from which these three families were derived by selfing certain individuals, while it might by itself conceivably represent a $15: 1$ family, cannot do so really. Because the chances are remote that, if the parent mutant were heterozygous for two factors. for red, three of its offspring taken at random as mother-plants of the next generation should all happen to be heterozygous for a single factor (therefore giving 3:1 ratios) and none of them homozygous or heterozygous for two factors. ${ }^{1}$ The evidence taken as a whole is therefore clear that rubricaly $x$ originated in one individual which was heterozygous for a single factor for red.

\section{Duplicate Factor Mutations.}

This fact is thus emphasized because later generations produced some families with 15:1 ratios, hence representing two factors for red, in addition to families with $3: 1 .^{2}$ Furthermore, certain $15: 1$ families came from members of families showing a $3: 1$ ratio. These must therefore have been due to secondary mutations. The evidence, part of which has been considered elsewhere, ${ }^{4}$ shows with a high degree of probability that, as we have seen, the original

I If the original mutant were heterozygous for two factors for red, it would give in its offspring 1 plant which bred true to red, to 8 yielding rubricalyx and rubvinervis in the ratio $15 \mathrm{R}: 1 \mathrm{r}$, to 6 yielding ratios $3 \mathrm{R}: 1 \mathrm{r}$, to 1 pure rubvinervis. It gave in fact three families all of which were $3: 1$.

Gates 1915b.

Some 5:1 ratios were also obtained, which are probably to be explained by linkage.

4 Gates 1915e. 
mutant was heterozygous for a single factor for red. Shull (1914a), unfortunately, from a study of hybrids between rubricalyx and $E$. grandiflora which he mistook for pure rubricalyx, drew erroneous conclusions regarding the origin and hehaviour of this striking form. Another important feature in its history, already mentioned, is the fact that members of a family of rubricalyx which contains a single factor for red, as shown by the $3: 1$ ratio, can give rise to individuals which are heterozygous for two factors for red. How this may come about has been discussed under the name duplicate mutation.'

That two or even three factors for the same character may exist in a given strain, was first shown by Nilsson-Ehle (1909) for wheat, and has since been demonstrated in a number of other forms. Nilsson-Ehle showed for example that while Extra Squarehead wheat has only one factor for red kernels, Sammet and Grenadier have three, and in a later paper (1911) that Swedish Binkel has two. A list of such duplicate determiners has been given by Shull (1914h). It includes glume colour, hairiness of glumes, length of glumes, width of leaves, etc., in oats, and various character's in beet, turnip, gourd, Hax, tobacco, bean, pea, velvet bean, wheat, and maize among plants; also hody weight in ducks, fecundity in fowls, skin colour in man, ear length and body size in rabbits, piebald coat colour in mice and the hooded pattern in rats. Of course some of these cases are much better substantiated than others, and the number of cases has since been considerably increased. The Howards (1912) have demonstrated one of the clearest instances of duplicate factors for red in wheat.

Nilsson-Ehle did not consider the origin of this condition of duplicate factors in wheat, but it appears probable that it has the same explanation as the duplicate condition of the factor for red in E. rubricalyx. There are, as previously pointed out, ${ }^{2}$ at least two ways in which such a result is likely to have come about. (1) Through a locus in a second chromosome having independently undergone the same change or mutation. (2) An individual which would normally be homozygous for one factor for red $\left(R R^{\prime}\right)$ might, by a mismating of the chromosome pairs in fertilization or after, become heterozygous for two factors for red $\left(R r R^{\prime} r^{\prime}\right)$. In this way an individual giving a 15:1 family of offspring could arise from a homozygous member of a $3: 1$ family. It is necessary to assume

Gates 1915b.

Gates 1915b. 
that such a regrouping of chromosomes took place at fertilization or soon after, so that the nuclei of the whole germ track ${ }^{1}$ would have the same chromosome grouping. The difficulty with this view, and it appears now to be a fatal one, is that it seems necessary to assume that the other chromosomes with which these two "red" chromosomes are mated will differ from them in other factors as well and will therefore introduce new differences in the offspring. Morgan has shown in Drosophila that eye-colours so closely alike as to be indistinguishable except by the expert, may arise in different chromosomes, as independent mutations. ${ }^{2}$ Hence it appears more probable that these factors for red in $E$. rubricalyx, which are as yet quite indistinguishable, may have arisen in the same way through successive parallel mutations in different chromosomes of the same race.

Shull (1914h), however, uses the second hypothesis, mismating of chromosomes, to account for the origin simultaneously of the duplicate condition for triangular capsule form in Capsella bursa. pastoris and the mutant $C$. Heegeri with round capsules. If, in the reduction division, the pair of chromosomes containing each a determiner for triangular capsule pass into the same daughter nucleus, this would produce an individual with duplicate factors for capsule form, while the other germ cell, lacking both these determiners, would later give rise to the mutant Heegeri. His modified suggestion that both these conditions, (1) duplicate factors for triangular capsule, (2) the origin of a mutant lacking both these factors and hence round, could come about through the detachment of the determiner for triangular capsule from the end of one chromosome and its attachment to the end of the next, seems more likely and more in accord with our present knowledge. The difficulty with it as a general explanation is that one cannot suppose that all duplicated factors have been conveniently located on the end of a chromosome, especially where a number have been described for the same organism, as is the case with wheat, maize and tobacco. The most likely hypothesis of the origin of most duplicate factors is then the independent origin of each through a chemical alteration of a locus in a different chromosome.

1 The term germ track, the English equivalent of the German Keimbahn, is used to represent the line of cells or cell divisions following each other from the fertilised egg to the pollen mother cells or the eggs. As de Vries pointed out (Intracellular Pangenesis), we may thus think of a pedigree of cells derived chiefly from apical cells and forming a connected system.

3 In the same way, the factor for red midribs described by Heribert Nilsson (1912) in a derivative of the Swedish race of $C E$. lamarckiana appears to
be differeut from that in the Amsterdam race. 
However, the recent breeding, experiments with Drosophila have disclosed cases (Bridges 1917) of duplication in which the genetic behaviour is as though a group of genes from the middle of one X-chromosome has become attached to the end of the other $\mathrm{X}$-chromosome in a female. Another exceptional case, discovered by Bridges and reported by Morgan (1919), is explained on the assumption that a piece from the second chromosome has become attached to the middle of the third chromosome. In the resulting race, when these chromosomes separate and recombine in reduction and fertilization, zygotes which receive the deficient second chromosome fail to develop unless they also receive the third chromosome with the additional (duplicate) piece. We are therefore at liberty to suppose that a redistribution of certain chromatin elements, rather than a fresh transformation of a new determiner has taken place in certain instances. But such cases will usually involve a group of factors simultaneously rather than a single one.

\section{Recessive Mendeliau Factor Mutations.}

If we turn now to Enothera gigas nanella as the type of a recessive Mendelian factor mutation, the manner of its origin seems clear from its hereditary hehaviour. De Viries (1915) has brought together the evidence concerning its behaviour. $C E$. gigas produces this dwarf in $1-2 \%$ of its offspring, i.e., as mutations. But certain individuals of gigas are known, from observations of Schouten, Gates and de Vries, to produce as many as $18 \%$ of dwarfs. Such individuals are evidently heterozygous, arising from the union of a normal gigas germ cell with one which has mutated so as to carry the dwarf factor instead of that for tallness. Theoretically they should give $25 \%$ of dwarf offspring but the number is reduced by their lesser viability. This phenomenon of producing in the offspring a large number of a new form has been called by Bartlett (1915) mass mutation. In such a case it is obvious that the original change or pre-mutation, an invisible change in a germ cell, must have occurred in a plant at least two generations earlier than that in which the mass mutation exhibits itself. The 1 or 2 per cent of mutants arising from other gigas plants are the result of the chance meeting of two germ cells both of which have mutated so as to carry the dwarf instead of the tall condition. This interpretation is clearly substantiated by the fact that $C E$. gigas nanella when crossed with E. gigas behaves as a simple Mendelian recessive. It has 28 chromosomes, like the parent form. 
Thus it would appear that many recessive Mendelian characters originate either as single individuals. from the union of two mutated germ cells, or with a frequency approaching $25 \%$ in the offspring of individuals which have in turn arisen as a heterozygous combination of a mutated and a non-mutated germ cell.

In races or species where self-fertilization is the rule, a viable recessive mutation is very likely to "come out" in two or three generations, but in many animals, including man, where a large amount of inter-crossing of strains takes place, recessive mutations may accumulate over a considerable period, and some of them may then come out as soon as in-breeding begins. Thus in the case of cross-breeding organisms, it is impossible to say, when a recessive Mendelian mutation appears, how long it may have been carried in the germ plasm in a heterozygous condition without getting a chance to express itself. The premutation may have taken place many generations earlier.

As one more case of a presumptive Mendelian mutation in Enothera we may consider $E$. brevistylis. Although it has never actually occurred as a mutation in controlled cultures, yet the fact that it was found by de Vries growing wild with $\sigma$. lamarckiana although it ripens practically no seeds, indicates that it must have been derived from lamarckiana, with which its pollen crosses freely. In this way it maintained itself for seventeen years. When seeds can be obtained it is shown to breed true, and the chromosomes number 14. De Vries (1913) found it to behave as a simple Mendelian recessive, and Davis (1918) confirms this from a more extensive series of crosses. He finds that the reciprocal crosses with lamarckiana are uniform and indistinguishable, the characters of lamarckiana being strongly dominant. But measurements show that in heterozygous individuals brevistylis has an influence in shortening the styles, slightly broadening the leaves and bracts, making the bud cones a little thicker and the sepal tips somewhat shorter. The resulting segregation in $\mathrm{F}_{2}$ is sharp and complete, but the percentage of brevistylis is usually below expectation in all crosses, owing to brevistylis zygotes being apparently less viable.

This is a very good example of a type which was able to survive for an indefinite period in competition with its parent form, because while producing practically no viable seeds it was perpetuated by occasional crosses of its pollen giving rise to heterozygous lamarckiana plants. 


\section{Mutations arising at or after Fertilization.}

De Vries assumes that all mutations take place in the formation of the germ cells, that is presumably at the time of the meiotic divisions, and there is a great deal of evidence that many germinal changes arise at this time. During this period the pairs of chromosomes are heing redistributed, and the intricate mancuvres of the chromatin material just previous to this separation of the chromosomes gives an opportunity for a variety of rearrangements and aberrant distributions of particular chromatin particles. That the hereditary behaviour known as crossing-over, by which part of the factors which were in the same chromosome cross over to its mate, has its basis in changes occurring at this time has been shown experimentally for Drosophila by Plough (1917), He found that by subjecting the females to high or low temperature the amount of crossing-over was increased. Further experiment showed that the critical period, during which crossing-over in the offspring was affected, was during the period of conjugation of the chromosomes in the maturation of the eggs. From this it follows that crossing-over takes place at that time and not earlier.

In the Enotheras it has been shown that many of the irregularities leading to new chromosome numbers arise during meiosis. The origin of mutations with an extra chromosome and the phenomena of non-disjunction in Drosophila, of the sexchromosomes (failure to separate in meiosis), are cases in point; also the origin of the supernumerary chromosomes in Metapodius (Wilson 1909), which arise through irregularities in chromosome distribution during spermatogenesis. In addition, there is evidence both in plants and animals that germ cells with a double number of chromosomes are occasionally produced, through an alteration in the meiotic phenomena. These matters will be discussed in connection with triploidy and tetraploidy. It will be found that the hypothesis of de Vries (1913) that triploid and tetraploid mutants arise only through the union of germ cells one or both of which is diploid is unnecessary, since both these conditions may arise in other ways.

The period of fertilization is an equally critical time in the life cycle of an organism, and the evidence indicates that a number of germinal readjustments or mutations date from this period. Both triploidy and tetraploidy may perhaps arise at this time or shortly after. It has already been pointed out ${ }^{2}$ that in crosses such as

1 The Mutation Factor, p. 222. 
E. nanella $\times$ lamarckiana and its reciprocal, where both parent types split out in the $F_{1}$ generation and hoth subsequently breed true, it is reasonable to conclude that some determining reaction occurs in the fertilized egg, in which one parental germ cell or the other gains the ascendancy. This was formerly explained by De Vries on the basis of pangens in different conditions. But since the important work of Muller (1918) on balanced lethal factors in Drosophila, it is evident that linkage to such lethal factors may explain this result, though more will need to be known concerning such lethal factors in Enothera before the explanation can be applied in detail. Differential sterility depending on whether the lethal factor is linked to (i.e., is in the same chromosome with) the factor for dwarfness or that for tallness, would seem to meet the case.

Concerning the origin of $C E$. lamarckiana mut. nanella, we may assume that it appears through the breaking of the linkage between the dwarfing factor and a lethal factor, for if it were a simple Mendelian recessive we should find occasionally a Lamarckiana plant which was heterozygous for dwarfness and gave $25 \%$ dwarf offspring. But such are never found in lamarckiana although, as we have already pointed out, they do occur in $E$. gigas. This suggests that gigas has lost some of the lethal factors present in Lamarckiana. As a mutant, nanella has a frequency of only $1-2 \%$, so that the cross-over between the dwarf and lethal factors must be an infrequent one. The discussion of lethal factors will be taken up again later.

That mutations in other forms may date their origin from fertilization has also been held, and Punnett (1919) has recently concluded that this is the time of origin of the well-known cretin mutation in the sweet pea. This mutation differs prominently from the type in having a straight stigma protruding through a cleft keel, and it is invariably sterile on the female side. It behaves in crosses with the parent as a simple Mendelian recessive, a total of 80 families in six years giving 4198 normals : 1322 cretins, which is not far removed from a $3: 1$ ratio, the viability of the cretin being evidently somewhat less than that of the normal form.

The cretin appeared in a cross between two white sweet peas, Blanche Burpee with long pollen and Emily Henderson with round pollen. From three purple $F_{1}$ plants large $F_{2}$ families were raised in 1905. From one of these $F_{2}$ families containing 187 plants, the seed of 29 individuals was saved for the $F_{3}$ generation, These 29 
families in 1906 resulted in 2083 plants, all normal. Seeds for the $\mathrm{P}_{4}$ generation were saved from 14 individuals of one of the $\mathrm{P}_{3}$ families numbering 181 plants. The $\mathrm{P}_{4}$ from these 14 plants gave 1118 plants, one of which was the cretin. This appeared in a family of 52 plants raised from the $\mathrm{F}_{3}$ plant $304^{6} / 1906$. Thirteen sister plants yielded no cretin in a progeny of over 1000, nor did one appear among the 2083 plants of the $\mathrm{F}_{3}$ generation. The $\mathrm{F}_{5}$ of 195 plants grown in 1912 from $9 \mathrm{P}_{4}$ plants, also failed to produce one, so it remains an isolated case.

Punnett points out that under these circumstances it is unlikely that the cretin originated from two germ cells, each of which had lost the normal factor, for in that case the parent plant would have been heterozygous, giving $25 \%$ cretins, and they would also have appeared in the $\mathrm{P}_{5}$ or in collateral families. Hence he concludes, in agreement with the argument above, that the cretin plant must have arisen through "some radical alteration in the zygote after union between two normal gametes had already taken place," and that it was " due to a change in the individual at some stage after fertilization whereby the factor for the normal flower was either dropped out or altered during the somatic divisions." Since the germ cells of this plant were uniform, it is reasonable to suppose that the change took place in the fertilized egg itself.

Morgan (1919), in discussing this case, suggests that the mutation occurred in one chromosome far enough back in the germ track of the parent individual to give rise to pollen and ovules (say in one flower) each carrying the mutated genes. But in that case other germ cells would have been carrying these genes, and these would surely have appeared later either in the heterozygous or homozygous condition.

As regards Drosophila, the great number of mutants it has produced apparently all belong to one type, and behave in the same way. They are nearly all classed as Mendelian dominants or recessives in inheritance, though in a few dominance is variable and subject to environmental influence. Morgan (1919), states that only 12 are dominant out of over 150 . These dominants have each appeared in a single individual. Mutants from recessive genes, on the other hand, usually came to light in about $25 \%$ of the offspring of a pair, showing that the pair were both heterozygous for the new factor, which must have arisen at least one generation earlier. Whether both members of a pair of chromosomes undergo the change simultaneously is unknown, since if it occurred in the egg 
one chromosome will be extruded into the polar body, and if in the spermatocyte the chances are small that more than one sperm from the same spermatocyte will function. Still, as far as it goes, the 12 single mutant individuals suggest that perhaps a single sperm and hence a single chromosome of a pair has the new factor. In the case of Enothera lata and semilata, which arise through an irregular heterotype division, evidence is available, for these mutants sometimes occur in pairs, suggesting that the change occurred in a pollen mother cell and that the two resulting 8-chromosome pollen grains both functioned.

\section{Mutations in Drosophila.}

The evidence for mutations in animals was rather scanty until Morgan took up the study of the fruit fly, Drosophila melanogaster, about 1910. The rapid breeding and easy handling of these flies in large numbers, makes it an ideal form for genetic experiments, and combined with this is the advantage that it has only four pairs of chromosomes. It is not, therefore, surprising that in the last decade, Morgan and his pupils have accumulated a mass of breeding data, closely analyzed and correlated, which is unequalled in any other organism. With plants growing only one seedgeneration a year, it would probably require 150 years to produce an equal number of generations.

The Drosophila work has therefore given us a look into the constitution of the germ plasm such as no annual-breeding plant or animal could furnish in a lifetime. The Mendelian behaviour, sex-linked inheritance, and other features are similar to those found in many other organisms, so there can be no doubt of the wide applicahility of the conceptions of mutations and the germ plasm derived from these experiments. In many respects they are in accord with those derived from the Enothera work. Although the simple Mendelian mutations in the latter are comparatively few, we have already seen that the behaviour of the others can probably be accounted for on the basis of sterility or lethal factors, explanations which now enter into many features of the CEnotheras. Again, the duplication of a chromosome in $E$. latn and other forms is paralleled by the phenomena of non-disjunction in Drosophila, although there are certain differences which will be pointed out. - But in Drosophila the rapidity in breeding large numbers in many generations has made it possible to carry the analysis of the germ plasm much further than in any plant. 
In the single species Drosophila melanogaster, the "vinegar fly," over 200 mutations have been observed. These include more than 25 factors for eye colour, and many more for body colour and form of wings, while many structural differences are also involved in other mutations. The majority of these have appeared but once. Some mutations are, however, more frequent. White eyes, a mutant from the wild red-eyed fly, are known to have occurred three times in the New York experiments (Morgan, 1919, p. 248) and several times in the cultures of other observers. Vermilion eye-colour has appeared at least six times, "rudimentary" wings five times, cut wing four times, truncate wing frequently but probably owing to different changes. As with the Einothera experiments then, certain mutations repeat themselves, but apparently with much less frequency. This suggests that in Einothera the mutation often appears much later than the germinal change (pre-mutation) which gave rise to it, being suppressed in many cases by lethal factors causing sterility.

A number of cases of probable reversion from the mutant character to the original wild type have occurred, but most of these are uncertain on account of the possibility of contamination. In the experiments of May (1917a) with bar-eye, however, this possibility is excluded. This character is dominant to normal (round) eye, and the reversal takes place with sufficient frequency to eliminate the possibility of error. Reverted individuals give only normal offspring. Bar-eye differs from the normal in having fewer facets, and the stock showed considerable variability. In an experiment in selecting for more or fewer facets, May obtained six full-eyed males and five females heterozygous for full-eye. They were indistinguishable from normal and were explained as simple reverse mutations. In a later paper (May 1917b), however, a more complex explanation of this reversal is favoured. It is assumed that the normal wild fly carries a limiting factor with respect to facet number, and that by "partial non-disjunction," the factor passes from one chromosome to another (presumably during meiosis) so that one chromosome is without a limiting factor while the other member of the pair has two. The egg retaining the latter chromosome would produce a bar-eyed individual. If in such a race a second non-disjunction occurs, separating the two factors, one chromosome would result having triple factors and one with a single factor. The latter would give a reversion to a full-eyed male or a heterozygous female. But it is doubtiul af such \& 
method of explanation by splitting up the factor could be applied to reversions in other factors which show no such variability as bar-eye.

A chemical reversal seems more likely to supply a general explanation of reverse mutations, and this is important in its bearing on the nature of a mutational change. For if a recessive mutant factor can revert to the wild condition, then the mutation was not due to an irrevocable loss of a particle, but rather to the transformation of a particle or locus of a chromosome, first in one direction and afterwards back to the original condition.

As regards the infrequency of simple Mendelian factor mutations in Enothera, it would appear that this is partly due to their presence being masked by the greater number of lethal factors. And since lethal factors must produce non-viable gametes or zygotes, i.e., sterility of pollen, ovules or seeds, this is in accord with the large amount of sterility in Enothera. For this reason, except in the case of mutations involving visible changes in the chromosomes, we can seldom be sure in Enothera that the germinal change in a locus of a chromosome which marks the origin of a mutation, did not happen several or many generations previously. It is this contingency with regard to various mutations that has made it possible to suggest that the phenomena are merely the result of the splitting out of factors acquired in some previous hypothetical cross. This argument has been used, notwithstanding the fact that mutations occur in such well-authenticated and selfpollinated species as $C$. biennis Linn.

It is an interesting "and significant fact that although Drosophila, like most animals, can only be perpetuated by a crossing of two individuals in every generation, while in such species as $E$. biennis natural crossing is a very rare event at best, yet the bogey of hybridization which is so often raised as a complete explanation of the mutations in Enothera, has never, so far as I am aware, been suggested for Drosophila. Probably the reason is that in Drosophila the evidence is clear that most of the mutations at any rate have had their beginning in the germ plasm at the time they make their external appearance. A great deal of ink would have been spared if it had been recognised that for plants as for animals, for Enothera as for. Drosophila, mutation is a process sui generis, a "spontaneous" disintegration or alteration of elements in the germ plasm which finds certain physical parallels or analogies in the behaviour of the atom of radium and other 
radio-active substances. To attempt to explain away mutations by assuming that nothing new has really appeared is tantamount to a denial of evolution. Zoologists are fortunate in being free from this bogey, and in being able to recognise that whatever effects crossing may sometimes have on germinal behaviour, mutations take place which have no direct reference to it.

Some of the more intricate details connected with the Drosophila experiments will be referred to later. We wish here merely to point out the way in which the plant and animal studies on mutation are reacting on each other for their mutual benefit. The clear-cut conception of lethal factors derived from Drosophila has been a great advantage in replacing the more indefinite conceptions of "sterility" in Enothera. Again, the duplication of a chromosome in Enothera is paralleled in several features by the non-disjunction of the sex-chromosomes which sometimes occurs in Drosophila. 


\section{CHAPTER 111.}

Forms Having an Extra Chromosome.

For a long time it was generally supposed that $E$. lata and forms showing similar characters were the only ones containing an extra chromosome. Fifteen chromosomes had been announced in certain other forms by Miss Lutz (1908), but without convincing evidence. Then a very different form, $E$. incurvata, having 15 chromosomes, was described from the Swedish lamarckiana, ${ }^{1}$ and Miss Lutz $(1916,1917)$ has more recently published her studies, which seem to show that the occurrence of mutations with an extra chromosome is much more frequent than was formerly supposed. Hance has als? (1918) found 15 chromosomes in the mutant scintillans. This raises problems with regard to the relationship between these forms.

It was natural to suggest that there might be seven distinct types in this series, ${ }^{2}$ with a different chromosome of the haploid series figuring in each case. The number of types apparently with 15 chromosomes is now considerably in excess of seven, but as will be observed from Table I, some of these appear to arise only from lata $\times$ lamarkiana. This is undoubtedly a significant fact.

Now if we call the haploid series of chromosomes in Enothera ABCDEFG and assume that $\mathrm{A}$ is the extra chromosome in lata, then its chromosome formula would be AAABBCCDDEEPFGG; and when the odd chromosome passes undivided to one pole in the reduction division without further irregularities, the gametes formed will be ABCDEFG and AABCDEFG. That is, there are three members of the $A$ chromosome, two of which enter one gamete and one the other. It seems clear that such 15-chromosome forms as semilata Gates, exilis, exundans and Miss Lutz's type $\mathbf{5 3 6 5}$ are derived through a secondary modification from lata. The evidence is strong that semilata Gates at any rate arises only from lata $\times$ lamarckiana. It appears very probable, on account of its characters intermediate between those of lata and lumarckiana. and also from its origin only from lata, that the extra chromosome is the same in both.

In order to have a different chromosome hecome the extra one in the sense in which it appears to be in lata, by selfing this mutant (See Table 1), we must suppose that a gamete, which is, say,

The Mutation Factor, p. 147.

Gates and Thomas, 1914. 
TABLe I.

Mutations in Enothera with an extra chromosome.

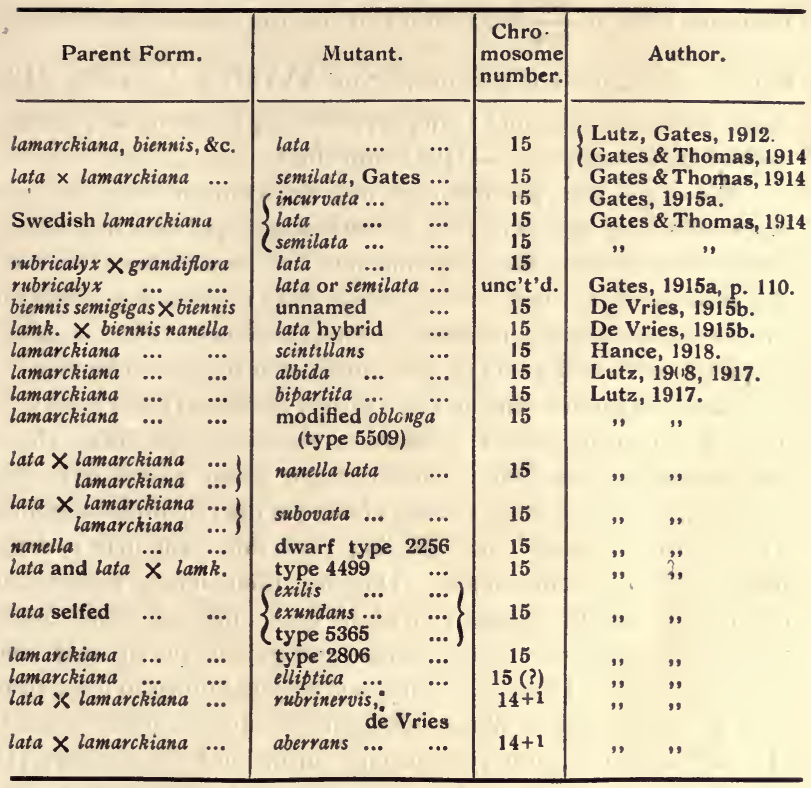

ABBCDEFG, fertilizes one which is ABCDEFG. Such gametes could arise from an $\frac{\mathrm{AA}}{\mathrm{ABB}}$ meiotic separation in lata in the first case, and an $\frac{A B}{A A B}$ separation in the second case, the $A B B$ and $A B$ groups (disregarding the other chromosomes) then uniting in fertilisation to form a nucleus with $2 \mathrm{~A}$ 's and an extra $\mathrm{B}$, although derived from a plant in which there were two B's and three A's. The chances of this happening are small, especially when we remember that lata produces practically no functional pollen grains, and that these nearly all have $\mathbf{7}$ chromosomes. Nevertheless it is not impossible.

In lata $\times$ lamarckiana the chances of getting a mutant with a new extra chromosome are greater than in lata selfed, for we may suppose (1) that a 7-egg, i.e., ABCDEFG, is fertilised by a sperm having two members of some other pair than $A$, the latter condition having arisen through an irregular separation involving the non- 
disjunction of that pair in meiosis, i.e., $\mathrm{AB} q+\mathrm{ABB} \delta$, or (2) that an $\mathrm{AAB}$ egg (i.e., having 8 chromosomes) is fertilised by a $\mathrm{BB}$ sperm resulting from a $\frac{B B}{A A}$ segregation in meiosis in lamarckiana or (3) that the segregation in the megaspore $A A A B B$ is $\frac{A B B}{A A}$, the $A B B$ megaspore surviving and being fertilized by a sperm $A B$, i.e., the normal type, to give an $\mathrm{AABBB}$ individual.

While it is thus possible for a new extra chromosome to arise in the offspring of lata or lata $\times$ lamarckiana, yet the chances are considerably greater that the same one will remain the extra one. The probability of such forms as exilis and exundans depending on the same extra chromosome as lata, depends partly on their frequency in the offspring of lata, which is at present unknown.

Returning now to the lata-like forms, de Vries (1909) described a form which he called semilata, and this arose three times independently from lata. One of them when selfed gave 358 offspring, of which 3 were nanella, 4 lata, and the remainder semilata. There is some reason ${ }^{1}$ for believing that this form may perhaps have had 16 chromosomes. On the other hand, the writer described what afterwards proved to be a different form ${ }^{2}$ under the name semilata. This stands midway between lata and lanarckiana, has $\mathbf{1 5}$ chromosomes and is only known to arise from lata $\times$ lamarckiana. When selfed this semilata gives semilata (15 chromosomes), lata (15 chromosomes) and lamarckiana (14 chromosomes). ${ }^{3}$ The relation between these two 15-chromosome types is therefore a close one, and the differences between them can hardly be due to the presence of a different extra chromosome. It is conceivable, for example, that semilata might arise from a lata egg luaving 7 chromosomes + a lanarckiana male cell with 8, derived through a fresh irregular division. But this explanation would appear to apply better to other 15-chromosome mutants. Semilata appears rather like a somewhat modified lata, and the fact that, as shown elsewhere ${ }^{3}$ it exhibits a series of stages running on the one hand towards lamarckiana and on the other towards lata, supports this view. We may therefore suppose it originates from an 8.egg + a 7-sperm.

Another important fact in this connection is that $G$. scintillans, another mutant from Lamarckiana, in now known (Hance 1918) to

'See Gates, 1915a, p. III, footnote.

I.c., p. 112.

- Gates and Thomas, 1914, p. 532. 
have 15 chromosomes. De Vries showed (1909, Vol. 1, p. 244) that this form also behaves in a peculiar way in inheritance, usually giving rise to an average of about $57 \%$ Lamarckiana, $32 \%$ scintillans $9 \%$ oblonga and $1 \%$ lata. In one family as much as $69 \%$ scintillans was obtained. It is significant that several of the original scintillans mutants were from lata pollinated by Lamarckiana. From these results it would appear that scintillans originates from the union of two germ cells, one carrying 8 chromosomes and the other (or perhaps the same one) carrying the oblonga qualities. On the other hand, it is not impossible, though very unlikely, that the oblonga type to which it gives rise, has 16 chromosomes, as Miss Lutz (1917) suggests. Also, while lata had a mutation frequency in de Vries' cultures of $0.413 \%$, the frequency of scintillans was only $0.038 \%$.

As predicted in $1915,{ }^{1}$ the cytological study of scintillans, resulting in the determination of an extra chromosome in its nuclei, throws much light on its origin and behaviour. It seems reasonable to interpret scintillans as arising from a germ cell with an extra chromosome + one bearing the oblong $a$ characters, just as we picture lata arising from a germ cell with an extra chromosome + one having the typical Lamarckiana characters. This will depend, however, on the chromosome counts in the various oblonga types, which are at present uncertain. That the offspring of scintillans were always found to include $1 \%$ or more lata, shows a close relationship between these two types, and indicates, though it does not prove, that the extra chromosome may be the same one in both cases. Another alternative is that any chromosome, if present in duplicate in a germ cell owing to non-disjunction in the reduction division, will give the lata features if combined with a Lamarckiana germ cell or scintillans if combined with an oblonga germ cell. This is improbable for many reasons.

In regard to the relation between these forms, lata, semilata, and scintillans, we thus appeared at one time to be left with only two alternatives, either that the extra chromosome is the same in every case, as the breeding data suggest, ${ }^{2}$ or that any of the 7 haploid chromosomes when duplicated will give the same morphological result. The latter alternative is highly improbable for general cytological reasons. However, the frequency of lata is apparently greater in the offspring of scintillans than of Lamarc. kiana, and it is conceivable that the unbalanced condition of scintillans may lead to more frequent chromosome irregularities.

The Mutation Factor, p. 142.

2 It seems highly probable that in lata and semilata at least, the extra chromosome is the same. 
The Swedish race of $E$. lamarckiana also yielded not only lata and semilata but also another form, having 15 chromosomes, called incurvata. ${ }^{1}$ One of the latter when selfed yielded 5 incurvata and one like lamarckiana. In this case there is more probability that a different chromosome was involved as the extra one, since no latas appeared in the offspring of incurvatn. But there is no certainty owing to the small numbers involved, an unfortunate result of the great amount of sterility in all these forms.

Other forms having $\mathbf{1 5}$ chromosomes will be considered in the discussion of parallel mutations, but it may here be pointed out that a race of $E$. biennis produces a lata mutation which is an exact parallel to the lata from lamarckiana, and which has 15 chromosomes. In the biennis from the Holland sand dunes, known to have been naturalized there since the time of Linnaeus, Stomps (1914) obtained a semigigas mutant. When pollinated by de Vries (1915b) with pollen from pure $E$. biennis without the flowers being castrated, it produced 19 offspring,-one dwarf, 10 biennis with 14 chromosomes and 8 of a new unuamed type having 15 chromosomes. The latter shows no resemblance to lata, but from the description it appears to have several characters in common with incurvata. It strongly supports the evidence from incurvata that independent 15-chromosome types exist. Regarding its origin in 8 individuals from a cross, one must suppose that the reduction divisions in the megaspores of $E$. biennis semigigas produced embryo-sacs, about half of which contained eight chromosomes in their nuclei and half seven cliromosomes, the remainder having been extruded or lost through irregularities in division. That such extrusion was not a haphazard and irregular phenomenon, however, is indicated by the fact that these 8 individuals all belonged to one type.

Another lata-like mutant was obtained by de Vries (1915b, p. 186) from $\sigma$. lamarckiana $\times \mathscr{E}$. biennis nanella. It had in addition to the marks of lata the characters of the ordinary hybrid type $\mathcal{E}$. lanarckiana $\times$ biennis, and confirms the conclusions of the writer regarding the origin of $E$. lata rubricaly $x$ and other lata-like forms in hybrids.

Finally we may consider the important studies of Miss Lutz $(1916,1917)$ on forins with an extra chromosome. It is to be hoped that her counts of chromosomes, which appear hitherto to have been made almost entirely from root-tips and other somatic tissues

1 The Mutation Factor, p. 147.

2 Gates and Thomas 1914.

- Gates, 1914, p. 265. 
may be supplemented and confirmed by studies of the germ-cells. For, while her counts are probably correct, yet the phenomena of fragmentation of chromosomes in somatic cells make it highly desirable that they should all be checked by observations on the chromosomes during meiosis. She has determined the chromosome number in 234 plants, including sixteen different mutant types, 11 of which types had 15 chromosomes, three had 16, and two were triploid. That $E$. mut. albida has 15 chromosomes has been verified by counting the number in thirteen more plants. As will be seen from Table $I$, she finds an extra chromosome also in a new mutant called bipartita, in subovata, elliptica (?) and " type 2806," all from lamarckiana. In addition, a second dwarf type, unlike nanella lata, is found, lata as well as lata $\times$ lamarckiana give "type 4499 " with 15 chromosomes, while lata self-pollinated produces exilis, exundans and "type 5365." None of these latter forms are described, so it is impossible to judge of their claims to separate status, but it seems clear that the three forms appearing in the offspring of lata selfed are secondary in origin, i.e., bear some special relation to lata. All that can be said about these forms at present is that there appear to be at least seven distinct types which might arise through duplication of different chromosomes, and that in addition a number of these types appear to be more closely related to lata. This is certainly the case with semilata Gates, and probably to a different degree or in a different way with several others. This may be connected with other differential factors, but it is useless to speculate about the matter until the facts themselves are clearer. Mut. oblonga apparently has some forms with 15 chromosomes and some with 14. The same is true of rubrinervis. In this case the true rubrinervis of de Vries, a rather weak form, has 14 chromosomes plus a small one. The form which other investigators have called rubrinervis, derived from seeds of de Vries, is taller and more robust and certainly has 14 chromosomes. It is the form of my early cytological studies (Gates 1908), the form from which rubricalyx originated (Gates 1911), and may be called rubrinervis Gates for identiflcation. It is more like the subrobusta of de Vries, which is derived from rubrinervis $x$ lamarckiana, and may perhaps be identical with that form or with the closely related erythrina (de Vries, 1919) to be discussed later.

Miss Lutz concludes that a very large percentage of the mutant offspring of $E$. lamarckiana have 15 chromosomes, there being both a larger number of distinct types and a higher percentage of mutant individuals with the extra chromosome. One would feel safer 
about this conclusion if control counts of chromosomes had been made in the germ cells.

At least two of these reputed 15-chromosome forms, rubrinervis de Vries and albida, "breed true." Miss Lutz points out that this can only take place (1) by apogamy, of which there is practically no evidence, or (2) when two gametes having different chromosome numbers only (one odd and one even) unite to produce viable seeds. Moreover, it is possible as regards rubrinervis that this individual derived from lata $\times$ lamarckiana and having a small extra chromosome (Table l) may differ in some respects as yet unobserved from other rubrinervis mutants derived from lamarckiana direct and possibly not having the extra fragment. More critical study of albida may lead to a similar result.

A number of other mutants recently described, such as cana, pallescens, lactuca, and liquida from $\mathscr{E}$. lamarckiana (De Vries 1916b), which split in their offspring and are closely related to each other in several features, may contain an extra chromosome. The same may be true of $C E$. stenomeres mut. lasiopetala (Bartlett 1915c). These forms will be considered later.

One of the most interesting results obtained by Miss Lutz (1916), is the existence of two types with a small extra chromosome-a fragment. In rubrinervis (one plant) 125 mitotic figures showed the small chromosome, and in 52 of them all the chromosomes, $14^{+1}$, could be counted. The small chromosome is constantly larger than in the new type aberrans, of which there were two individuals. In one plant 30 figures and in the other 8 figures all showed $14^{+1}$ chromosomes.

In a former paper (Gates and Thomas, 1914) it was shown that a variety of irregularities occur in the meiotic divisions in pollen formation of $O E$. lata, semilata and other forms which are more or less sterile in pollen. This included cases of fragmentation or pulling apart of chromosomes, particularly the odd one, on the heterotypic spindle. It might be expected that such fragments would occasionally be included in the daughter nuclei, and if they afterwards persisted they might be perpetuated by the mitotic mechanism. This is apparently what has happened in rubrinervis de Vries and aberrans, and it is significant that these three individuals all appeared in the offspring of lata $\times$ lamarckiana. The writer does not agree with Hance (1918) that they probably represent merely a temporary fragmentation of certain somatic chromosomes. Obviously if new forms can arise having gained a 
small chromosome fragment, others may have lost a fragment; and this renders probable another type of germinal change, in which the redistribution of fragments of chromatin may take place. It was formerly pointed out (Gates and Thomas 1914) that all these "irregularities" will become the basis of germinal changes if they are perpetuated by mitosis. Some of the differences between 15 chromosome types may yet be explained on this basis.

This brings us to another subject closely connected with the extra chromosome, but which concerns also the question of chromosome constancy in Enothera. Hance (1918), in the paper already referred to, has studied variations in the number of somatic chromosomes in CE. scintillans. The writer ${ }^{1}$ first pointed out such variations in the somatic cells of $E$. lata, the number ranging from 12 to 20 or 21 . Hance finds that the number of separate bodies in metaphase ranges from 15 to 21 , the higher numbers being produced by transverse segmentation of certain of the chromosomes. This matter is of minor importance and will be referred to later. A fact of more interest is that more or less constant differences are found between the lengths of the different chromosome pairs in the group of 15 . The pairs of chromosomes form a graded series, each somatic pair differing in length from the next longer by about $9 \%$. This conclusion is based on careful measurements of enlarged drawings of the metaphase chromosome group in 114 somatic cells from different individuals, selected on account of their special clearness and flatness. Of these cells 51 or $45 \%$ contained 15 chromosomes, and in each case the sum of the lengths of all the chromosomes was approximately the same, showing that increase in number was due to transverse fragmentation. This demonstration of constant differences in the length of the somatic chromosomes is an important advance in our knowledge of Enothera chromosomes. While differences in size have been previously observed, they have been assumed to be due merely to fluctuation, not being great enough to demonstrate except by comparison of measurements from many cells.

Hance assumes that the odd or extra chromosome in E. scintillans is the shortest of the 15 . It might equally well be the longest so far as his data show. His only direct evidence is the difference in total length of the chromosomes in the two telophase groups of 7 and 8 chromosomes respectively in the heterotypic mitosis of the pollen mother cells. This difference is

3. Gates 1912b. 
2.6 un its, but since the chromosomes of the germ cells are shorter and stouter than in the somatic cells this difference cannot be directly compared with the length of the odd chromosome. Hance also concludes that there is no evidence of pairing of the somatic chromosomes. In this we cannot agree, as we believe that in other Enothera forms the pairing, though weak, is sufficiently indicated in certain cases so that the extra or unpaired chromosome may sometimes be directly determined by this method (see Gates and Thomas 1914, pl. 35, Figs. 5, 6, 7, 10, 11, 15). Again, we have not found that accurate drawings of the chromosomes will show them to be of uniform width with even margin throughout, as Hance's flgures would indicate, although the departure from uniformity in width is not. as a rule, great.

Coming now to the question of chromosome number in somatic tissues, it would seem at first impossible to reconcile the apparently contradictory results of Hance and Miss Lutz. A critical study has been made of the process of chromosome fragmentation in somatic tissues, although only incidental references to this work have been published. ${ }^{1}$ We believe Hance has over estimated the significance of these somatic segmentations. We observed numerous " clear areas" and constricted portions of chromosomes, but the segments were almost invariably in alignment, showing clearly which belonged to the same chromosome. Moreover, delicate linin connections are usually visible connecting the two segments. Miss Lutz (1916) has made similar observations. Constrictions or incomplete segmentations have also been studied in Vicia Faba by Fraser and Snell (1911) and Sakamura (1915). In nearly all such cases it is clear which portions make up a given chromosome, and so it is much more sound to treat them as a whole chromosome than to attempt to rearrange these "fragments" on a hypothetical basis from measurements. Formerly we observed no segmentation of chromusomes in prophase nuclei, but more recently the writer has ohserved several cases of fragmentation in prophase. Nevertheless, we are inclined to look upon the phenomenon as a temporary one, related only to the mitotic cycle, and the segmentations in the prophase of one mitosis as probably bearing no relation to those of the next to follow. The name "extra" or "supernumerary" chromosomes applied by Hance to these segments is not a suitable one, for the actual number of whole chromosomes can be determined without difficulty by observation, as Hance himself has done in $E$. scintillans

- Gates and Thomas 1914. 
The determinations of chromosome numbers from root tips by Miss Lutz are therefore probably correct, although it is certainly desirable that they should be confirmed by study of the germ cells Although Hance regards the diminutive extra chromosomes of Miss Lutz in $E$. rubrinervis De Vries and $E$. mut. aberrans as mere temporary fragments, yet the evidence seems to indicate that they are permanent products of a fragmented meiotic chromosome dividing by mitosis, and therefore present in every nucleus. Their conștant difference in size in the two forms also supports this view.

Summing up the results regarding 15-chromosome forms of CEnothera, we may conclude that while several of the types have probably arisen from lamarckiana through having different chromosomes as the extra one, yet several others, which have appeared only in the offspring of lata $\times$ lamarckiana or of lata selfed, evidently have a closer relationship to lata than to any other form, and semilata Gates at least probably has the same extra chromosome. The differences between the other forms may be accounted for partly by the presence of other factors or mutant characters in addition to the extra chromosome, and partly by fresh rearrangements of the $\mathbf{1 5}$ chromosomes.

The same irregular meiotic division, or non-disjunction of a pair of chromosomes, also takes place no doubt in other forms, and may be expected to lead to the appearance of occasional aberrant members in other species. Winge (1917) apparently found such a case in Staphylea pinnata, which has 12 pairs of chromosomes, but one haploid group with 13 was found in pollen formation. Also in Cornus glabrata, anaphase groups of 11 and 12 were observed. Nawaschin (1911) found in the meiotic divisions, in the pollen mother cells of Tradescantia virginica that one pair of chromosomes in the heterotype division is left near the equator, where it forms a vacuole which later becomes included in one of the daughter cells. He finds it dividing later, so that two cells of a tetrad usually receive 11 chromosomes and two $11+$ this body, which is called a chromatin nucleolus or heterochromosome. But the brief account leaves many points undetermined. In the pollen formation of Callitriche verna, Winge (1917) has described somewhat similar conditions. 'J"he diploid number of chromosomes is 16 , and in the heterotype division 7 pairs are usually distributed regularly, while the other two frequently pass to positions in line with the equatorial plate but far from the spindle, where they form nuclei. 
When cell walls are formed later a hexad of pollen grains is fiequently produced, four large ones containing seven chromosomes and two small containing one or two chromosomes each. It is doubtful if any of these pollen grains are functional-regular meiosis takes place occasionally - but it is interesting that a pollen grain with only one chromosome, though diminutive, can still form its exine covering in an apparently normal manner. And such irregularities always make it possible that an extra chromosome may find its way into one of the daughter nuclei, as in the origin of E. lata. 


\section{CHAPTER IV.}

\section{Non-Disjunction in Drosophila.}

Analogous to the irregular distribution of meiotic chromosomes, which gives rise to such mutants as Enothera lata and E. scintillans, is the phenomenon in Drosophila which Bridges (1916) has called non-disjunction. To make this matter clear it must be remembered that Drosophila melanogaster has four pairs of chromosomes of different sizes, including a pair of sex chromosomes $\mathrm{XX}$ in the female and an unequal pair $\mathrm{XY}$ in the male. These pairs separate like the others in meiosis, so that half the sperms have an $\mathrm{X}$ chromosome and half a $\mathrm{Y}$, while all the eggs after maturation have an $X$. Furthermore, we need to know that the $Y$ chromosome, as in other insects, is inactive, carrying no known factors and taking no active part in sex-determination. A large number of sex-linked characters are now known, including many eye colours, and as these characters are distributed in crosses exactly as the $\mathrm{X}$ chromosomes are distributed-each daughter receiving one $\mathrm{X}$ from her father and one from her mother while each son receives his single $\mathrm{X}$ from his mother-we must suppose that sex-linked characters are determined by the presence of the $\mathrm{X}$ chromosome and that, in short, the determiners for such character-differences are borne by the $\mathrm{X}$ chromosomes. Moreover, the phenomena of "crossing over" or separation of two sex-linked characters which went into the cross from the same parent, i.e., carried by the same $\mathrm{X}$ chromosome, determine the relative position of such determiners in the chromosome, on the assumption that the farther apart they are along its length the more frequently crossing over (from the wrapping of the chromosomes around each other and subsequently breaking apart in new positions) will take place. On the basis of the percentages of crossing over, chromosome maps have been constructed for all four chromosomes, in which are indicated the relative positions of the various genes or determiners along their length. It will be understood that crossing over occurs between the members of a pair of chromosomes, but not between one pair and another. The amount of breeding work involved in thus determining that all the mutations fall into four linkage groups, and the relative positions of the members of each group with reference 
to each other, has been prodigious and is an achievement in itself. The data for sex-linked characters alone involved the breeding of over half a million tlies.

Chromosome No. 1, the X, (see Morgan et al. 1915), contains all sex-linked mutations, since this is the sex chromosome. Such factors already number over $\mathbf{5 0}$, including a series of eye colours, bar eye with a reduction in the number of facets, yellow and sable body colours, forked bristles, club, miniature and rudimentary wings, and several lethal factors which prevent development when present in the homozygous condition. Chromosome No. 2 is the longest pair and contains such mutation factors as purple eye, curved and vestigial wings, and black body. No. 3 , the next longest, as shown by linkage percentages, contains such eye colour's as pink and peach, rough eye due to a peculiarity of the facets, ebony, sooty and sepia body colours, and beaded wings. The fourth group of factors, more recently discovered, and transmitted independently of the others in the Mendelian sense, contains only two known factors, bent wings and the eyeless condition. It evidently corresponds with the fourth, very small, pair of chromosomes.

It has long been known that crossing over, which may occur between the various members of each group, is confined to the female. The amount of crossing over is also independent of the way in which the factors enter an individual in a cross. Thus if they enter from the same parent (i.e., in the same chromosome) any two factors tend to cross over with a certain frequency, while if they enter from different parents they tend with equal frequency to cross over so that both will be in the same chromosome in the offspring. In the male of Drosophila there is no crossing over between the $\mathrm{X}$ and $\mathrm{Y}$ or between any other pairs of chromosomes.

The probable reason for this has only recently been discovered (see Doncaster 1920, p. 235) by Metz. It apparently depends upon the fact that while in the egg there is a stage during maturation when the long, thin chromosomes are twisted round each other, there is no such stage in the male during the period preceding the separation of the chromosome pairs, the chromosomes remaining in a fairly condensed state during the whole growth period of these nuclei. Once again cytology furnishes a basis for the peculiarities in the phenomena of inheritance observed. In some other organisms (moths and fowls) crossing over takes place only in the male and not in the female, while in Primula, grasshoppers and rats it takes place in both sexes. That crossing over involves a break in the chromosome at a definite point, and not an indiscriminate 
exchange of genes between a pair of chromosomes, is shown by the fact that when a number of factors are involved whose position at intervals along the chromosome is known from the crossing over. percentages, a group of them go over en blcc and the rest remain in the chromosome (i.e., group) where they were before. Thus (Morgan et al. 1915, p. 66) if a hybrid female is made up, having received from her mother the mutant factors yellow, white, abnormal, bifid, vermilion, miniature, sable, rudimentary, and forked, and from her father the normal allelomorphs of these together with the dominant mutant factor for bar eye, her formula may be written as follows: \begin{tabular}{lll}
$\mathrm{y} \mathrm{w} \mathrm{a} \mathrm{bi}$ & $\mathrm{vm} \mathrm{m} \quad \mathrm{f} \mathrm{b}^{\prime}$ \\
\hline $\mathrm{YWAB}_{i}$ & $\mathrm{VMS}$ & $\mathrm{RFB}^{\prime}$
\end{tabular} these factors all being present in the two $\mathrm{X}$ chromosomes. When such females were bred, they were found to produce the following kinds of eggs, with the frequency indicated:

Non-crossover eggs.

\begin{tabular}{|c|c|c|}
\hline $\begin{array}{l}y w a b i \\
\text { YWABi }\end{array}$ & $\begin{array}{l}\mathrm{v} \mathrm{ms} \\
\text { VMS }\end{array}$ & $\begin{array}{l}\mathrm{r} \mathrm{f} \mathrm{b}^{\prime}-6 \\
\mathrm{RFB^{ \prime } - 8}\end{array}$ \\
\hline \multicolumn{3}{|c|}{ Single-crossover eggs. } \\
\hline$Y W a b_{i}$ & $\mathrm{v} \mathbf{m ~ s}$ & $r f b^{\prime}-2$ \\
\hline YWAB & $\mathrm{v} \mathrm{m} \mathrm{s}$ & $r f b^{\prime}-2$ \\
\hline$y w a b_{i}$ & VMS & $\mathrm{RFB}^{\prime}-2$ \\
\hline YWAB $_{i}$ & $\mathrm{Vms}$ & $\mathrm{r} f \mathrm{~b}^{\prime}-1$ \\
\hline YWABi & VMS & $\mathbf{r} \mathbf{f} \mathbf{b}^{\prime}-1$ \\
\hline$y w a b_{i}$ & $\mathrm{v} \mathrm{m} \mathrm{s}$ & $\mathrm{RFB}^{\prime}-1$ \\
\hline
\end{tabular}

y w a bi VMS $\mathrm{RFb}^{\prime}-1$

But such types as $y \mathrm{WaB}_{\mathbf{i}} \mathrm{VmS} \mathrm{rfB}^{\prime}$ were not found, showing that indiscriminate reassortment of the factors between a pair of chromosomes does not occur.

Double crossing over, in which the ends of a pair of chromosomes exchange while the central portion remains as before, lessens the effect of single crossovers and so is called interference. The result is as though the percentage of crossing over between certain points was reduced.

Now if a female with vermilion eyes is crossed with a wild red-eyed male, the vermilion being recessive the daughters will have red eyes like their father because they received his $\mathrm{X}$ chromosome with the red factor which is dominant to vermilion. But the sons will have vermilion eyes like their mother, since they received her $\mathrm{X}$ chromosome and only the inactive $\mathrm{Y}$ from the father. This criss-cross inheritance will always happen when the 
father bears a dominant sex-linked character. About 50 such sex-linked mutations are now known in Drosophila.

But occasional exceptions occur, in which a female produces a daughter like herself or a son like the father. These primary exceptions by an ordinary XX female were found to be the result of an egg in maturation either retaining both $\mathrm{X}$ chromosomes or allowing both to pass out into the polar body. Such an egg will be $\mathrm{XX}$ or zero as regards its sex chromosomes. If such eggs are fertilized by ordinary sperm from a red-eyed male, the result will be as

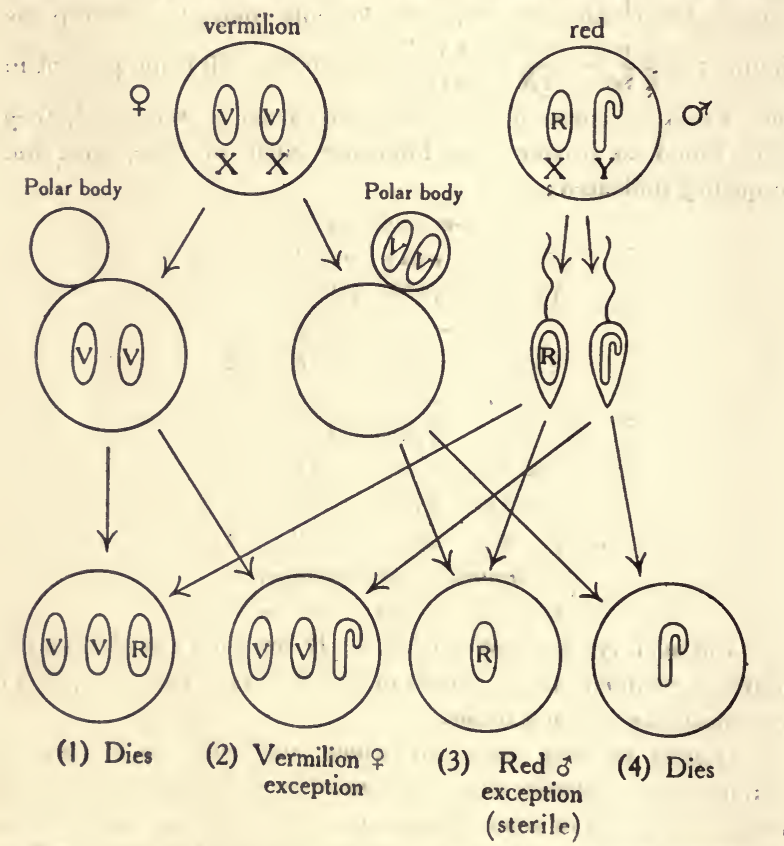

Fig. 1. Diagram of primary non-disjunction. Modified after Bridges.

shown in the diagram (Fig. 1). Four new types will result: (1) The XX egg $+\mathrm{X}$ sperm $=\mathrm{XXX}$ females which die. (2) The $\mathrm{XX}$ egg $+\mathrm{Y}$ sperm $=\mathrm{XXY}$ female having vermilion eyes and hence an exception to the criss-cross rule. (3) The $O$ egg $+X$ sperm $=\mathrm{XO}$ male which is sterile. It has red-eyes and is apatroclinous exception to the criss-cross rule. (4) The 0 egg $+\mathrm{Y}$ sperm $=\mathrm{OY}$ zygote which is not viable. Hence only: 
half of the primary exceptions survive. The XXY females are fertile and can be used for further breeding.

Non-disjunction also occurs in the male, giving $X Y$ and $O$ sperm. The XY sperm would produce XXY daughters, like the XXY females above but with red eyes. They are therefore not exceptions, but will give exceptions in their offspring. Wilson (1909) observed three spermatocytes of Metapodius, another insect, in which $X$ and $Y$ went to the same pole in the reduction division. The XXY females give about $4 \%$ of secondary exceptions (i.e., $4 \%$ of daughters like the mother and $4 \%$ of sons like the father) when crossed with a male having other sex-linked characters. This was

$\begin{array}{lllll}\text { Eggs } & X X & X Y & X & Y\end{array}$

Sperms. $X \quad Y$

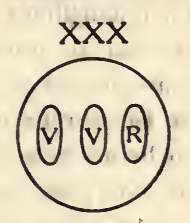

(1) $q$ dies

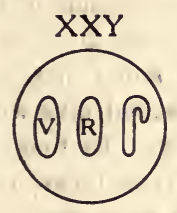

(2) $\%$ red

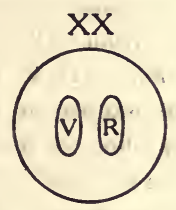

(3) 9 red

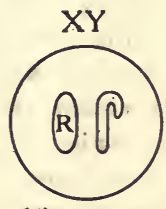

(4) ot red exception
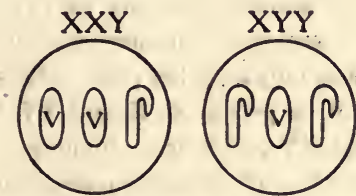

(5) + vermilion (6) of vermilion exception

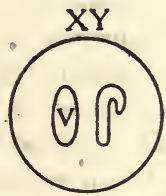

(7) ठิ vermilion

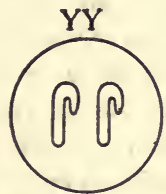

(8) dies

Fig. 2. Offspring of XXY females.

at first supposed to be due to a factor for non-disjunction. The exceptions were afterwards found to be due to the presence of the Y. After further breeding experiments it was predicted that eytological examination of the daughters of an exceptional female would show the presence of an extra chromosome in half the daughters while the other half would be normal. This prediction was completely verified.

Let us consider now what will happen in XXY females. Synapsis may take place between the two $X$ chromosomes, leaving the $\mathrm{Y}$ unmated (homosynapsis), or it may be of the XY type (heterosynapsis). About $84 \%$ of the cases were found by breeding 
to be homosynaptic. After heterosynapsis the reductions will be $\mathrm{XX}-\mathrm{Y}$ or $\mathrm{X}-\mathrm{XY}$. From the former the eggs after maturation will be $\frac{1}{2} X X$ and $\frac{1}{2} Y$; from the latter, $\frac{1}{2} X$ and $X Y$. Also from homosynapsis, the reductions will be $\mathrm{X}-\mathrm{XY}$ or $\mathrm{XY}-\mathrm{X}$, since the unmated $Y$ may remain in the egg or enter a polar hody, and the eggs will therefore be $\frac{1}{2} \mathrm{X}$ and $\frac{1}{2} \mathrm{XY}$. Hence 4 classes eggs result : $X X$ and $Y 4 \%$ each, of single origin; $X$ and $X Y 46 \%$ each, of cumposite origin. Therefore if such an $\mathrm{XXY}$ female having vermilion eyes is crossed by a wild male (red eyes), there will be 8 classes of zygotes, as shown in the diagram (Fig. 2).

Of these eight classes, (2) are not exceptions but would produce exceptions in the next generation, (4) are produced by the reverse of the ordinary method, i.e., by the union of a Y egg and an $\mathrm{X}$ sperm. While themselves exceptions, they are ordinary males and can neither produce exceptions nor transmit the power of doing so, (6) are not exceptions, but some of their daughters will get the extra $\mathrm{Y}$ (from $\mathrm{XY}$ sperm $+\mathrm{X}$ egg) and so produce secondary exceptions. It was found that homosynapsis occurs much oftener than heterosynapsis, but otherwise the chromosome distribution is according to chance. That matroclinous exceptions had developed from fertilised eggs was shown by the presence of paternal characters derived from other chromosomes.

In XYY males, synapsis may be of the XY or YY types. If these are simply by chance there should obviously be twice as many XY as $\mathrm{XY}$ synapses. The synapsed chromosomes disjoin and the other one apparently goes equally to either pole. Hence in $X Y Y$ males 4 classes of sperm will be produced, $X$ and $Y Y$ from heterosynapsis (small classes) and $X Y$ and $Y$ from homosynapsis (twice as large and from two sources). These four classes of sperm fertilizing an ordinary female would give the following results :

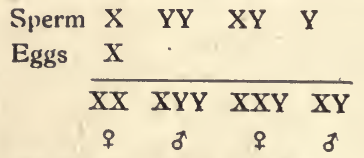

Part the daughters will therefore be $\mathrm{XX}$ and part $\mathrm{XXY}$, while some of the sons will be $X Y$ and some $X Y Y$, again producing exceptions. Primary non-disjunction in the female, or failure of the sex chromosomes to separate in the egg, occurred 12 times in breeding experiments involving 20484 flies, or 1 in 1700 . The fact that $\mathrm{XO}$ males are sterile shows that the $\mathrm{X}$ chromosome has some function in spermatogenesis, if only to serve as a balance wheel. 
In the cytological examination one female was found with 10 chromosomes, i.e., XXYY. She was from a stock culture in which half the females should be XXY and about half the males $X Y Y$. Nearly half the eggs of such females are XY, and one-third of the sperm of an XYY male are XY. Hence XXYY females should frequently occur in this stock.

The relations of non-disjunction to crossing over are still more intricate and surprising in their results. In XXY females, in

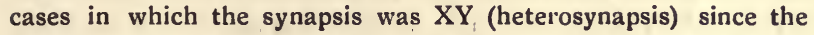
$\mathrm{X}$ chromosome was in synapsis with $\mathrm{Y}$, there could be no crossing over with $\mathrm{X}$. The $\mathrm{XX}$ eggs should therefore always be noncrossovers, and this was shown to be true. Linkage experiments show that there is about $33 \%$ of crossing over between eosin and vermilion, i.e., if they entered the cross in separate $\mathrm{X}$ chromosomes one-third of the eggs would carry neither factor or both in their single X. But when an XXY female carried eosin in one of her $\mathrm{X}$ chromosomes and vermilion in the other, the exceptional daughters were always like their mother in that they still carried eosin in one $X$ and vermilion in the other. On the other hand, in the XY and $\mathrm{X}$ eggs from an XXY female, crossing over took place in the ordinary way.

Such XXY females have been obtained from three sources, (1) $\mathrm{XX}$ egg $+\mathrm{Y}$ sperm, (2) XY egg $+\mathrm{X}$ sperm, (3) X egg $+\mathrm{XY}$ sperm. In all cases the frequency of secondary exceptions is the same, which means that the method of synapsis is the same whether the two chromosomes came from the same or from different parents.

One must agree with Bridges that these results, which are only summarized here, furnish a definite proof of the chromosome theory of heredity. Exceptions which seemed at first to be unconformable to any possible chromosome theory of heredity have turned out to be a brilliant confirmation of the whole position. In no other case have breeding and cytological work been combined with more convincing results. The correctness of the point of view involved has been independently demonstrated, first by breeding experiments and then by cytological observation.

There are certain interesting and significant differences between the results of duplication of a chromosome in plants and animals. As we have seen, individuals containing an extra $Y$ chromosome in the nuclei, or even an extra $X$ as well (XXYY), show no external peculiarity and are only distinguishable by the 
differences they show in hereditary behaviour owing to the different factors they carry, or by actually counting their chromosomes. The same is true of Metapodius (Wilson, 1909), in which some individuals were found having as many as six supernumerary chromosomes owing to irregular distributions of the $\mathrm{Y}$ chromosome in the reduction division, yet they were apparently indistinguishable from others with the normal equipment of chromosomes. This is in contrast to the conditions in plants, where, as shown in Chapter III, the extra chromosome is constantly associated with new external characters. Whether this is a general difference between plants and animals is unknown, but it may result from the fact that the cell unit in plants is a more rigid thing and less subject to regulation (in the physiological sense) from the structural point of view.

In Drosophila then, the detection of the presence of an extra chromosome is only by means of the factors transmitted; or by direct observation of the chromosomes. In Enothera there is also a difference in the hereditary behaviour, nearly all the 15 . chromosome forms splitting at least into the two parental types. But in addition the external characters are directly affected. Although the breeding results with plants are necessarily much slower, yet it is hoped that the nature of the chromosomal differences between the various 15-chromosome types will ultimately be determined.

It has been necessary to dwell upon these results in Drosophila at some length, for although an animal it is obvious that the results concerning linkage, crossing over, lethal factors and the conceptions of the linear arrangement of factors in the chromosomes will fundamentally affect our conceptions regarding the basis of heredity and the constitution of the germplasm in plants as well. Indeed, this has already been the case. Once it is generally recognized that in the morphology and constitution of the chromatin lies the chief hasis for the inheritance of differences, then we shall be on safe ground for future experimental progress. 


\section{CHAPTER V.}

\section{Palzal.i.li. Mutations.}

For many years $C$ E. lamarckiana was the only Enothera known to exhibit mutations. Then mutations were discovered in a race of $C E$. biennis, one of which showed all the peculiarities of lata, but had the small flowers and other specific features of bicnnis. From this form the conception of parallel mutations and the recognition of their significance originated (see Gates, 1912a). Shortly afterwards Stomps (1912a) described independently the mutants nanella and semigigas from hybrids between $E$. biennis and $\mathcal{E}$. biennis leptomeres Bartl. ( $=\mathscr{E}$. biennis cruciatn de V.) but apparently without recognizing the significance of their parallelism to forms derived from lamarckiana. $E$. biennis mut. lata was later ${ }^{1}$ described in detail and shown to have 15 chromosomes. It was clear that the same kind of germinal change was involved in both species. Two other probable mutations in $E$. biennis, one a red-nerved form parallel to rubrinervis Gates, the other resembling lavifolia, were also obtained. On these results the conception of parallel mutations was founded, and it has since been generally adopted by mutationists (see Stomps 1914, de Vries 1915b).

Equally striking mutations have now been obtained from several species of Enothera, including such wild species as $E$. grandiflora, $E$. stenomeres and $E$. pratincola. In the last two species, some of the mutations are parallel to those described in E. lamarckiana or $E$. biennis, others are entirely dissimilar. A number of cases of clearly parallel mutations are put together in Table II, but a great many cannot readily be arranged in a table, and these will be discussed separately. From the table it will appear that three species have produced lata mutations (with 15 chromosomes), while five have produced mut. gigas (28 chromosomes) or mut. semigigas (21), and the same five species have given rise to dwarfs. These mutations have also occurred in various crosses. Virescence has also appeared independently in three species of CEnothera.

Let us now consider the history of some of these mutations, especially in $C$. biennis Linn., $C E$. stenomeres Bartl. and $C E$. pratincola Bartl., all of which have small flowers, are self-pollinated and rarely undergo natural crossing. The writer $(1912,1914)$

\footnotetext{
- Gates \& Thomas 1914.
} 
obtained mut. lata from an $Q E$. biennis race, also a red-nerved (rubrinervis type and a lavifolia. Stomps (1912a), in the cross $E$. biennis $\times \mathscr{E}$. biennis leptomeres Bartl. (leptomeres $=E$. biennis cruciata de Vries) observed one dwarf mutant (biennis nanella) and one semigigas (with 21 chromosomes). The biennis parent was descended from a rosette collected by Stomps on the sand dunes near Wykaan-Zee in 1905, which gave a uniform race. The biennis leptomeres was derived from a plant originally collected in 1900 by Ernst de Vries near Santpoort, Holland, and from which a constant strain was obtained. In 1903, one dwarf ( $E$. biennis leptomeres nanella) arose in about 600 of the tall cruciate variety. The original leptomeres plant, when found in 1900 , was surrounded by a number of normal biennis, and evidently had arisen as a mutation.

TABLE II.

Parallel Mutations in CEnothera.

\begin{tabular}{|c|c|c|c|c|c|c|c|c|c|c|}
\hline \multirow[b]{2}{*}{ Species } & \multirow[b]{2}{*}{ క్ } & \multirow[b]{2}{*}{ 芯 } & \multirow{2}{*}{ 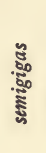 } & \multicolumn{3}{|c|}{ Dwarfs } & \multirow{2}{*}{ 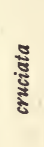 } & \multirow{2}{*}{ : } & \multirow{2}{*}{ 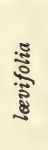 } & \multirow{2}{*}{ 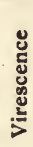 } \\
\hline & & & & 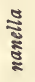 & 芯 & 离 & & & & \\
\hline $\begin{array}{l}\text { E. lamarckiana Ser. } \\
\text { E. biennis Linn, } \\
\text { E. grandiflora Sol. } \\
\text { E. stenomeres Barti. } \\
\text { E. pratincola Bartl. } \\
\text { E. Reynoldsii }\end{array}$ & $\underset{\mathrm{X}}{\mathrm{X}}$ & $\begin{array}{l}\mathbf{X} \\
\mathbf{x} \\
\mathbf{x} \\
\mathbf{x} \\
\mathbf{X}\end{array}$ & $\begin{array}{l}\mathbf{X} \\
\mathbf{X} \\
\mathbf{X}\end{array}$ & $\begin{array}{l}\mathbf{X} \\
\mathbf{x} \\
\mathbf{X} \\
\mathbf{x}\end{array}$ & $\mathbf{x}$ & $\mathrm{X}$ & $\frac{(\mathrm{X})^{1}}{\mathrm{X}}$ & $\mathrm{X}$ & $\begin{array}{l}(\mathrm{X})^{1} \\
(\mathrm{X})^{1}\end{array}$ & $\underset{\mathrm{X}}{\mathrm{X}}$ \\
\hline $\begin{array}{r}\text { Bartl. } \\
\left.\begin{array}{r}\text { E. suaveolens Desf. } \\
\text { E. multiflora } \\
\text { Gates } \\
\begin{array}{r}\text { E. grandiflora } \times \\
\text { biennis }\end{array} \\
\mathrm{F}_{\mathrm{s}} \text { and } \mathrm{F}_{\mathrm{s}}\end{array}\right\}\end{array}$ & $\mathrm{X}$ & & $\mathrm{X}$ ? & $\mathrm{X}$ & & & & $\mathrm{X}$ ? & & $\mathrm{x}$ \\
\hline
\end{tabular}

The significance of the various species and varieties with cruciate flowers will be considered later. The first experiments with pure $E$. biennis were undertaken by Stomps (1914). He collected a rosette of this species at Beverwyk, Holland, in 1905, from which he obtained a pure line. Among over 900 plants belonging to the third and fourth generations, Stomps found 6 mutants, 1 nanella, 1 semigigas and 4 sulfurea. The last differs from

' When enclosed in parentheses, the form is a presumptive mutation, but has not actually been obtained in a pedigree culture.

2 For a description of this "species," probably of hybrid origin, see Gates, 1914b.

Davis, 1913. 
the type of biennis only in having pale yellow petals. It is found occasionally on the sand dunes and must have originated as a mutation.

The well-known uniformity and constancy of $E_{E}$. biennis, together with the apparent impossibility of crossing in the regions from which these plants were derived, greatly enhances the importance of the mutations obtained from them. This species, the only one with which Linnæus was at first acquainted, was originally brought from North America in 1614-the first evening primrose to be brought to Europe. It was soon naturalized on the Dutch sand dunes, where it has retained its characters with remarkable uniformity for three centuries until the present time. Davis (1914) admits that no species in cultivation has greater claims to be regarded as a pure species, and at one time was willing to admit that if mutations were produced by it they would go far to prove the correctness of the mutation hypothesis that the production of new forms is not merely a phenomenon of hybridity. Indeed it would be difficult to find any species whose claims to "purity" or freedom from crossing are better authenticated. Not only is it self-pollinated, so that crossing would be a rare event at best, but for three centuries in these Dutch localities it has been more or less completely isolated from its American relatives. Even if its ancestors were crossed before they left America, 300 generations of self-fertilization would be more than ample to-reduce it to a homozygous condition again, ${ }^{2}$ unless a condition of balanced lethal factors maintained it in a heterozygous state.

But the Drosophila work shows (Muller, 1918) that such a condition of balanced lethals is not the result of crossing, but of alterations which arise in the germ-plasm. Another fact against the hybridity theory is this. The mutant sulfurea, which has been shown to arise occasionally in cultures, is also "far from rare" on the Dutch dunes (de Vries, 1915b). Apparently it was first mentioned in 1687 by Hermannus in Hort. Acad. Lugduno-Batavi

1 For the early history of some of these forms see Mut. Factor, p. 47.

3 Without dealing with the mathematical formulæ for inbreeding involved (see East and Jones, 1919, p. 91), it may be pointed out that even if a large number of independent differences were involved in an original cross, the population from self-pollination would be practically all homozygous by the tenth genergtion. The population would then be expected to contain-a number of different homozygous types. It might be anticipated that the weaker of such types would fail in the struggle for existence. But if we examine the facts, we find that $\mathscr{E}$. biennis in Holland is remarkably uniform and has always been so, never showing any variations on the dunes except the sulfurea mutation, and leptomeres with cruciate petals. There is thus a complete absence of data on which to found a hypothesis of hybridity, while the evidence to the contrary is strong. 
Cat. under the name Lysimachia corniculata non papposa, Virginiana major, flove sulphurea.' It must then have been appearing as a mutation in the original stock brought from America. Other wild American self-pollinated species recently brought into cultivation have been shown to be doing the same thing, i.e., producing mutations with varying frequency. We must recognize that the germ-plasm of a species is a vast aggregation of units, among which complicated relationships arise which express themselves in throwing off at intervals new forms.

The frequency with which the mutations in $\mathscr{E}$. biennis appear has been studied by de Vries (1915b). He grew 8500 plants from the pure line of Stomps, derived from a single wild plant from which they were descended in the third and fourth generation. They included 8 dwarfs (mut. nanella) or $0.1 \%$, and dwarfs also occurred in later generations. The population of 8500 also contained 4 semigigas, or $0.05 \%,{ }^{2}$ and 27 sulfurea, or $0.3 \%$. The latter appeared among the offspring of all seven parent plants. This gives a total of 39 mutations, or $0.45 \%$. This is a lower percentage than in $E$. Lamarckiana, but much higher than in Drosophila. Cultures of $E$. biennis sulfurea from four of Stomps' mutants also gave two dwarfs among over 1000 plants which flowered. These give the race $E$. biennis mut. (1913) sulfurea mut. (1914) nanella. In this connection de Vries also obtained two other mutations from crosses. E. lamarckiana $\times \mathscr{E}$. biennis nanella yielded 55 plants, which had the characters of lamarckiana $\times$ biennis, except one lata mutant. Again, in the cross $E$. biennis semigigas $\times \mathscr{E}$. biennis, he obtained 19 plants, 1 dwarf mutant, 10 biennis with 14 chromosomes, and 8 of a new type (described elsewhere) with 15 chromosomes. The appearance of two uniform types in this cross is signiflcant, for it shows that the meiotic processes were taking place so as to reduce the chromosome number in the gametes to 7 or 8 . Moreover the fact that the 15-chromosome type was uniform indicates that the same chromo. some must have been the extra one in every case.

This brings us to the meaning to be attached to the term parallel in connection with mutations. It is obvious that each mutation of a given type is parallel to every other of that type.

' See Mutation Faclor, pp. 66, 158. The fact that the early writers, although they recognized sulfurea, found no other variations of $\mathcal{E}$. biennis, shows that it was as uniform then as it is now.

"If mut. gigas, appeared only from the union of two diploid gametes, its frequency. should then be about $1,4,000,000$. 
Por example, each time lata appears as a mutation from lamarckiana the change involved must be the same. Again, in the sense in which the term originated, $E$. biennis lata, lamarckiana lata and suaveolens latn are all parallel forms. Going farther afield the cruciata forms from limarckiana and biennis, if independent in origin, are obviously parallel, hut a number of wild species (shortly to be considered) which are unrelated to each other have cruciate flowers as a specific character. Some of these may have a common descent from a cruciate ancestor, others have almost certainly originated independently as parallel mutations. Nor is it certain that the change involved is always the same. The Drosophila work has shown that two mutations may be so closely alike as to be scarcely distinguishable, and yet have different relations in the germ-plasm.

The conception of parallelism is perhaps even more fertile when applied to the comparison of variations in different genera. A cruciate mutation has appeared in Epilobium and a similar variation probably occurs in other genera. Again, the phenomenon of doubling in flowers, to be considered later, shows that doubling may occur as parallel mutations in wild as well as cultivated species of many families. The same of course is true of white varieties, which almost any species of flowering plant may produce. Laciniation of leaves, maximum anthocyanin development, nanism, lack of chlorophyll (though such a condition may arise from various genetic causes), doubling, and a number of other characters may be looked upon as probably at any rate parallel mutations. Thus $\mathbb{E}$. rubricalyx and the copper beech may be parallel in that they involve in their origin the same kind of germinal change. But this cannot be assumed with safety until it has been proved by breeding experiments with each. Thus some forms of flower-doubling are dominant and some recessive, and white varieties may originate in a number of ways. The same is true of gigantism. The gigas mutations from four species of Enothera (Table II) show exactly the same peculiarities of stoutness, increase of cell size, 4-angled pollen grains and tetraploid chromosomes, so that the change is obviously the same in all cases. But in other genera gigantism may occur with or without tetraploidy. This whole subject will be considered further in connection with the variations of wild species of plants and animals. 
The cruciate character.

Coming now to the cruciata type of mutation, ${ }^{1} E$. biennis var. leptomeres of the Holland sand dunes differs from the species in having narrow, linear petals, somewhat crumpled and more or less greenish yellow. This constant form Stomps (1913) regards as a case of incomplete sepalody, in which the petals have become imperfectly transformed into sepals. In Epilobium he describes a somewhat different form, E. hirsutum cruciatum de V., which originated from a group of a dozen plants (perhaps derived by stolons from one) and breeds true. The plants were found by Mr. John Rasor in Woolpit, Bury St. Edmunds, and seeds were sent to de Vries. They differ from the type in having, in place of the large, obcordate, lilac petals, small greenish scales shorter than the sepals, and pointed. That this is not a case of arrested development is shown by examining the young buds of the species. The petals are broad and obcordate even while still small and colourless. The buds of the cruciate form show also a tendency to dry up and fall when young. This appears to be a more complete case of sepalody. Crosses between type and variety gave a Mendelian ratio. Thus E. hirsutum cruciatum $\times$ E. hirsutum gave an $\mathrm{F}_{2}$ of 323 plants, of which 245 were type and 78 variety. Also the reciprocal cross produced 177 plants in $F_{2}, 130$ of which were type and 46 variety, while one failed to flower. The sum of the two ratios is $375: 124$, showing that the cruciata mutation is a simple Mendelian recessive character.

Not only does the cruciate mutation from $A E$. biennis differ from that of $E$. hirsutum externally, but also in its hereditary behaviour. For in reciprocal crosses of $W$. biennis cruciata with the parent type, while the $F_{1}$ is normal and the $F_{2}$ splits into the two original forms, yet the ratios are not Mendelian. Stomps unfortunately gives no figures, but states that whichever form is used as the male parent, that form appears in the greater number of the $\mathrm{F}_{2}$ progeny. The cruciate forms in these two genera, while comparable in general, are not therefore strictly parallel forms.

Elsewhere (1913a, p. 25) the writer has shown that, whatever the origin of $E$. lamarckiana var. cruciata, both normal and cruciate flowers may occur on the same plant. This somatic

1 See also Mutation Factor, p. 21. In addition to the specimen collected by Ernst de Vries, others have been found on the Lüneburg Heath, and they have been reported from other parts of Holland, probably from independent
mutations. 
segregation is apparently the same type of behaviour as was found ${ }^{1}$ in the $\mathrm{P}_{2}$ and $\mathrm{P}_{3}$ of crosses between the large-flowered $\mathcal{E}$. rubricalyx and the small-flowered $E$. biennis, in which large and small flowers frequently appeared on the same plant, and even long and short petals, of varying lengths, on the same flower. It is possible that this race of $\mathscr{E}$. lamarckiana var. cruciata, which emanated from the Bremen Botanic Garden, may have originated by a cross between $E$. biennis leptomeres and $\mathcal{E}$. lamarckiana. This hypothesis is supported by the short style in the flowers of this race, so short that, like $E$. biennis, nearly all the flowers were self-pollinated. But in crosses between $C E$. biennis and its cruciate mutation there are no reports of this vegetative segregation, with both types of flowers on the same plant.

As a result especially of the studies of MacDougal (1905) and Bartlett (1914a), a number of cruciate species and varieties are now accurately known. As Bartlett points out, it is clear that these have not had a common origin, but they have arisen independently from different stocks, some more remotely and some more recently, just as var. leptomeres apparently originates even now from $E$ biennis $\mathrm{L}$. The first cruciate form to be discovered was $E$. cruciata Nutt. Its taxonomic history is given by Bartlett. Nuttall found it in Massachusetts and sent seeds of it to several botanists. Don grew it in 1824 and described it under Nuttall's name. The species which is still cultivated in botanical gardens under this name is quite likely descended from this original source. Its variable petals indicate that it has been crossed with a broadpetalled species, and it is now called $E$. cruciata, var. varia, de Vries. ${ }^{2}$ In the sixth edition of Gray's Manual (1889) it was classed as probably a rare garden sport, since no specimens had been collected except in gardens, subsequent to the original collection over 60 years earlier. In later years cruciate specimens were collected in Vermont.

The interest awakened in wild North American Enotheras by the work of de Vries, soon led to the discovery of other forms. Seeds of a cruciate form which had been collected at Sandy Hill, New York, near Lake George, in 1902, were divided, part of them being grown by MacDougal (1905) at New York, and a larger number by de Vries at Amsterdam. This material contained two

1 See Gates, 1917a.

. De Viries found that this variety segregated roughly into three groups, (1) cruciate, (2) intermediate, (3) broad-petalled. The latter is constant except for rare cruciate bud mutations. 
distinct types, one with rather broadly linear petals and rather thick flower-buds, the other with narrowly linear petals and slender flower-buds. A third cruciate type grown at Amsterdam in 1903, from seeds collected at Jaffrey, New Hampshire, differed in having a much longer calyx tube, and a more slender, less nutating stem. MacDougal (1905) gave descriptions of a third type from the Lake George seeds, which he identified with the New Hampshire form, but this identification is doubtful, as Bartlett points out. None of these three types is the same as $E$. cruciata Nutt. which came from Massachusetts. The two Lake George forns were described (Bartlett, 1914) as $E$. atrovirens Shull and Bartlett and $Q E$. venosa Shull and Bartlett. These may of course be cruciate varieties of the local species where they occur, but it seems more probable that they represent independent species. This would indicate that they have undergone further evolution since the cruciate mutation took place, or that the parent broad-petalled type has since become extinct.

Herbarium specimens with cruciate flowers, which have been placed under $C E$. cruciata Nutt., but no doubt belong to several distinct types, have been recorded (Bartlett, 1914), from Nova Scotia (Sable Island), Maine, New Hampshire, Vermont, New York and Massachusetts. Another cruciate type with small flowers is represented by a specimen in the British Museum ${ }^{1}$ collected in British Columbia in 1909-evidently an independent local variety or species. Bartlett also grew 50 plants from seeds of one individual collected at Springfleld, Missouri. They were uniform with the exception of one plant, a single branch of which bore cruciate flowers. The petals were narrowly oblong, rather than linear. This suggests previous crossing with a cruciate mutant, which may very well have occurred in the field. Bartlett has cultivated a cruciate $\mathrm{F}$ nothera from Mobile, Alabama, and describes another one, $C E$. stenomeres, from Montgomery, Co. Maryland, which has given rise to mutations. Yet another cruciate species has been cultivated by Shull from Long Island, and has been described as $E$. cleistantha Shull and Bartl. (Bartlett, 1915e). It is not closely allied to any other known species, and the origin of the cruciate feature is therefore probably of ancient date. The flowers as a rule never open, and the most striking features of the species are its extreme leafiness and dense branching. It is ohvious that the possibilities of natural crossing in this species are

, Gates, 1915a, p. 21. 
very remote indeed. A minute but distinctive difference is in the large hairs of the calyx. On the bud-cone they are strongly ascending except around the top of the hypanthium where they are retrorse or perpendicular.

The cruciate form from Jaffrey, New Hampshire, is described by Bartlett, in the same paper, under the name $\mathscr{E}$. Robinsonii. There is said to be "enough likeness between $\mathscr{E}$. venosa and $\mathscr{E}$. Robinsonii, so that a close relationship between them seems not unlikely." The differences from venosi are chiefly in the smaller size of Robinsonii, its more sharply dentate leaves, narrower bracts, longer more slender buds with dense erect viscid puberulence, and shorter calyx tips. The range of variation in bud length overlaps, however, and most of the differences are only obvious in the living plants. These two forms evidently represent closely allied elementary species rather than species in the Linnean sense. Both having cruciate flowers, one from New York State, and the other from New Hampshire, in the absence of local species of which they could be varieties the common character of cruciateness probably originated some time ago, and we may suppose that the series of small differences which distinguish the two species throughout have originated since.

Contrasted with these forms, in which the cruciate character appears to be of relatively ancient origin, is another cruciate species, CE. stenopetala Bicknell, described from Nantucket Island in 1914. It is closely allied to the broad-petalled species $Q E$. Oakesinna Wats., from which it is probably descended. Yet the two have diverged in certain respects. In the case of $\mathscr{E}$. biennis leptomeres, which apparently is still appearing as a mutation from biennis in Holland, the single difference in the flowers is unaccompanied by any other differences. This series is a most instructive one as a basis for contrasting the conspicuous unit difference of sudden and repeated origin, with the other smaller differences relating to all parts of the plant, by which the species have subsequently become differentiated. Whether the same type of evolutionary change is represented in both cases, is a matter worthy of close and prolonged study. By comparison and crossing of these cruciate forms, definite evidence might be obtained on this point. In many cases such elementary -species differ from each other in physiological characters or methods of reaction to environment. An intensive study should make it possible to determine what relation if any these physiological and morphological differences bear to each other. 
Cruciateness affords the most conspicuous and instructive examples of parallel mutations among wild Enotheras. There are indications that the red hypanthium, which is the most conspicuous feature of the mutant rubricalyx, may also be paralleled, though in a less degree, by certain wild species. Thus $E$. rubescens Bartlett (1914b) has buds and hypanthia which are pale red. It would appear to agree in this feature with the form, probably hybrid in origin, which the writer ${ }^{1}$ described from Lancashire under the name E. rubrinervoides. A small-flowered undescribed species, $E$. cohumbiana, from near Washington, is said by Bartlett to have "conspicuously red hypanthia." The writer has pointed out elsewhere $^{2}$ that the deep red of rubricalyx may become pale red by crossing and then back-crossing with a greenish-budded species. Thus in $(E$. rubricalyx $\times$ grandiflora $) \times$ grandiflora, if the female parent is heterozygous for the red factor, segregation into types with red or green hypanthia will take place, but the red will be much paler than in the selfed offspring of the female parent plant. In other words, the colour is diluted and the red remains permanently pale in the selfed offspring of such plants, deep red only being restored by a back-cross with rubricalyx. Red or reddish hypanthia in plants from all these different sources, indicate its appearance through independent variations in different species.

Parallel Mutations in Drosophila.

Various features of the Drosophila work have already been discussed. In D. melanogaster (ampelophila) certain mutations have occurred repeatedly. Thus (Morgan, 1919) white eyes have appeared independently three times, vermilion eyes at least six times, rudimentary wings flve times, cut wing four times, truncate and notch wings each several times, but in the last two cases the change involved may not always have been the same.

In the last flve years a number of mutations in six other species of Drosophila have been recorded. This includes a new eye-colour (scarlet) in D. repleta (Hyde, 1915a), another sex-linked mutation (light grey thorax) in the same species (Sturtevant, 1915), a wing mutation (jaunty C) in D. confusa (Hyde, 1915b), one in D. tripunctata (Metz and Metz, 1915), three mutations (extra bristles, triangle wing veins and short wing veins) in $D$. obscura Pall., and one (chocolate eye-colour) in D. similis Will. from Cuba (Metz, 1916b). In " species B," now known as $D$. virilis Stt., a more detailed study

\footnotetext{
'Gates, 1914b. 'Gates, 1914a, $1915 f$.
} 
of the mutations has been made. In four successive papers (Metz, 1916a, 1916b, 1918, 1920) a great many interesting facts have been recorded. D. virilis is known (Metz, 1914, 1916c, 1916d) to have six pairs of chromosomes, including one pair of small or $\mathrm{m}$. chromosomes, whereas $D$. melanogaster has 4 pairs. In the latter species it has been shown that the 200 or more mutations all fall into the corresponding four groups. In D. virilis Metz (1920) has recently reported a total of 27 mutations, including 14 which are sex-linked (Group I), 3 in Group II, 4 in Group III, 3 in Group IV, and 3 in Group V. No mutations have yet been found corresponding to the small pair of chromosomes, but the late appearance of mutations from such small chromosomes is to be anticipated on the laws of chance, and the two known members of the corresponding group in $D$. melanogaster were not discovered until a very large number of mutations were known.

In an earlier paper (Metz, 1918) dealing with eight sex-linked characters in D. virilis, half of them were found to correspond closely to mutations of $D$. melanogaster. These four were yellow body-colour, magenta eye-colour, glazed eye-surface, and forked bristles on the thorax. The yellow mutation is slightly darker than in the case of $D$. melanogaster, but this is to be expected if the changes correspond, since the normal virilis is a darker species. In the forked mutation " the morphological correspondence is complete even to the smallest detail." Yellow and forked are not only sex. linked mutations, and hence in the $\mathrm{X}$ chromosomes, in both species, but their linkage relations are shown to be similar, so that they occupy corresponding positions in the $\mathrm{X}$ chromosome, yellow being terminal and forked about 55 units from it as measured by the percentage of crossing over. There are indications that the actual amount of crossing over is greater in $D$. virilis.

Confluent, referring to the veins on the wings, is another mutation which has its counterpart in $D$. melanogaster. It is a dominant, is not sex-linked, and when present in a homozygous condition has a lethal effect, as shown by the ratios of confluent in crosses and by the absence of homozygous individuals, though there is still a possibility that some may occur in D. melanogaster. Black body and morula-eye are other non-sex-linked mutations occurring in both species.

The six pairs of chromosomes in $D$. virilis have apparently been derived by transverse segmentation of two long boomerangshaped pairs of chromosomes in D. melanogaster, the other two 
pairs remaining unaltered. The evidence from those parallel mutations with similar linkage relationships shows that even the finer elements of the germ-plasm have maintained their relative positions and potentialities from species to species. This indicates a degree of static fixity combined with mutation in single elements which is truly remarkable, indicating that even the finer details of structure in the germ-plasm may maintain their spatial relationships for long periods. A number of the mutations in $D$. virilis have not appeared in D. melanogaster, though it does not follow that the latter species is incapable of producing them. At present it is quite unknown why one mutation rather than another appears at any given time, though the evidence is strong that each represents an actual transformation of a germinal element, and not merely a loss.

Clearly, the conception of parallel or homologous mutations is destined to be a very useful one in germinal analysis and in the study of relationships. In the next chapter we will consider its application to the study of variations in wild species. 


\section{CHAPTER VI.}

Presumptive Mutations in Wild and Cultivated Plants.

Obviously, if the mutation theory is to be of any use the conceptions derived from controlled breeding experiments must be applicable to plant and animal species and varieties as they occur in nature. A beginning has only been made in this vast fleld of application, but it is sufficient to show that the mutationist conception of germinal changes is widely applicable to the variations observed among wild species. As an aid in the analysis of the populations that go to make up a wild species it is undoubtedly of great service, and its illuminating infituence is also beginning to make itself felt in the flelds of systematics, phylogeny and relationships. Innumerable records of species, varieties and forms in the literature of systematic botany and zoology and the journals of naturalists show how universal is the incidence of this principle.

That the relationships and origin of nearly related species can also in many cases be most clearly interpred in terms of unit differences has been shown by Bateson (1913) for the North American warblers (Helminthophila) and flickers (Colaptes) and other forms. In plants, the same principle has been applied (Gates, 1916) to species of Spiranthes, Clintonia, Streptopus, Maianthemum, Ranunculus, Actæa and Spiræa, and in a preliminary way to the genus Trillium (Gates, 1917b). Similar analytical conceptions have been applied to the differentiation of species and varieties, their relationships and phylogeny, in the North American Melanthaceæ (Gates, 1918a) and Convallariaceæ (Gates, 1918b). The results are in no sense revolutionary, but wherever the mutational principles are applicable they do appear to give a more clear-cut and accurate analysis of specific differences, and also of the phylogenetic and distributional relationships within a group. Moreover, there is the beginning of a physiological element in classification on these principles, which is a distinct gain. More recently Small (1917-19) has successfully applied these principles to a study of the development of the Compositæ, though obviously his present results are mainly tentative.

It is obvious tliat in older groups, and wherever extinction has taken place, the actual succession of mutations in the development of any group will be obscured or lost altogether. These principles can be most readily and widely applied to modern expanding groups 
in which the origin of new divergent characters is now or has recently been taking place.

Turning now to the recorded cases of mutation in the literature, they form such an array that it would be a colossal task to attempt even to enumerate them. The condition is so conmon in flowering plants that it may be considered exceptional to find a species without any mutational varieties. A few instances will be selected, almost at random, for mention here. First we will consider doubling.

\section{Doubling.}

The gardeners' tradition that "doubling" or the transformation of stamens into petals, ${ }^{\prime}$ is a result of cultivation has long been disproved. It is evident from the records that doubling of flowers occurs "spontaneously" both in wild and cultivated species. It is a typical mutation, although the completeness of the transformation of stamens into petals, and the associated changes in the flower, may vary in different cases. Breeding experiments have shown that the double condition is in some forms a Mendelian dominant, but more usually a recessive. Bateson (1909, Chap. XI) has considered the cases studied before 1909. The work of Miss Saunders on the inheritance of doubleness has been most ample, and some of her results may be summarized here. Taking the simpler cases first, she finds (1917) that in the Welsh poppy, Meconopsis cambrica, doubleness is dominant, the $\mathrm{P}_{2}$ from a cross containing three doubles to one single. The doubleness results from a variable degree of petalody of the andrœcium and gynœcium. In the hollyhock (Althaa rosea and $A$. ficifolia) the $\mathrm{F}_{1}$ is intermediate and the $\mathrm{F}_{2}$ gives the $1: 2: 1$ ratio, i.e., neither condition dominant; in carnations (Dianthus caryophyllus) doubleness is a simple dominant, ${ }^{2}$ while in sweet william (D. barbatus) singleness is dominant and the $\mathrm{F}_{2}$ from a cross contains three singles to one double.

In Chelidonium majus Sax (1918) finds that doubleness is apparently a simple recessive, but the $\mathrm{F}_{2}$ gives a continuous series from singles to full doubles. Statistically considered, there is much

' Doubling may also occur, as in Fuchsia, by an increase in the number of petals without any change in the stamens, or it may result from change of carpels to petals, or from all these conditions combines.

- According to the breeding work of Norton and of Batclielor the doubleness of carnations appears to be of two distinct types or degrees, full doubles and standard doubles, the latter having some stamens. Full double $\times$ single gives an $F_{1}$ which is standard double, and an $F_{2}$ with the three types in the ratio $1: 2: 1$. Miss Saunders finds, however, all degrees of doubling in the DD's and DR's, which are therefore indistinguishable. 
greater variation in the doubles than in the singles, and a high negative correlation between petal number and stamen number in $\mathrm{F}_{2}$ plants, as would be expected if stamens are replaced by petals.

The more complicated cases of doubling have been elucidated by the well-known work of Miss Saunders on Petunia (1910, 1916a, 1916b), Matthiola (1911,1913,1915a, 1915b), and the wall Hower Cheiranthus cheiri (1916c, 1917). According to Frost (1915), doubleness is dominant in Petunia, and Miss Saunders (1916b) concurs in this statement to the extent of finding that all truebreeding singles of $P$. violacea, $P$. nyctaginiflor and various garden strains, when pollinated from doubles give an $F_{1}$ containing both singles and doubles. This indicates the heterozygous character of the doubles, and hence the dominance of doubleness over singleness. But since the doubles are sterile and $P$. violacea itself is a selfsterile species it has not yet been possible to eliminate the possibility that singleness is dominant, though Frost's hypothesis of selective sterility accompanied by dominance of doubleness would appear to fit the facts. In the wallflower, as in sweet william, singleness is dominant.

In the case of Stocks (Matthiola) the prolonged experiments of Miss Saunders have gone far to clear up the hereditary relationships. Singleness is dominant, and it is well-known that in the various strains both pure-breeding and double-throwing (eversporting) singles occur. The inheritance of singleness or doubleness is independent of the pair of Mendelian characters for hoariness or smoothness, and also of cell-sap colour, but is linked with plastid colour (whether white or cream). All the singles derived from an eversporting individual appear again to throw doubles. And in all cases there is an excess of doubles in the offspring in the ratio of - something more than 7 singles : 9 doubles, from which it is concluded that two factors are primarily concerned in producing a single or a double.

Moreover, breeding experiments show that all the functional pollen grains of eversporting individuals carry doubleness, while some of the ovules carry the factor for doubleness, and some that for singleness, in the above proportion. Miss Saunders (1911) explained the absence of doubles in the offspring of true-breeding singles when crossed together, by an unequal distribution of the factors among pollen grains and ovules. In the light of more recent work it is probably simpler to explain the fact that some singles breed true by assuming linkage of one determiner to a lethal 
factor. This does not of course explain the important fact of differential viability of certain types of gametes as between pollen and ovules.

Miss Saunders assumes that singleness in stocks is due to the presence of two factors $\mathrm{X}$ and $\mathrm{Y}$, that in the eversporting singles these two factors show partial coupling, and that they are both carried only by the ovules. Also a factor $\mathrm{W}$ represents colourless plastids, while in cream forms that breed true $W$ is absent. There is also a sulphur-white race, heterozygous for $W$, in which $W$ is present in some of the ovules but absent from the functional pollen. This relationship appears to be explained by coupling of $W$ with either X or Y. Again, in the singles which breed true for singleness it is assumed that $X$ and $Y$ are linked, so that in crosses with eversporting singles recombinations cannot occur. These complicated relationships of factors are quite in harmony with results obtained from breeding experiments with other organisms.

Another feature of the double stocks is that they show greater viahility than the singles, and hence appear in a higher percentage from old seed and also when the more vigorous plants are selected before flowering.

The various varieties of stocks must have originated through mutations, and Miss Saunders (1915b) traces the historical order of their appearance.

In Puchs' herbal (1542) the purple, red and white forms were already known, but Ruellius a few years earlier makes no mention of the red. The purple and white varieties of Matthiola incana date back to Dioscorides. The first record of the double stock appears to be in Dodoens' herbal (1568). This gives also the first European record of the double wallflower. Double violets are apparently first mentioned in a work published in $\mathbf{1 5 3 5 .}$

The records indicate that the double stock perhaps originated in cultivation in some Dutch garden, and they show that it was completely double and sterile from its first appearance-no doubt a mutation. Sowerby (Eng. Bot.)' figures a hoary stock obtained from the cliffs of Sussex in 1806. This shows partial doubling in some flowers. The species must have independently developed a factor for doubling in this locality.

Prost (1912) describes an "early" dwarf mutation with few nodes from ten-weeks stocks. It is said to behave as a simple Mendelian dominant, but the evidence is not very clear.

' See Saunders (1917). 
A much earlier record of a double wallflower has, however, since been found (Saunders, 1916c). There is a reference to it in an Arabic "Book of Agriculture" of the 12th Century, the statements in which are based on an earlier work probably written about 1073. As we shall see, the records show that doubling is by no means rare in wild species, so it is quite possible that a double wallfiower was taken into cultivation as such. Doubling appears to have occurred at least twice in cultivation. The older, fully double wallflower (Saunders, 1917) was wholly sterile like the double stocks. It appears to have originated only once as a sport, and have since been propagated by cuttings. The partial double is more recent in origin and shows grades of doubling forming a continuous series. This double form is therefore not in the same series with the full double, but represents an independent germinal change.

Bateson and Miss Sutton (1919) have found greater irregularity in Begonia. A double monœcious $q \times$ single $\delta$ gave singles generally dominant, but segregation was irregular and transitional forms appeared. An average of 1 double in 32 was obtained, and back crosses were also irregular. B. Davisii from Peru crossed on common doubles gave only double. This single is believed to be genetically double on the side.

The first double Dahlia is mentioned and figured in a work on the natural history of Mexico, published at Rome in 1651. ${ }^{1}$ Hence it apparently did not originate in cultivation. There are a number of early American records of wild species with double fiowers, some of which may be summarized here. In Saxifraga Virginiensis we have found nine records of double flowers, as follows: (1) A double found near Hingham, Mass., in 1849. ${ }^{2}$ (2) Asa Gray ${ }^{3}$ found a double at Danvers, Mass., 1866, which continued so from year to year. (3) A specimen found on the Delaware River below Easton with extra petals. ${ }^{4}$ This was apparently not fully double. (4) A wild double from Canaan, Conn., was reported by A. Gray. It bore 70 or 80 flowers, all pure white and fully double, without stamens. This very ornamental plant was divided, and part of it cultivated in the Cambridge, Mass., Botanic Garden. (5) Two more specimens were found ${ }^{6}$ on the banks of the Schuylkill, near

- Gard. Chron. 59 : 336, 1916.

3. L. R., Amer. Nat. 2 : 610, 1869.

- Amer. Nat. 2 : 484, 1869.

- Porter, Thos. C., Bot. Gazette 1: 5, 1875.

- Amer. Nat. 11 : 366, 1877.

- Martindale, I. C., Amer. Nat. 11: 432, 1877. 
Philadelphia, having larger flowers than in the previous case. Meehan ${ }^{1}$ records finding a double on the Wissanickon about 1854 . (7) One near Beverly Bridge, Mass., ${ }^{2}$ with panicle smaller than normal, the flowers full double, petals replacing both stamens and pistil. (8) Meehan' ${ }^{3}$ reported a double from North Woburn, Mass. These records, through trivial enough in themselves, acquire interest when considered as a whole. For they show that in a large part of its area and for over a quarter of a century S. Virginiensis was producing sporadic doubles as mutations. It is probably doing so still, and it may be that, as in stocks, some individuals are eversporting, giving rise to fresh doubles in each generation.

Before leaving Saxifraga we may point out some of the other derivative forms which have heen described in this genus. Sterns ${ }^{*}$ describes a form of S. Virginiensis on Manhattan Island which he called var. pentadecandra. In two plants observed nearly all the flowers had 15 stamens, the extra 5 replacing the petals. In these apetalous flowers the stamens were exposed in the bud. Such a change of petals to stamens is relatively rare. Several other plants in this location had apetalous flowers, but the stamens were ill-formed and more or less aborted. Three more specimens were found $^{\text {' }}$ in the locality in the following year. The same variation occurs in the cultivated European species S. granulata, as recorded by Masters.

This must be regarded as a case of parallel mutations. In $S$. crassifolia an abnormal increase in the number of pistils has been repeatedly observed, while $S$. Virginiensis var. chlorantha Oakes was described from Topsfield, Mass., 1847, having tiny green pubescent petals. Var. pentadecandra was found in profusion in a slate rock locality in Essex Co., Mass. The Saxifrages are evidently subject in the wild condition to many mutations besides doubling.

Thalictrum anemonoides is another species for which there are a number of records of doubling. A semi-double found near Cincinnati, Ohio, in $\mathbf{1 8 3 4}$ was taken into cultivation and in five years

' Amer. Nat. 2 : 484, 1869.

- Russell, J. L., Am. Nat. 3 : 327, 1869.

Amer. Nat. $6: 487,1872$.

4 Sterns, E, E. Some anomalous forms of Saxifraga Virginiensis. Bull. Torrey Bot. Club $14: 122-125,1887$.

Bull. Torrey Bot. Club 15 : 166, 1888.

- See also Rhodora 19: 143, 1917. 
produced full double flowers. ${ }^{1}$ Many other instances of doubling in this species are on record from Asa Gray, Thomas Meehan and others. Doubles are also recorded in many species of Ranunculus. Thus $R$, rhomboideus is sometimes found double in Floyd Co., lowa. ${ }^{2}$ One such specimen was transplanted and continued to produce only double flowers. A specimen of $R$. repens L. collected near Camden, New Jersey, had 10 petals (an extra whorl). ${ }^{3} R$. multifidus Pursh at Grand Rapids, Mich., frequently has double and quilled flowers, often with the scales (nectaries) changed to tubular appendages." $R$. acer, $R$. bulbosus and $R$. ficaria are all said by Meehan' to have double forms. He points out that doubling is rarely due to cultivation, although numerous double forms of Ranunculus now occur in seed catalogues.

Records of doubling in the Canadian mayflower, Epigaa repens, also abound, though the change is not so regular as in other forms, there being great variation in the nature of the doubling. A specimen from Worcester, Mass., continued to produce doubles for several years. ${ }^{\circ}$ The stamens were partly converted into petals, the outer series being more or less coalescent into a tube. Other records are from New Brunswick and Massachusetts, the latter being a specimen with flower having three corollas, one within the other, the stamens absent or abortive. ${ }^{7}$ At Plymouth, New Hampshire, double flowers were observed ${ }^{8}$ year after year, with great variation in the degree of doubling. Three-fourths had two whorls of 5 petals each, and 5 stamens alternate with the inner petals. In a few flowers nearly all the 10 stamens were transformed into petals, and in all the carpels were transformed to leaves.

In Hepatica triloba Gil. one specimen with strongly double flowers was found (Hilbert, 1913) near. Sensburg, Germany, in 1894, surrounded by singles. In 1912 another double specimen with blue flowers was found in the same place. It was transplanted to a garden and flowered double the following year, but gave no seeds. The stamens were changed to petals. There is also in cultivation

- Amer. Nat. 2 : 610, 1869.

Arthur, J. C., Amer. Nat. 6 : 427, 1872.

- Bot. Gazette 1 : 5, 1875.

4 Bot. Gazette 2 : 90, 1877.

- Amer. Nat. 2 : 484, 1869.

- A. Gray, Am, Nat. 6 : 429, 1872.

' Bailey, W. W., Bot. Gaz., 6 : 238, 1881.

- Wilson, Kate E., Bot. Gaz. 15 : 19, 1890. 
a strongly double red form. A double Anemone Pulsatilla is flgured by Helwing as early as 1719. Doubling is well-known to be of frequent occurrence in the Ranunculacex. A Convolvulus sepium with double flowers is described from New Brunswick, New Jersey. ${ }^{1}$

An interesting record is that of Sagittıria variabilis, ${ }^{2}$ Engelm., a large patch of which, on an island in the Susquehanna, had completely double flowers. All the carpels of pistillate flowers and all the stamens of staminate flower's were converted into petals, giving the flowers the appearance of tiny snowballs. This probably represented a single individual mutation which had spread from rootstocks Elsewhere (Gates, 1917b) we have assembled numerous records of doubling in Trillium grandiflorum, the same root stock producing each year a double flower. There are various interesting records of double wild Rhododendrons. Rehder (1907) found in the woods at Glacier, British Columbia, a bush of $R$. albiflorum Hook. with double flowers. It was growing among normal bushes. In the double flowers, petalody of the stamens was combined with an increase in the number of staminal whorls. In the Alps, $R$. ferrugineum has been observed at least twice with double flowers, Kerner having found a large number of such shrubs in one locality. Miyoshi (1910) has described the occurrence of doubles in $R$. brachycarpum Don. The double form is called var. Nemotoi Makino. In the location (on a volcanic mountain) where it was found both white and rose varieties occur, but only the white showed doubling. Seven plants were observed with double flowers and ten with normal. In another place a group of five bushes was found, all with double white flowers. Nakai $^{3}$ found double and white varieties of $R$. Kaempferi in the vicinity of Karume, Japan.

That cultivation does not produce doubling, even in a genus where doubles occur wild as mutations, is clear from the case of $\boldsymbol{R}$. Metternichii, which is much cultivated in Japan but no double is known. If there is any relation between the environment and the occurrence of mutations in this genus, it remains elusive, as in most other organisms. We still have no better term than "spontaneous" to apply to it.

Makino cites also the finding of one double Oxalis corniculata, and Deutzia scabra entirely double in a locality in Nikko.

1 Bull. Torrey Bot. Club, 17 : 23s, 1890.

Porter, Thos. C., Bot. Gazette 1: 5, 1875.

- Bot. Mag. Tokyo, 29 : 261, 1915.

4 Journ. Coll. Sci. Tokyo, 1910. 


\section{Presumptive Mutations in Wild \& Cultivated Plants 63}

In a study of the variations of tobacco in the East Indies, Lodewijks (1911) states that double flower's are the most common aberrations, although gigantism, fasciation and other types of change also occur. Doubles appear yearly on almost every plantation, and the doubling is of the hose-in-hose type. All parts of the plant are also changed, so that doubles can easily be distinguished before they come into bloom. The stem is zig-zag, shorter and not winged; the leaves are very small and thicker owing to local outgrowtlus on their ventral surface; the midrib is twisted, and the stigma shows similar growths, though to a less extent. All these peculiarities apparently result from a single mutation, and the type breeds true. In crosses with the normal the latter dominates almost without exception, and the $F_{2}$ gives a $3: 1$ ratio $(46 \mathrm{~S}: 10 \mathrm{D}, 306 \mathrm{~S}: 105 \mathrm{D})$. It is a curious fact that the heterozygotes were distinguishable from pure singles by their leaves having outgrowths on the underside. Thus of the 306 singles above, 204 were shown in this way to be heterozygous and $102 \mathrm{SS}$. Again, in the $\mathrm{F}_{2}$ from single $x$ double the ratio was $32 \mathrm{~S}: 58 \mathrm{DS}: 31 \mathrm{D}$. It is very interesting that in this set of mutant characters, the double flowers are wholly recessive and the leaf peculiarity at least partially dominant, though they behave as a unit in inheritance.

In a work on the mountain cherries of Japan, in which is embodied an elaborate study of the group of plants which plays such a prominent part in the national life of that country, Miyoshi (1916) recognizes four species, Prumus serrulata Lindl, P. mutabilis Miyos., $P$. sachalinensis (Fr. Schm.) Miyos., and $P$. fruticosa Miyos., and a very large number of forms, especially of mutabilis (65) and serrulata (68). Cultivated double varieties have been known for over a thousand years. A great number of forms have arisen in the intervening period, but only the best have been preserved and many old varieties have been lost. In Yoshino, the oldest and most famous cherry neighbourhood, trees have from time to time been planted from the neighbouring mountains for over a thousand year's. At Koganei, near Tokyo, is the greatest assemblage of wild cherries, none of which show any influence of cultivation. There are three other main centres for cherry varieties, and many - places noted for a local form or even a single tree, but the larger centres have been the source of new forms and races from time immemorial. 
Prom a study of the early records, Miyoshi concludes that a large number of cultivated sorts existed two centuries ago, and has been largely added to during the last hundred years. The many forms which receive botanical names for the first time are distinguished by such features as leaf colour, fiower colour, singles or doubles, fragrance, inflorescence, and pubescence. The multiformity of the group is comparable with that of the North American Cratægus, or with Draba verna or Viola tricolor, and the forms appear to have arisen as mutations. Seeds in most cases yielded a uniform offspring, hut it seems possible that some mutational characters may have been transferred by crossing.

\section{Pelorit.}

Peloria, or the sudden development of actinomorphic flowers in a zygomorphic species, has been studied most extensively in the Scrophulariaceæ where it occurs most commonly, although it is also found in the Labiatae, Leguminosae, Orchidaceæ and other families with zygomorphic flowers. It is of evolutionary interest because zygomorphy is supposed to have been gradually developed in relation to the visits of insects, while peloria is a sudden re-expression of symmetry.

Peloria behaves in part as a recessive character, is known to occur as a variation in numerous wild species, and in a few cases has become a specific character, indicating that in such cases zygomorphy is not essential for survival. De Vries ' studied peloria in Linaria vulgaris for thirteen years and gives the literature of the subject up to the time of his work. He mentions Mentha aquatica as a species whose apical flowers are always peloric, and Uropedium Lindenii, found in Colombia, as the peloric form of Cypripedium caudatum. It is not impossible that the Ranunculaceous genus Aquilegia, with its flve spurs, arose as a peloric mutation from a zygomorphic one-spurred ancestor. The increased number of nectaries should give it an advantage as regards insect visits.

The genetical studies of peloria appear to have been conflned to the Scrophulariaceæ, but in this family the genera Linaria, Antirrhinum and Digitalis have given valuable results. The earliest discovery of a peloric condition in Linaria vulgaris was made by Zioberg in 1742. On an island near Upsala he found among the normal a plant bearing only regular flowers, and Linnæus described it under the name Peloria. There are numerous later records of

3 The Mutation Theory, Vol. II. 
the same wild mutation elsewhere. The flowers have five spurs and this type is now known as peloria nectaria. There is another type, peloria anectaria, in which the flowers are actinomorphic, but without spurs. Another race studied by de Vries, which he called hemipeloria, produces usually a single (terminal) peloric flower on each plant. Such a flower may not appear in some years, or occasionally more than one may appear, and this seems to be controlled to some extent by the environment, but the capacity for producing a peloric flower is evidently inherited through the seed. In breeding from such a half-race de Vries finally obtained mutations to the full peloric condition, in the fifth and sixth generations of culture. This mutation occurred with a frequency of about $1 \%$, and although highly sterile it probably breeds true. Whether there are any plants which never produce a peloric flower is uncertain.

A similar peloric condition (Digitalis purpurea monstrosa) has long been known in foxgloves, in which a single, erect terminal peloric flower occurs on the plant, and opens before the other flowers, which then follow in acropetal succession. The peloric flower frequently also shows an increase in the number of parts. This condition is found by Keeble, Pellew and Jones (1910) to be inherited as a simple Mendelian recessive. The peloric flowers are perfectly fertile with their own pollen, the inheritance being the same through peloric or normal flowers of the plant.

In Antirhinum majus, as in many other plants with zygomorphic flowers, sporadic peloric flowers occasionally occur. There is also a completely peloric race, which Baur (1911) used in his extensive crosses. He concluded that zygomorphy depended upon the presence of two factors $\mathrm{P}$ and $\mathrm{E}$. In the absence of $\mathrm{E}$ the plant will have only peloric flowers, but plants having $\mathrm{E}$ without $P$ (EEpp) produce both peloric and normal flowers. This is an interesting case of somatic segregation in the presence of one pair of factors, and presumably there would be no difference in inheritance from the two types of flower on the same plant. If such an EEpp individual is crossed with a fully peloric race (eePP), the $\mathrm{F}_{1}\left(\mathrm{Ee} \mathrm{Pp}\right.$ ) bears only normal flowers, while the $\mathrm{F}_{2}$ gives (1) normal-flowered plants, (2) plants with both normal and peloric flowers, (3) plants with only peloric flowers, in the ratio $9: 3: 4$. The numbers actually obtained were $70: 13: 45$, and the departure from expectation (72:24:32) is explained by the fact that badly nourished plants belonging to class (2) produce only peloric flowers, 
and hence fall in class (3). Bateson (1902) first pointed out that in reciprocal crosses made by Darwin between normal and peloric snapdragons, the peloric character behaved as a simple Mendelian recessive, giving 90 non-peloric to 37 peloric in $F_{2}$. Darwin, however, speaks of two of the 90 plants as being " in an intermediate condition between the peloric and normal state." The exact nature of these intermediate plants is not clear. If they correspond to Baur's class (2), then the actual numbers $88: 2: 37$ should be compared with an expectation of $72: 24: 32$ for the ratio $9: 3: 4$. Hence if the behaviour was the same as Baur describes there would be a large excess of normals to account for, and a corresponding defect of " intermediates."

It is thus obvious that peloria, like doubling, though originating through mutations, behaves differently in different genera.

Other mutations in wild and cultivated plants.

These records are sufficient to show the frequent occurrence of doubles in wild species as parallel mutations, and also of peloria, especially in the Scrophulariacex. That they are obviously not in any phylogenetic line of descent however, and are more or less incapable of reproducing themselves, detracts somewhat from their evolutionary interest. We may therefore consider some other types of polymorphism which have arisen in wild species or in cultivation. It has been found practically impossible to draw a line between mutations occurring in controlled cultures and the obviously similar changes which are frequently found wild. We therefore feel justified in extending the mutation conception to these wild forms and varieties.

Linaria alpina, a species of the Alps and Pyrenees, has two varieties, rosea and concolor, whose genetic relationships have been investigated by Miss Saunders (1912). In the typical alpina, which is most common in the Alps, the corolla is blue, with an orange palate, which is partly due to the presence of a viscous orange-yellow fluid in the epidermal cells and the hairs of the beard and partly to the yellowish colour of the cuticle. The var. rosea, which is rare and confined to certain stations, is pink with orange palate and behaves as a simple recessive to the type. Var. concolor is blue without the orange palate, and this is dominant to the type. Each of the varieties therefore differs from the type by one factor, but it is uncertain which was the original form. In L. vulgaris, which is yellow with orange palate, de Vries ${ }^{1}$ found on crossing with

i. Mutationstheorie, II, p. 152, 
var. perlutescens, which is yellow throughout, that the yellow palate was dominant. Thus yellow palate is dominant in one species and recessive in the other-a quite unexpected result. It is evident that dominance or recessiveness cannot safely be used in determining which is the original or parental type. Even though these are parallel mutations, the alternation in dominance probably depends on an effect of the other specific differences.

In Digitalis purpurea several varieties, evidently mutations, have been studied. Saunders (1911), Shull (1912) and others have bred the form called by Chamisso heptandra in 1826. The flowers are characterized by dialysis and staminody of the corolla, giving a flower with a petaloid upper lip and seven stamens. But many flowers of a heptandrous plant may show the abnormality in varying degrees, like a wave of reversion advancing up the plant. 'This variety is a recessive in inheritance. ${ }^{1}$ A form nudicaulis with smooth stems and leaves less hairy on the upper surface is found by Miss Saunders (1918) to be a simple dominant to the type. Although this condition corresponds to the half-hoary type in stocks, yet in the latter it is due to several factors and behaves as a Mendelian recessive to hoary. This is another example of externally similar characters which are wholly different in their genetic relationships, and it shows that certainty regarding variety relationships can only be attained by actual breeding experiments. D. purpurea nudicaulis occurs wild in various parts of England mingled with pubescens, the hairy type. The latter is usually more abundant and the indications are that nudicaulis has originated from it as a mutation. That a new dominant character can arise by a mutation is known from the case of Enothera rubricalyx among plants or such mutations as bar eye in Drosophila among animals.

From an almost unlimited number of cases of new varieties or forms probably originating as mutations in wild species and often already in process of spreading, we may select a few almost at random.

1 An exactly parallel mutation has long been known in a North American member of the Ericaceæ, Kalmia latifolia. In 1871 Asa Gray (Am. Nat. 4: 373) described a plant from South Deerfield, Mass. showing dialysis with staminody. It was grown in the Arnold Arboretum and figured by C. S. Sargent (Garden and Forest $2: 452$ ). It seeds freely, but apparently its inheritance has not been tested. In 1909 Stone (Rhodora $11:$ 199) independently reported the same form (var. polypetala Nicholson) from the roadside in Leverett near Mt. Toby, and Rehder (Rhodora $12: 1,1910$ ) adds a number of varieties, evidently mutational, of this species. Fernald (Rhodora $15: 151,1913$ ) records near St. John's, Nfid., a considerable colony of $K$. angustifolia with white corollas (forma candida). This form was also found at Sherborn, Mass., and evidently occurs as a sporadic negative mutation which will spread if left to itself. 
The ordinary poison ivy, Rhus toxicodendron of North America, has fruits glabrous or nearly so. A. H. Moore,' records from Bristol, Maine, a form malacotrichocarpum with fruits abundantly pilose. Oxalis stricta, var, viridiflora was desçribed by Hus from St. Louis, ${ }^{2}$ differing from the type in having green petals. The same form was afterwaris found in plenty by Bartlett ${ }^{3}$ near Thomson, Georgia, doubtless arising from an independent mutation. The petals are broader, apparently owing to a change in the shape of the cells, and the presence of chloroplasts may perhaps represent an independent change. Melica (Avena) stricta Michx. has glumes strongly tinged with purple. Forma albicans Fernald, ${ }^{4}$ the prevailing form on some of the mountains of Maine and Eastern Quebec, has glumes whitish or pale straw-coloured. Drosera rotundifolia var. comosa is a dwarf variety found by Fernald ${ }^{5}$ in a hog at the mouth of the Grand River, Gaspé Co., Quebec. It has a sub-capitate inflorescence of few flowers, petals coloured, and the ovary tending to develop into a rosette of grandular leaves. This dwarf occupied a considerable area in abundance almost to the exclusion of the normal. It is evidently a mutational form able to survive in favourable conditions.

Gaylussacia resinosa, the common huckleberry of America, has black berries without a bloom. Var. gluucocarpa Rohinson is common in Eastern Connecticut ${ }^{6}$ where it occurs in distinct clumps generally associated with the species, from which it differs in having blue glaucous fruits and also in its greater vigor and glaucous leaves. Fernald (1917) describes a colony of Bidens by Lake Pocotopaug, Connecticut, which differs from the species $B$. connata of that region in having flat 2 -awned achenes like $B$. heterodoxa of Prince Edward Island. He interprets it as an outlying colony of the northern species, but since its leaves resemble $B$. connata and its var. petiolata it more probably represents a parallel mutation.

The American saxifrage, Tiarella cordifolia L., extends from New England to Minnesota and southwards. In Maine, New Hampshire and Vermont two forms are found. The plants differ

'Rhodora, 11: 162. 1909.

- Rept. Mo. Bot. Garden, 18 : 99, 1907.

- Rhodora, 11 : 118, 1909.

4 Rhodora, 7 : 244, 1905.

- Rhodora. 7 : 8, 1905.

- Sheldon, J. L., Rhodora, 4 : 14, 1902.

Danforth, C. H., 1911. A dimorphism in Tiuvella cordifolie. Rhodora, 13 : $192-3$, 
in a single character, having yellow or orange anthers. This is due to a difference in the pollen, which is clear yellowish green in one form and reddish brown in the other. The latter colour is caused by the presence of an orange colouring matter in the cytoplasm, which exudes through the cell wall when the pollen is placed in alcohol or water. Both types of pollen germinate, and plants with the yellow type of pollen appear to be at least twice as numerous as those with the orange pigment. This is of particular interest as showing dimorphism in a gametophytic character.

Leptospermum scoparium is a polymorphic shrubby species occupying vast tracts of New Zealand, with a series of forms also in Tasmania and Australia. It has conspicuous white flowers sometimes stained with pink. In the north of North Island (Cockayne, 1907) a variety is abundant having invariably pale pink flowers, the colour in the petals being confined to the base of the claw. About 1897 a plant was discovered in Otago having petals bright rose colour over their whole surface. This form is known in commerce as L. Chapmani and is multiplied by cuttings. Later, on the sandhills 200 miles from where Chapmani originated, a plant with rich crimson flowers, was found. It also differed in its more slender, drooping habit, darker foliage, and the flowers were not terminal. From open-pollination a few seedlings like the type were obtained. The evidence indicates that the polymorphism of this species is due to mutation, two of the forms having already established themselves as local varieties.

Coreopsistinctoriı Nutt. is an annual North American Composite, often cultivated and escaped from gardens. It is polymorphic, producing (1) dwarfs, and forms with (2) brown ray florets, (3) tubular ray florets and (4) ligulate disc florets. Raciborski (1908) found in an escaped colony near Lemberg a peculiar type first described by Al. Braun in 1870 . It has numerous adventive shoots arising on the internodes and also on the under surface of the leaves along the midrib and was called var. prolifica. The seeds from such a plant with brown rays yielded 84 offspring, all but 11 of which showed the adventive shoots. Some of the latter were tall, some short, and a few had yellow rays. Seeds of another (yellow) prolifica gave 420, of which all but 16 showed the abnormality. This indicates that the abnormality is probably a recessive, the normals being due to vicinism. Normal plants, however, never gave seedlings with the abnormality, nor could it be produced by wounding or cultivation on rich soil. 
Pernald ${ }^{1}$ describes Silene antirrhina, L. forma Deaneana as differing from the type only in the absence of the glutinous band found on some of the internodes in the type. This form is occasional throughout the range of the species, and is constant in the colonies where it occurs. A considerable number of mutations in wild species are given by Hus (1911), and a number of others have been discussed by the writer ${ }^{2}$ in their relation to phylogeny. Betula nana, L. var. Michauxii, of Newfoundland and adjacent portions of Canada, ${ }^{3}$ differs from the type chiefly in that the bracts of the pistillate aments are commonly simple and oblong instead of 3-lobed. Similarly B. alba, L. var. elobata, Fernald, which occurs on Mt. Albert in Gaspé Co., Quebec, differs from the type in the same respect and is evidently a parallel mutation. Near New Boston, New Hampshire, a tree of $B$. lenta was found having deeply serrate leaves, ${ }^{4}$ a unit variation. Laciniation of leaves and petals is one of the commonly recorded types of variations in plants.

Rhammus curoliniana, Walt. is glabrous or glabrate. The var. mollis, Pernalds differs in having its leaves densely velvety beneath. The pubescent variety occurs in different parts of the range of the species. There is no evidence as to which is the older type. In Erigeron ramosus the reverse change has apparently taken place. Var. septentrionalis, Fern. and Wieg. ${ }^{6}$ differs in having greener foliage, the leaves being sparsely hispidulous or nearly glabrous, instead of cinereous-strigose. The glabrous variety is more northern than the species, occurring in Newfoundland, Eastern Canada, New England and Idaho. This may be because it is better adapted to a cold climate, or merely because it happened to arise in a more northern latitude, but the former seems more probable. A number of species have northern glabrous varieties, but in other species a pubescent variety of a glabrous species is more northern in its distribution. A somewhat different case is found in Fragaria Virginiana, var. terra-nova, ${ }^{7}$ which differs from the type in having the pubescence of the petioles and leaves closely appressed. The variety is abundant in Newfoundland, Southern Labrador, and the Gaspé Peninsula where the type is a rarity. It occurs as far

'Rhodora, 17 : 96, 1915. Also 12 : 129, 1910.

Gates (1917c).

- Fernald, M. L., Rhodora, 15 : 168, 1913.

- Sanford, S. N. F., Rhodora, 4, 83, 1902.

shodora, 12 : 79, 1910.

- Rhodora, 15 : 59, 1913.

'Fernald and Wiegand. Khodora, 13 : 106, 1911. 
south as Maine and Vermont, where type and variety sometimes occur together in the same colonies.

The sunflowers of the middle Western States of America are a polymorphic group represented by great numbers of individuals. In 1910 a single mutant of Helianthus lenticularis with red instead of yellow rays was found at Boulder, Colorado by Cockerell (1912). It proved to be heterozygous and has since behaved as a simple Mendelian dominant in crosses with other species. In the history of its origin it forms an exact parallel to Enothera rubricalyx. Cockerell (1915) has since studied many elementary forms in the wild species. He quotes from Church the history of the cultivated $H$. annuus, L. which is a gigantic nonbranching form. Like maize, its origin in cultivation is only a matter of conjecture. Its seeds furnished the oil supply of preColumbian America, and apparently it is a product of Peruvian agriculture. It is very likely a gigantic form of some unknown species perhaps native of Mexico. Its cells should he examined, and their size compared with the cells of other species. Its relation to $H$.tuberosus, the girasole or Jerusalem artichoke, another Indian food plant, is also a matter of interest. In the latter species Cockerell (1919) has described a number of varieties, in cultivation and possible mutations in the shape of tuber, including multituberculatus, fusiformis, purpureus and purpurellus. 
CHAPTER VII.

Mutations in Animals.

IN animals, the evidence for polymorphism arising through 1 mutation is equally extensive, and a study of any group systematically reveals innumerable instances. As with plants, many of the forms arising in this way, especially in conditions of captivity where selection is eliminated, are to be classed as abnormal, but there are many others to which this does not apply. They represent innocuous or occasionally even advantageous changes, or changes which would be advantageous in certain environments.

One of the convincing cases of an expanding polymorphic group whose various types are mutational in origin is to be found in the land-snails. Gulick (1905) studied the Achatinellidx of Hawaii, and the consideration of isolation as an evolutionary factor is frequently based on his work. More recently Crampton (1917) has investigated the related land-snail genus Partula of the Society Islands. It is well known that each valley often has its own peculiar species or varieties of snails, and this is the classical case of evolution under isolation. From the later studies it has become clear that isolation is not a factor of evolution but a condition in which evolution by mutation may take place.

Crampton's extensive study of the genus Partula in Tahiti has led to definite and well-substantiated conclusions. Over 80,000 individuals were collected during visits in the years 1906 to 1909 . Accurate records of the distribution of species and varieties had been made by Garrett in 1884, and it was thus possible to determine what changes in the snail fauna had taken place during the intervening 25 years. During this period a number of new forms have 
arisen, evidently by mutations, and others have extended or in some cases retracted their area of distribution. The writer states that "mutation has been demonstrated in numerous instances, and in many species belonging to several islands." It is concluded that the morphological differences which appear are due to "spontaneous congenital causes that remain unknown in themselves" but whose effects are produced independently of environment, isolation of the forms in different valleys merely preventing an intermingling of populations.

To mention a few cases of variation in the Tahitian forms, Partula otıheitana rubescens, an exclusively sinistral sub-species, occurs in red and yellow varieties, the former being apparently a a simple Mendelian dominant. P.o. affinis has a dextral coil, but sporadic sinistral mutants occur. Similar reversals of symmetry are also known in other Gasteropods, such as Crepidnla. In afinis the dimensional characters were found to vary from valley to valley. A banded form found by Garrett in a restricted locality now occurs in 20 separated regions of Tahiti, apparently as the result of independent mutations in the local populations. A red-banded form was also found by Crampton-an entirely new bicoloured pattern. Giants also appear in the sub-species affinis and sinistrorsa, and dwarfs in certain colonies of rubescens and other large snails. With regard to inheritance of banding in land-snails, Lang (1912, etc.) has interpreted it in Mendelian terms from breeding experiments with the European Helix hortensis and H. nemoralis.

In the plumage of birds, dichromatisn or the existence of two interbreeding colour varieties, is a characteristic of many species, and the condition has apparently arisen through a mutation. As a typical case, the red and grey phases of the North American owl, Otus asio, have been discussed elsewhere, ${ }^{1}$ the red being apparently a simple Mendelian dominant to the grey phase.

A remarkable case of an inherited variation in goats, which involves the nervous system, is recorded (Hooper, 1916) from Tennessee. In the central and eastern part of the State there is a breed in which, when suddenly frightened, the hind legs become stiff and the animal jumps along. If greatly frightened the front legs also become stiff and the animal falls to the ground rigid. These stiff-legged goats are preferred because they do not jump fences, but it is obvious that in nature such a variation in any mammal with preying enemies would be eliminated by natural

Gates (1917c). 
selection. It seems reasonable to suggest that the so-called deathfeigning instinct in many insects probably originated in the same way. So far as I know, this is the first suggestion of a mutation in an instinct. It would be selected in those insects in which such action would save their lives.

The hornless condition in cattle is another mutation of much interest. Horns are known from the palæontological record to have undergone a gradual progressive development in various groups of Mammals, while in the polled breeds the horns have apparently been suddenly lost through a mutation. Punnett ${ }^{1}$ has suggested that the hornless condition may have co-existed in a species along with the gradual development of horns. 'Since the polled condition is dominant, however, at least in cattle, the recessives would all be devoid of a factor for hornlessness. And since the horns are a highly serviceable and necessary weapon of defence in the wild species, it seems very probable that the original hornless type would be stamped out by selection as soon as horns developed far enough to become a valuable weapon. This would take place whatever the causes of the progressive development of horns. There are no traces of hornless cattle before the historic era, although Herodotus describes the domestic cattle of the Scythians as hornless. In the last two centuries many hornless varieties have arisen and the origin of some polled breeds is known. ${ }^{2}$ The hornless mutation is in a sense a reversion as regards that character, and as such is comparable with peloria in flowers. The polled Hereford breed uriginated from a mutant at Atkinson, Kansas in 1889.3 Being dominant, it cannot be supposed to have been present in the germplasm before its external appearance.

An interesting and little known work by Bonavia (1895), while containing some unacceptable ideas, devotes a chapter to monstrosities as probable factors in the creation of species. Among fishes are cited the sword-fish Histophorus gladius with its upper jaw prolonged, Hemiramphius and various others with the lower jaw prolonged; also Zygœna the hammer-headed shark, which may have originated monstrously by a projection of both ocular regions. A hairless condition is normal in certain races of Chinese and Mexican dogs. It occurs as an anomaly in horses cattle and dogs, and hairlessness in man " may have occurred all of a sudden

, Mendelism. MacMillan.

- See MacDonald and Sinclair, 1882. History of polled Angus cattle.

- Walter, H. E. Genetics, MacMillan, 1913. 
as a monstrosity." Peatherless birds are not unknown, or only certain pterylæ may be affected, as in the bareneck fowls (Davenport, 1914), a condition which is dominant in crosses. A well known case cited by Stebbing is that of Dorippe dorsipes with four legs, and four more small ones on its back. It is therefore clear that even mutational monstrosities have played their part in the production of species, and it is quite certain that if some family and ordinal characters could have been seen at their first appearance they would have been considered monstrosities.

Dwarfs and giants are as common in animal species as among plants. A dwarf-bearing strain of guinea pigs is described by Miss Sollas (1914). It produced in all 192 normals to 64 dwarfs, the latter evidently behaving as a simple Mendelian recessive. The study of inheritance of melanism in British Lepidoptera has in recent years attained considerable proportions. These results can only be touched upon here, but they show that the melanic variety usually behaves as a Mendelian dominant, sometimes a recessive, and in certain cases gives blending inheritance. A number of cases are discussed by Bateson (1913, p. 135 ff.)

Sumner (1917) has obtained mutations in the Californian deermouse, Peromyscus maniculatus, both in the wild state and in captivity. A "yellow" mutation of P.m. gambeli was trapped at LaJolla, California in 1914. The normals have a dark gray pellage and black eyes. In cages a total of 14 normal to 7 yellow appeared, in broods which were traced back to a single pair of grandparents. There were no other yellows among over 400 gambeli bred. Hence the appearance of the yellow was due to a recessive mutation factor carried in the two grandparents. Castle has reported similar "yellow sports" in wild species of Microtus. 


\section{CHAPTER VIII.}

\section{Limitations of the Cell Theory.'}

The work of the present century in experimental breeding and cytology has led to many new points of view and new lines of approach to old problems. It therefore seems desirable to examine our present bearings from the point of view expressed in previous chapters. That the experimental method of attack upon the problems of variation and heredity, as well as those of embryology, is sound and of the utmost value cannot be gainsaid. On the other hand, it does not follow that the older conceptions of evolution, natural selection, and the inheritance of acquired characters are necessarily unsound or, if adhered to, subversive of the modern experimental results. We wish to show (1), that the experimentalist point of view resulting from the work in mutation and Mendelism is frankly antagonistic to the views of many palæontologists, anatomists and others who deal with the non-experimental data of evolution involving orthogenesis and the inheritance of acquired characters (2), that while these two factors bear entirely different relations to evolutionary changes, both are necessary to account for evolution as it has taken place.

It may be said that the divergence between the geneticist point of view and that of the biologist who relies upon the listorical back. ground of evolution for his interpretation of evolutionary factors has long been manifest; and that is true. Yet we venture to think that no one has clearly visualized or set forth the fundamental character of this antagonism, in relation to the structure of the organism. Moreover, those who have recognised the opposition between the principles of germinal variation and inheritance of acquired characters in evolution have usually endeavoured to solve the difficulty by denying or ignoring one principal and affirming the other. Rather, we think it necessary to harmonize these two conflicting views into a more complete and balanced conception of the evolutionary process.

We propose, then, to show that higher organisms exhibit two sharply contrasted types of characters which differ fundamentally, (1) in their manner of origin, (2) in their relation to the structure of the the organism, (3) in their relations to such phenomena

1 The following chapters are cliefly based on a discussion "On the Existence of two fundamentally different types of characters in Organisms," which took place at the Linnean Society, February 5 th, 1920. 
as recapitulation, adaptation, inheritance, and distribution. The first class of characters are (as already expressed in Chapter 11.) cell-characters, which have arisen through mutations, are represented in every cell of the organism, and are usually inlierited as distinct units. Since they arise in and are carried by the nuclei they may be called karyogenetic. To the second category belong characters which arise gradually in the organism through impact of the environment or through "orthogenesis," " may apply only to localized portions in the life-cycle of the organism, and at first are not incorporated in the germplasm. Such characters we may call organismal, in contradistinction to cell-characters. Organismal characters may imply an increase in the length of the life-cycle, as strikingly evidenced in so many animal larvæ which undergo metamorphosis, or they may show stages in shortening, as in the gametophytes of many higher plants.

The attitude of experimental biologists to the questions of recapitulation and inheritance of acquired characters (although the former has never fallen into the same disrepute as, the latter) has been generally one of skepticism and denial. Reasons for adopting a different position may be given as follows: (1) the difficulty of explaining adequately the abundant facts of recapitulation in plants and animals by means of mutations or changes originally germinal; (2) the logical necessity of the principle of functional inheritance in some form to explain the origin of embryonic recapitulatory characters involving adaptation; (3) the approach to an understanding, through such agencies as hormones and enzymes, of how the transmission and ultimate germinal fixation of somatic modifications may take place; (4) the slowly accumulating direct experimental evidence for parallel induction and the transmission of modifications.

In contrasting organismal with cell characters we are contrasting two points of view regarding the organism which are at least as old as Aristotle and Empedocles. Modern representatives of these views speak of the organism as a whole on the one hand, and of elementalist or particulate theories on the other. It scarcely needs pointing out that elementalist conceptions, particularly of

- An orthogenetic result may also of course arise from a succession of germinal changes or mutations following each other in any line of phylogeny.

? In the Linnean discussion, Professor F. E. Weiss suggested the obvious antonym cytogenetic for this category of characters, since they are apparently cytoplasmic in origin. This term had already been considered, but was finally discarded because "organismal " expressed better the idea desired. Nevertheless it will be a useful term in certain connections, 
heredity and variation, have had a wide vogue in recent years. On the other hand, Loeb (1916) and from a different point of view, Ritter (1919), among others, have recently championed the organism-as-a-whole. The latter writer has pressed this view farthest, in the endeavour to eliminate elementalist conceptions altogether. We believe a truer attitude lies in the recognition of a fundamental truth in both these aspects.

In a former work ${ }^{1}$ and in earlier chapters of this series we developed a cell theory of mutations emphasizing the fact that each new form arises as a germinal difference from the parent type. The cell unit, in all such variations, is the thing which has changed, and the new external characters which appear in every part of the organism are the structural result of an ontogeny built up with a different unit as basis. ${ }^{2}$ This situation was particularly clear in Enothera gigas, where it was shown ${ }^{3}$ that the volume of the nuclei and cells has increased in varying proportions in different tissues. Tupper and Bartlett (1916) have confirmed and extended these results in the case of $E$. stenomeres mut. gigas which is also tetraploid or $4 x$ in the constitution of its nuclei.

Without going farther afield for confirmatory data, which are amply furnished in the contemporary literature, we may conclude that the mutation theory of germinal variations is firmly grounded upon the cell theory, and if the cell theory were universal in its application then mutations or germinal changes might be supposed to supply the whole of the material for evolution in organisms. Facts such as those pointed out above lead to the concept of the species cell. This is a conception which has been independently arrived at by different lines of approach (see, for example, Lang, 1909). It is a sounder and less extreme conception than that of the organism as a cell-state, i.e., merely an aggregation of more or less independent cell units.

Biologists have long recognized the necessity for limitations of the cell theory of organic structure. On the one hand we have the legitimate and necessary conception of the species cell, briefly set

- The Mutation Factor in Evolution.

2 If this be the case, then the mitoses during ontogeny do not bring about the unequal division and sorting out of portions of the chromosomes, as Weismann supposed; but all these divisions are, as they appear, equational so far as the chromosomes are concerned. This conclusion has also been reached from the study of cxperimental embryology (Conklin, 1916) and from other lines of approach. So far as the chromosomes are concerned, their materials are apparently not as a rule segregated by differential divisions during ontogeny. On the other hand, differential divisions of the cytoplasm are of frequent occurrence.

Gates, 1909a, 
forth above, implying that germinal changes arise in a fixed life. cycle through a change in the cell unit which is represented in every nucleus and therefore may modify every stage of the new organism.' On the other hand, if the more fundamental facts of recapitulation mean anything, they imply that at some time an actual lengthening of the life-cycle has taken place, either by the addition of cell divisions at its end or by their intercalation at some point. Such a process can not easily be accomplished by a variation in the structure of the cell or nuclear unit itself, but must rather be the result of the organism as it were overcoming its cell shackles and by its own energy producing new developments, though such novel additions are themselves cellular in structure.

From the time the foundations of the cell theory were laid by Schleiden and Schwann in 1838-39, its universal sway was scarcely questioned for over half a century. During this period it was established that cells arise only from the division of previous cells, and the cell theory culminated in such conceptions as the physiological division of labour among cells, the mosaic theory of embryonic development, the individual as the sum of the activities of its various cells. In short, it came to be assumed that cells make the organism, while the contrary fact that the organism after all makes its cells was tacitly or explicitly denied. In the same way it was assumed that each cell of a multicellular organism necessarily corresponded with the whole organism in the Protozoa.

One of the first reactions from this extreme development of the cell theory, which made the organism not a master in its own house but a slave of its constituent cells, was a well known paper by Sedgwick (1894) on the inadequacy of the cell theory of development. His views were hased on studies of the embryos of Peripatus capensis, which he believed were essentially cœnocytic in structure; also upon the development of mesenchyme and nervous tissue in Elasmobranch embryos. As far as Peripatus is concerned, delicate cell walls have recently been demonstrated (Glen, 1918) both in the ectoderm and endoderm layers, by careful preparations and the use of an immersion lens. But their demonstration does not affect the fundamental question of the relation of the cell to the organism, for, to mention only a few cases, it is well known that in the formation of the blastoderm of the insect egg, as well as in the early stages of development of the female gametophyte and proembryo in Gymnosperms, a stage is passed through in which

1 It appears that, especially in animals, the change is frequently visible or obvious only in certain organs. 
there is multiplication of free nuclei, ${ }^{2}$ which arrange themselves in a particular manner, but without the formation of cell walls until later. That cells can develope within a cell is also well exemplified in the development of the embryo-sac of Angiosperms.

In the same year Whitman (1894), in a notable paper, attacked the cell theory on fundamental theoretical grounds. He concluded that the formation of the embryo is not controlled by the form of the cleavage. "The plastic forces heed no cell-boundaries, but mould the germ-mass regardless of the way it is cut up into cells." His position was that "organization precedes cell-formation and regulates it."

It is impossible here to enter into a discussion of the various views which grew out of the extensive studies on cell-lineage, but granting the accuracy of the above limitations of the cell theory, it will be seen that they are in no way out of harmony with the view of mutations as cell variations, or rather nuclear variations, previously expressed. Another limitation of the cell theory will be considered in the next chapter.

1 Incidentally it may be pointed out that any comprehensive theory of heredity must be one which is applicable equally to those cases in which regular cleavage of the egg takes place and those in which in one stage the embryo contains free nuclei. Since the nuclei are the only structures in common, and the laws of inheritance remain the same in both cases, ergo the nuclei and not the planes of cleavage must determine those laws: 


\section{CHAPTER IX.}

The Recapitulation Theory.

The recapitulation theory has had many vicissitudes both in its application to plants and to animals. The conception has been stated and restated many times in varying terms, but that ontogenetic stages may have a phylogenetic significance has rarely been denied and has more often been implicitly assumed. The principle was tacitly recognized even hefore Darwin, and he accepted it practically without reserve. Indeed it was one of the foundation stones in his argument for evolution.

It is desirable also to point out that any theory of recapitulation which is to have any significance in the interpretation of life histories must recognize that in the last analysis recapitulation implies that at some stage in the evolution of any group an increase in the life-cycle took place, by the addition of certain stages. This is in sharp contrast with a germinal change, which necessarily modifies every stage, at least internally as regards nuclear structure, but can hardly be held to add anything to the adult stage of development, or in other words to increase the number of stages in the life-cycle.

Recapitulation and the alternation of generations in plants.

As regards plants, it may first be pointed out that the theory of the antithetic alternation of generations, which has been widely adhered to by botanists and has been given its most notable expression in the classic volume of Bower (1908) on The Origin of a Land Flora, implies from the evolutionary point of view a continued lengthening and increase in complexity on the part of the sporophyte, and in seed plants a contemporaneous shortening and simplification of the gametophyte. This theory runs like a golden thread through all the speculations concerning the origin and larger relationships of the main groups of vascular plants, and there is nothing quite corresponding to it among animals. In the able hands of Bower, it implies that the sporophyte generation resulting from the fertilized egg is intercalated between two gametophyte generations and has gradually increased in complexity or length through the Bryophytes, Pteridophytes, Gymnosperms and Angiosperms in connection with their gradual transition and adaptation from aquatic or moist to typically terrestrial conditions.

True, the theory of homologous alternation in plants has also been held, though not so widely. It was for a time based chiefly 
on the facts of apogamy and apospory in Ferns, and experimentally induced apospory in Bryophytes (Lang, 1901). But even when of natural occurrence, these are generally admitted to be exceptional conditions of recent development. The careful cytological studies of apogamy and apospory, however, led Farmer and Digby (1907) to the conclusion that these phenomena leave the question of alternation essentially where it was. It need only be pointed out here that the theory of homologous alternation of generations in plants corresponds to such a view as would restrict the significance of recapitulation to a great degree; while an important phase of the antithetic theory is that it implies a lengthening of the sporophyte generation in connection with the adaptation of plants to a terrestrial habitat.

In his original studies of apogamy and apospory, Lang (1898) carefully refrained from giving his views a bias in either direction. More recently (Lang, 1909) he has propounded an interesting conception of homologous alternation from an ontogenetic point of view. ${ }^{1}$ Briefly the view begins with the concept of the species cell, based on the fact that any cell of the species is potentially able to reproduce the whole plant. This being the case, "the haploid and diploid germ-cells have potentially the same morphological properties." But they are believed to develop different generations because the germ cell is exposed to different conditions in initiating the two generations. This interesting suggestion, however, encounters many serious difficulties, some of which were pointed out in a criticism by V. H. Blackman (1909).

It cannot be said that the homologous view has received wide support as regards Archegoniates and their descendants, but on the other hand important evidence has developed for the occurrence of homologous alternation in Algæ. It is significant that in this group the gametophyte and sporophyte generations develop under the same relatively uniform conditions, exposed to sea water, and they are morphologically alike. Without discussing the subject in any detail, ${ }^{2}$ it may be pointed out that Yamanouchi (1906) found in the red alga Polysiphonia an alternation of generations, which he regarded as antithetic, between tetrasporic plants having 40 chromosomes and sexual plants with 20 , the cystocarp being a part of the sporophytic phase. Lewis (1909), in a study of another of the Rhodophyceæ, Griffithsia, has taken up a more advanced position

- See also the discussion on alternation of generations at the Linnean Society, published in New PHYTOL. 8 : 104-116, 1909.

3 For recent discussions of the life-cycles in Algæ see Fritch (1916) and Davis (1916). 
which appears to be well justified by the facts. The life history of Griffithsia is in general parallel to that of Polysiphonia, the tetrasporic plants apparently having 14 chromosomes and sexual plants 7, though there is some doubt about the accuracy of these counts.

According to the views of Lewis, there is (1) an antithetic alternation between sexual plants, representing the gametophytes, and the sporogenous cells of the cystocarp, representing the sporophyte, (2) a regular succession of tetrasporic and sexual individuals representing an homologous alternation of generations but not equivalent to the alternation in Archegoniates. He believes that the tetrasporic plant has been intercalated in the life history, not through the "gradual differentiation of a simple product of the germination of the zygote," which is the pith of the antithetic theory; but, as Yamanouchi suggested, through the suppression of chromosome reduction in the formation of a carpospore which then at once grew into a tetrasporic plant.

In concluding a brief survey of this very large subject of alternation, we may remark that the antithetic theory, which continues to receive the larger number of adherents, implies just such a lengthening of the life-cycle as is indicated by recapitulatory phenomena. The homologous theory, on the other hand, would account for the alternation through the sudden intercalation of a generation in Algr as the result of a change in spore development which is essentially mutational. In Archegoniates, the homologous view would apparently imply the gradual simultaneous progressive differentiation of gametophyte and sporophyte through differences in the environment in which the asexual spore and the fertilized egg develop. But as Farmer ${ }^{1}$ has pointed out, it is impossible to imagine how the Bryophyte sporogonium at any rate could have arisen through modification of the gametophyte. It seems clear that this structure at least must represent an intercalated phase progressively developed. Each group of plants must then, as Farmer has emphasized, be separately considered on its own merits, on the basis of the historical probabilities as determined by comparative morphology.

\section{Recapitulation phenomena in Gametophytes.}

It may be noted in passing that although plants " climbed out of the water" at a remote period, yet large groups of Bryophytes and Pteridophytes still survive although imperfectly adapted to life on dry land. This, as Bower points out, is probably because the

I New Phytol. 8; 113, 1909. 
sporophyte has developed far enough to make possible the production of spores in sufficiently large numbers to ensure the passage through the difficult stage in the life-cycle when water is a necessity for the accomplishment of fertilization. Only in vascular plants above the Cycads has complete adaptation to terrestrial conditions been accomplished, by the adoption of siphonogamy and the loss of swimming sperms. ${ }^{1}$ Nevertheless, the higher siphonogamous plants do not, except in rare instances, show recapitulation stages of their gametophytes. In other words, the gametophyte development is usually direct. This can hardly be because the gametophyte in its later evolution forms a reduction series, because among animals the most remarkable and convincing instances of recapitulation occur where degeneration has taken place as a result of parasitism or the adoption of sedentary habits. Typical recapitulation phenomena do nevertheless appear in plant gametophytes. For instance the archegonium, which is so characteristic an organ in Bryophytes, and has given an aggregate name to the three great groups in which it occurs, persists in a progressively reduced form throughout the Gymnosperms until we reach the higher Gnetales, although in certain Araucarians (Eames, 1913) it has become a positive hindrance to fertilization. In this case the archegonium neck cells have developed into a thick-walled structure which the pollen tube cannot penetrate. But the jacket-cells adjacent to the neck are actually eliminated, thus making it easier for the pollen tube to reach the central cell. No more striking case could be cited of the continued production of an organ which not only has lost its function but which is a positive hindrance to the functioning pollen tube, though its retention has entailed other structural changes in the jacket-cells to facilitate fertilization.

Thus throughout the Gymnosperms, the gametophyte is being reduced, and recapitulation phenomena which suggest an ebbing tide occur in its terminal stages. The archegonium itself shows a gradual series of reduction stages until it is finally eliminated. In the lower Gymnosperms it has already lost the neck canal cells found in the archegonium of Mosses and Ferns, and among the Conifers the ventral canal cell is gradually eliminated. In the Abietineæ (see Coulter and Chamberlain, 1910) a ventral canal cell is cut off, in the Araucarians the nuclear division takes place but no cell wall is formed; or in some species of Pinus a wall may be

' It is well known that similar types of adaptation from aquatic to terrestrial conditions have occurred in the Fungi, involving the loss of free swimming gametes and the development of some form of siphonogamy. 
formed in some instances and only a nucleus in others. In every case this ventral canal cell or nucleus is only a reminiscence which continues to reappear as a terminal stage although in its origin it dates back at least to the Liverworts. But it appears to be finally eliminated in the Taxodinex. The cases just cited, however, do not involve recapitulation so far as the individual ontogeny is concerned. They are only seen to be closely related to such phenomena from a comparative phylogenetic point of view.

Such a reduction series Coulter (1915) no doubt justly considers to represent the expression of an orthogenetic tendency, though whether it is the result of climatic differentiation is not so clear. The series derives its interest from the fact that the higher Gymnosperms, in which the archegonium is quite eliminated, must have had ancestors in which that reduction gradually took place. From our present point of view, the explanation cannot be found in a series of successive nuclear variations or mutations, for these would make themselves felt in other parts of the organism, affecting many characters in a correlated fashion. Though the argument is by no means conclusive as regards this matter, yet it seems most reasonable to consider these as organismal characters and to explain the shortening of the gametopluyte generation in the same way that recapitulatory characters find their explanation. The direction in which that explanation is to be sought will be discussed below.

Another support for this view may be found in the fact that the chromosome number is remarkably uniform throughout the Gymnosperms, being, with few exceptions, 24. If the evolution of the Gymnosperms had taken place largely through mutations, i.e., through clianges arising in the germinal chromatin, one would expect it to have produced some effect on the chromatin morphology in the various species. The Angiosperms, by contrast, in which there is evidence that much mutation has taken place and is now going on, are characterized by remarkable variety in number, size and shape of their chromosomes even within single families or genera. The same is true of insects.

Other cases of ancestral reminiscence in gametophytes, as though the organism repeated certain stages from force of habit or from some source of energy impelling its development forward, are to be found in Angiosperms. In the nuclear divisions within the embryo sac an evanescent cell-plate sometimes appears on the spindle. But this reminiscence of wall-formation soon disappears along with the spindles. The same is true of the prothallial cells 
in the male gametophyte of many Gymnosperms. There is one such cell in Cycads, which persists. Ginkgo has one ephemeral and one persistent prothallial cell which are cut off in succession by the side of the microspore, while in Pinus both prothallial cells dwindle promptly to șmall dark-staining masses, as though the life had quickly gone out of them. The nucleus may begin to disorganize even before the cell-plate is formed. Such structures represent momentary stages of an ebbing tide. In Picèa canadensis, Hutchinson (1915) has found all these and other conditions to occur as variations.

Recapitulation in the Sporophyte.

If now we turn to the sporophyte, we find again many of the most striking cases of recapitulation in Gymnosperms. Indeed they appear to be of more frequent occurrence in this group than in any other plants. A possible reason for this has already heen suggested, namely the relative infrequency of mutations. It is well to keep in mind also that recapitulation in the sporophyte usually indicates adaptation to altered conditions. Among well known instances in Conifers may be cited the genus Phyllocladus, characterized by an absence of leaves, the branches forming flattened leaf-like expansions. The seedlings, however, have a terete axis bearing ordinary leaves and this obviously represents the ancestral condition, from which for some unknown reason the genus departed. That such an alteration is not mutational is indicated, according to the present interpretation, by the fact that the ancestral condition is thus clearly present in the earlier stages of ontogeny. A mutational change, being represented in every nucleus from the fertilized egg onwards would have eliminated, or rather transformed, this juvenile stage. In Enothera, as de Vries (1909) pointed out, the first leaves after the cotyledons make it possible to recognize a mutant form.

To mention threeothercases of recapitulation in Gymnosperms : A feature of the genus Pinus is the occurrence of dwarf shoots, each bearing a fascicle of needle leaves. But in the seedling the leaves are scattered on the stem as in other conifers. Similarly the genus Larix, unlike most conifers, has deciduous leaves; but in the juvenile stage the leaves adhere for several years. In the Mariposa grove near the Yosemite valley in California I observed that Sequoia gigantea is a number of years old and many feet high before its foliage acquires the characteristic appressed form. When grown in the English climate, this appressed type of foliage appears never to be quite reached even in old trees. 
Other writers have carried the principle of recapitulation much farther, and notably Jeffrey (1917), who applies it to the histological structures of vascular tissues, and further finds that regeneration after wounding frequently leads to the reappearance of ancestral characters. This principle is freely used by him in the comparison of living with fossil forms, and in the interpretation of phylogenies. To cite examples from the Araucarian conifers, it has long been known (Thistleton-Dyer 1901) that in the adult stem of these trees, owing to the continued activity of a cambium the leaf traces have the peculiarity of being persistent for many years after the leaves have fallen. Another well known peculiarity of Araucarian wood is that the bordered pits in the xylem tracheids are alternate in origin, not opposite as in other living conifers. Jeffrey (l.c., p. 236) points out that in Mesozoic araucarian woods belonging to the genus Brachyoxylon the leaf traces persist only for a short time, and the bordered pits are not alternating and crowded as in the living genera. In seedlings of the modern Agathis and Araucaria, however, "the leaf trace persists only so long as it is related to a functional leaf," and the pitting is like that found in the Cretaceous Brachyoxylon. Such a striking case of recapitulation-and others of like nature are known-can hardly find its explanation in a germinal change which belongs equally to every cell.

While these principles of recapitulation seem for the most part well established, cảution must of course be used in their application, especially in these more complicated cases; for it would be easy to deduce incorrect phylogenetic conclusions by attaching more significance to such cases than they really possess. It is important also not to lose sight of the fact that recapitulation phenomena occur where there has been adaptation to new conditions. Such changes are often climatic, but may also be environmental in the widest sense.

One instance of more doubtful recapitulatory phenomena in plants must suffice. In a recent paper on Rhododendron seedlings, Professor Balfour (1917) has shown that many of the species in their earlier years pass through a series of changes in the pigmentation and pubescence of their leaves. Thus in $R$. adenogynum Diels the under surface of the leaves is red glandular in the seedling. But about the third year the redness disappears as well as the glandular hairs. After some seven years the buff-coloured tomentum of long, interwoven, branched hairs begins to show at the base of the (now green) leaves, and gradually in later years 
covers the whole under surface of the leaf. Similar developmental changes take place in a number of other species.

Balfour thinks this developmental modification is in relation not to a climatic change in the habitat of the species, but to the differences in environmental conditions as regards, light, moisture, heat and air currents encountered by the leaves of the young plant near the soil and of the older plant at a higher level. He points out that a higher temperature and a more rapid metabolism (subserved by anthocyanin) are important at first, while control of transpiration (subserved by tomentum) is important later.

The above case could not be regarded in itself as evidence of recapitulation, but it serves to show how indubitable recapitulatory phenomena shade into those which have only a physiological or ecological rather than an ancestral significance.

Summarizing the data of recapitulation in plants, we may say that recapitulatory characters are found chiefly $(1)$ in the seedlings of Gymnosperms and some Angiosperms, (2) in the terminal stages of gametophytes, (3) in wood structure; but as a rule they have been lost from the ontogeny through the cellular development becoming direct. If the antithetic theory of alternation of generations be correct, however, then a large part of evolution has been concerned with the gradual development of characters which were originally organismal and have become in some measure recapitulatory.

\section{Recapitulation in Animals.}

Important and significant as are the indubitable cases of recapitulation in plants, the phenomenon is much more prevalent in animal development. This may perhaps be connected with the fact that the animal in development may he said to have greater power over its cells owing to their thinner walls and greater plasticity. ${ }^{1}$ A striking phenomenon in the cleavage of animal eggs is the mutual readjustment of the cells with relation to each other which goes on after each cleavage. ${ }^{2}$ In this way the forces of the

1 A number of facts indicate that in some respects animals have greater powers of regulation than plants. One need only mention $(a)$ phenomena of metamorphosis in which tissues may break down and be used again in the building up of new structures; and $(b)$ the fact that in Metapodius (IVilson 1910) and Drosophila (Bridges 1916) the presence of one or even several extra chromosomes (duplicates of one member) in the nuclei produces no external alteration; while the duplication of one chromosome in CEnother'a produces striking external differences. The recent studies of Rosenberg (1918) on Crepis indicate that here also the duplication of a pair of chromosones alters the external features of the plant.

2 It is a well known fact that cleavage itself is a rhythmic process, in which a period of simultaneous nuclear division alternates with a period of nuclear growth, and this rhythmic alternation is accompanied by a physiological rhythm in $\mathrm{CO}_{3}$ production, permeability, etc. 
organism can, as it were assert a power over the cells in maintain. ing a unity of structure during development to a degree which is not possible with the thicker cellulose walls of plants, though in woody stems growth-pressure produces a certain amount of such readjustment of dead cells. In any case, whatever the reason, it remains true that while development in plants is usually direct, and recapitulation the exception, the animal embryologist is confronted with recapitulation on all hands with such amazing profusion that a comprehensive principle is more obviously required for their explanation.

Another explanation of the difference between plants and animals in the occurrence of recapitulation may lie in a greater frequency of mutations in the phylogeny of plants. Also, animal groups in their evolution have probably passed more frequently by adaptation from one habitat to another. Witness, for example, the number of groups from Ephemeridx to whales or penguins which have become secondarily modified for an aquatic life. Even when a like occurrence happens in plants, the stages of it are often nearly or quite obliterated by short-circuiting. It is therefore quite unsafe to argue in the case of plants that because a given adaptational character shows no recapitulation in development it must have originated through a germinal change. Such an attitude stands a better chance of being sound in the case of animals.

Concerning the facts of recapitulation, MacBride's textbook of embryology-Invertebrata (1914) is a veritable mine of information. His attitude represents a return to an interpretation of the significance of larval stages in relation to phylogeny on a frankly neo-Lamarckian hasis. Embryologists of the last two decades have largely endeavoured to avoid this attitude, but without conspicuous success. MacBride assumes that larval stages represent actual ancestral groups of organisms. It is also significant, as we pointed out in the case of plants, that the recapitulation seems always to have originated in connection with the adaptation of the animal to a new set of conditions.

Although we have never seen it explicitly stated that embryonic recapitulation implies the inheritance of acquired characters, ${ }^{1}$ yet it is probably the tacit recognition of this fact which has led to the denial of recapitulation by those who believe only in germinal variations as material for evolution.

1 Since this was written I have received from Professor MacBride (1917) a paper which I had not previously seen, in which it is definitely stated that recapitulation implies the inheritance of acquired characters, and citing a number of cases in support of this view. 
Zoologists are generally agreed that the nauplius and zoæa larvæ of Crustaceans and the veliger larva of Molluscs represent ancestral stages; similarly, that the trochophore larva of Annelids and Molluscs shows these two very divergent groups to have been derived from a common ancestor. MacBride would go further and say that the trochophore is a smaller and somewhat reduced or specialized representative of that ancestor. According to the interpretation here adopted, the various larvæ at one time represented terminal stages in their respective life-cycles, and by subsequent evolution they were not modified out of existence or out of recognition through germinal changes, but became subterminal through the addition of later stages to complete the ontogeny. In a field where every larva has its ancestral significance, it is almost invidious to single out particular cases for illustration. The tadpole of Ascidians, which gave the first hint of the Chordate affinities of this group, is a striking instance. Only the degeneration and special adaptations resulting from the adoption of a sedentary life can account for their remarkable transformation, and we fail to see how it can be adequately explained except on a neo-Lamarckian basis. An equally irrefutable case of recapitulation is that of the featherstar Antedon, whose egg developes into a free-swimming larva which later becomes fixed by a stalk. This fixed stage corresponds with the modern genus Pentacrinus. The adult feather-star developes cirri and, losing its stalk, becomes free again. Can anyone pretend to believe that this remarkable series of transformations does not recapitulate the history of the race? And, if so, how can one avoid the conclusion that the life-cycle has been lengthened?

A type of recapitulatory character corresponding to the appearance of evanescent stages in the gametophytes of the Gymnosperms, is found in certain nauplius larvæ. MacBride (1.c. p. 204) regards the nauplius as representing the common ancestor of all Crustacea. He says, "When the larva does not hatch out as a nauplius, a cuticle is produced and shed by the embryo whilst still within the egg shell when it reaches the nauplius stage, thereby showing that formerly this stage must have been passed through in the open, in the ancestors of the forms in which it is now purely embryonic." Again, in the oyster, which has no foot and becomes permanently attached by one valve of its shell, the veliger larva nevertheless possesses a functional foot which is therefore a recapitulatory character. 
Perhaps the most convincing of all cases for a Lamarckian interpretation of recapitulation is that of the parasitic Copepod, Achtheres ambloplitis, where as MacBride remarks, "we may almost say that the ancestor is known." The adult is a parasite on the gills of the rock-bass, and is a sac-like organism devoid of all semblance of Copepod structure, yet the animal passes through a brief larval stage which anyone would recognize at once as representing a typical Copepodan genus. Whatever explanation applies to this remarkably clear case must also apply mutatis mutandis to the whole series of larval stages which represent the remoter ancestry in other organisms. We think this case furnishes one of the clearest evidences of the sharp contrast we are endeavouring to draw between recapitulatory and mutational, or in other words, hetween organismal and karyogenetic characters. Yet it is admitted that even in this Copepodid larva there are modifica. tions from the typical details of Copepod structure. But they follow the usual lines of diminution in size of the larva and consequent reduction in the number of metameric parts. Another factor which tends to obscure ancestral stages is the well-known principle of telescoping, or the earlier appearance of embryonic organs, which has been called heterochrony by Lankester, or tachygenesis by French writers (Perrier and Gravier, 1902). That embryonic and larval stages can also undergo special modifications of an adaptational nature is another well recognized principle which tends to obscure ancestral relationships.

Many of the battles of recapitulation have been fought over the frog, so we may briefly examine his case. Some embryologists have gone so far as to deny any ancestral significance to the tadpole. While the other extreme view, that all larval. characters of the frog have ancestral significance, is certainly disproved; yet the truth evidently lies in a recognition of the fact that in the tadpole as in most other larvæ, there are some recapitulatory or palingenetic characters and some adaptational or cœnogenetic characters. The obvious recapitulatory characters are the fish-like tail, gill arches and blood system. It seems impossible to avoid the conclusion that these were once terminal developmental stages, in the frog's fish-ancestor. On the other hand Boulenger (1918) has pointed out that tadpoles have had an evolutionary history of their own and have developed special adaptational features. He enumerates (Boulenger 1897) "The horny beak and circular lip with its horny armature, the spiraculum, the enclosure of the fore. 
limbs in diverticula of the branchial chambers, and such special adaptations as the ventral disc or sucker of certain mountain forms." The existence of such adaptational characters is supported by the fact that certain species differ more widely in their tadpoles than in their adult stages. Thus (Boulenger and Annandale, 1918) the Indian species Rana tigrina and $R$. cancrivora are so similar as frogs that the latter was classed as a variety of the former. But Annandale (l.c.) has shown that the tadpoles differ markedly in buccal armature. Whether this is a case of convergence of the adult species, as Dr. Annandale thinks, or divergence of the tadpoles, as Dr. Boulenger believes, need not concern us here, though from analogy the latter interpretation appears more probable.

To return to the recapitulatory characters, the transformation of the fish-like gill-arches of the tadpole into the aortic arches of higher vertebrates is too well known to require comment here, except to point out that it comes about through the gradual substitution of one series of blood vessels for another, the branches to the gills being gradually pinched off and the blood stream diverted to the more direct route to the lungs. The specious, argument that the development of any recapitulatory character must go through such preliminary stages for purely structural developmental reasons is now seldom heard and can very well be consigned to oblivion. Developmental mechanics as well as comparative embryology tell strongly against it.

The experiments of Gudernatsch (1914) in greatly retarding or hastening the time of metamorphosis by feeding tadpoles on thymus or thyroid respectively, showing that growth and differentiation are separate factors, do not affect our present interpretation. They merely indicate that the processes of development and metamorphosis are physiologically controlled by something in the body of the nature of hormones or enzymes secreted by certain tissues. A recent paper (Morse, 1918) has attempted a further analysis of the processes that lead to atrophy of the tail in metamorphosis. The writer concludes that autolysis is the primary physiological factor. The first step in atrophy, according to Barfurth, is the growth of the pygostyle which, by occlusion of the blood vessels in the tail, causes an accumulation of $\mathrm{CO}_{2}$ and acids. This acidosis of the tissues induces autolysis. In this condition the phagocytes are chemotactically attracted to the atrophying organs, so that phagocytosis is a secondary, and not the primary factor as Metschnikoff supposed. Hormones or enzymes probably stimulate 
the development of the pygostyle, but something must in turn determine the development of these. Morse concluded from his experiments that it is possible to suppress metamorphosis, but that it cannot be induced in stages far removed from those in which it would normally occur. A certain cycle of events determined by heredity is necessary before any stimulating agent will cause metamorphosis.

Although we have spoken of recapitulatory characters having been at one time terminal stages in the life-cycle, yet it appears that they have not always been added terminally but have often been intercalated at a subterminal or earlier stage. Thus in plants the sporophyte ends inevitably with sporogenesis, so that the lengthening of the sporophyte generation must always have taken place through the addition of subterminal stages, involving the delay of sporogenesis. ${ }^{1}$ In animals, too, spermatogenesis or oogenesis is usually delayed until the ontogeny is complete, although the g1 eater freedom of the germ cells in their relation to the soma makes possible the occasional occurence of pædogenesis or reproduc. tion by larvæ.

In concluding this chapter it may be pointed out that the phenomena of recapitulation furnish another limitation of the cell theory, recapitulatory characters being organismal, and embryonic recapitulation apparently involving the inheritance of functional modifications.

1 This is a little different from Bower's well-known view of the sterilization of potentially sporogenous tissue. 


\section{CHAPTER X.}

INHERITANCE OF ACQUiRed Characthrs.

In the last chapter it was pointed out that adaptational recapitulatory characters have apparently not originated directly through chromatin variations, but indirectly via the cytoplasm. Under the influence of Weismann's conception of continuity of the germplasm, the very possibility of acquired characters or impressed modifications being inherited, was denied. Like so many other useful biological conceptions this was pushed to an extreme, and a nonexistent degree of isolation and insulation of the germ cells from the soma was freely assumed. But in the last decade there has been an increasing tendency to adopt a more reasonable attitude to these problems. Weismann's conception of blastogenic and somatogenic variations or characters has also tended to lay too great emphasis on a distinction which can scarcely be said to exist at all in plants, except in sporogenesis, namely the segregation between germ cells and somatic cells. The contrast we have ventured to draw between karyogenic or nuclear characters and organismal or recapitulatory characters, seems more in accord with our present knowledge of the development, cytological structure and genetic behaviour of organisms.

In the meantime, experimental evidence for the inheritance of acquired characters and related phenomena has been slowly accumulating, but space will permit of reference to only a few papers. We may first mention Agar's (1913) work on parallel induction in the Daphnid, Simocephalus vetulus, where references to the related literature will be found. Agar discovered that when Simocephalus is fed on a culture of Protophyta the valves of the carapace became reflexed, the degree of this abnormality gradually increasing during successive instars or moults. If such individuals were removed to normal conditions before their (parthenogenetic) eggs were laid, these eggs nevertheless developed into adults showing the same abnormality which their parents had acquired ontogenetically through environmental impress. But the effect soon wore off in later generations grown in normal conditions.

Similarly, grown at higher temperature the animals were very much smaller, developed more rapidly and produced smaller broods. Bggs laid shortly after removal to ordinary temperature developed into adults nearly as small as their parents, but in $\mathrm{F}_{2}$ little of the effect remained. 
The parallel induction in germ and soma is believed to be brought about by "altering the nature of the metabolic products included in the living protoplasm." That such effects are transmitted for one or two generations is an excellent example of a cytoplasmic effect temporarily inherited, and indicates that minimal quantities of such substances are multiplied so as to produce a powerful effect. Kammerer claims to have obtained such a result in experiments with a lizard, where the character white instead of red belly, impressed by high temperature, was transmitted through the sperm to the next generation of adults.

The experiments of Kammerer $(1909,1919)$ with Alytes obstetricans have been much discussed. His recent results are largely confirmatory of earlier papers published ten years ago, and a number of other contributions, including an elaborate series of experiments with salamanders, have appeared in the intervening years. It is well-known that Alytes differs from other European Anura in that its strings of eggs are not laid in the water, ${ }^{\prime}$ but are twisted round the legs of the male and carried for some time during their stages of embryonic development. Their hearer only resorts to the water when they are ready to hatch as advanced tadpoles having a single pair of gills covered by an operculum.

When these animals are kept at a higher temperature (25:$30^{\circ} \mathrm{C}$.) with access to water, the eggs are laid in the water, and they hatch earlier, when the gills are still exposed. If these conditions are continued, so that the animals are obliged to breed in the water, by the $\mathrm{F}_{4}$ generation the tadpoles will have three pairs of gills as in other frogs. A number of other interesting changes occur. The eggs of Alytes are much larger and less numerous than in other frogs and toads. Thus, Rana produces $600-4,000$ eggs with a diameter of only $1.7 \mathrm{~mm}$, while in Alytes the number of eggs is about 60 and they are $3.5 .4 \mathrm{~mm}$. in diameter owing to a great amount of yolk. Developing in the water, the eggs of Alytes become rapidly smaller in successive generations.

But perhaps the most critical of these results concerns the secondary sexual characters of the male. Here again Alytes differs from other Anura in the absence of the characteristic horny pad which developes on the thumb or wrist of the male during the breeding season, enabling him to retain his hold on the female while in the water. When pairing and egg-laying occur in the water, however, according to Kammerer this pad gradually appears in Alytes, until

I It is an interesting fact that in one locality, Münster in Westphalia (Kammerer, 1909, p. 452), the eggs are normally laid in water. 
hy the $\mathrm{F}_{3}$ generation it is fully developed. This is said to be accompanied by an increase in the musculature of the arms. The development and regeneration of the pad are found to be independent of hormones from the sex organs, since castration of the males does not affect it. Also it is said that when $F_{2}$ males in which the patch had partly developed were crossed with normal Alytes females without a patch, a Mendelian result was obtained. This will certainly require additional evidence before it can be accepted.

The fact that in all Anura this pad only becomes apparent during the breeding season, seems to indicate that it is of relatively recent origin and has not become fully established in the germplasm. It is still in the condition of an organismal rather than a nuclear character. Whatever interpretation is put upon these results, as indicating a return to ancestral conditions or otherwise, it seems difficult to escape the conclusion that functional inheritance has taken place in these experiments ${ }^{1}$, even if the gradual transition be looked upon as a reversion. Nevertheless, one can scarcely suppose that evolutionary adaptation takes place at any such rapid rate.

It is at any rate an advantage that the subject of inheritance of acquired characters is emerging from neglect into the region of critical experiment, and the attitude with regard to it is becoming less dogmatic and more cautious. Darwin found no difficulty in accepting both the Lamarckian and selection factors as contributory to evolution. We are endeavouring to show that from the point of view of our present knowledge of organic structure the neoLamarckian and mutation factors are not incompatible or mutually exclusive.

A recent paper which is of interest because it frankly subsumes the neo-Lamarckian factor (Roberts, 1919), developes the hypothesis that mechanical reaction to stress is the law in all tissues. Just as the flying buttresses of a Gothic cathedral were the result of an effort to shore up walls which were spreading under the increased

'. Maci3ride (1919) upholds Kammerer's contention. Bateson (1919) in a reply points out that the fingers in the photograph of the control frog in Kammerer's paper have been clumsily retouched or painted over, and that the critical photograph showing the Brunftschwielen of the moditied male shows what appears to be a sort of excrescence on the outside of the fourth finger of the right hand. This, however, does not alter the evidence for the presence of a Brunftschwiele, which is clearly shown in the photograph as a lump on the right wrist. Moreover, a series of nine histological drawings from sections of the horny pad are given, showing the details of structure of this region in males of Alytes in which it is wholly or partly developed, also during the breeding and resting seasons, and in females. These drawings must either be regarded as evidence, in which case they prove Kammerer's point, or treated as deliberate frauds. There seems no sufficient reason for adopting the latter alternative, but it is certainly to be expected that Dr. Kammerer will now be able to produce specimens showing the horny pad. 
weight of the roof; so alternate breakdown and repair have led to the present structural relationships in many parts of the human body. Thus the heart is described as an aneurism, and the stomach as a dilatation sac, whose thick muscular wall has developed as the result of disaster and repair. It is assumed that the transmission of these changes probably takes place by a morphogenetic reply in utero to increased functional stresses.

Brief mention must be made of the important work of Harrison (1920a) on melanism and other racial characters in certain Geometrid moths. After intensive observation and experiment with the genus Oporabia, Harrison concludes that the subspecies $O$. filigrammaria was evolved from $O$. autumnata during the Glacial period by the action of changed climatic conditions, and that "almost certainly" many of the racial and subspecific differences are "true Lamarckian effects," in particular the food instincts in O. filigrammaria and the period of emergence of the pinewood race of $O$. autumnata. Moreover, a Lamarckian explanation of melanism is considered necessary, the darkening resulting from metallic salts in the food, derived from the smoke in industrial areas and from sea fogs in coastal areas where melanism frequently occurs. Melanism is known to behave as a simple Mendelian dominant in many species (see e.g., Onslow, 1920). Harrison (1920b) has recently shown this to be true of the melanic variety of Tephrosia crepuscularia when crossed with the type, out in interspecific crosses between $T$. crepuscularia and $T$. bistortata a chaotic series of $\mathrm{P}_{2}$ and $\mathrm{F}_{3}$ forms was obtained, the behaviour being no longer describable in Mendelian terms. This recalls the result obtained by the writer (1915f) in crosses between the Mendelian dominant character in Enothera rubricaly $x$ and another species, $C$. grandiflora. In both cases dilution and modification of the character has resulted from crossing with a different species. If crossing will modify such a unit-factor, then it is not unreasonable to suppose that they may be capable of environmental modification.

If the Lamarckian explanation of melanism is a true one, then it would appear to be a case of parallel induction, because of its manner of inheritance in crosses, indicating that the nuclear structure is already altered. The function of hormones as an evolutionary means of handing on or accelerating modifications, as suggested by Cunningham (1908), Dendy (1911) and others, indicates a method by which modifications may be perpetuated until the change becomes germinal by producing an alteration in the nucleus. 
This is obviously a field where more definite conceptions will only be possible after much further experimental work.

To mention a single case of experimental morphogenesis in plants, Harper (1918) has carefully studied the organization and reproduction of Pediastrum colonies, and concludes that from the point of view of inheritance the characters are of different kinds. The four-lobed shape of the cells of a colony he thinks may be an adaptive character which arose as an environmental response to the pressure relations between cells and has now become fixed and transmitted by cell division.

In the ostrich ${ }^{1}$ there are two callosities on the ankle, one median which appears before hatching, hence inherited; the other on the side, which appears only after the bird uses this surface to rest upon and is not transmissible. It is indicated that the median callosity is much older, dating back to the Pliocene ostrich, which, having three toes, rested on its legs symmetrically and so developed the median callosities which have since become inherited independently of any external stimulus. This callosity is no longer used, the loss of the third toe, according to Duerden, having led to a shifting of the point of contact with the ground and the development of a new callosity which is not transmitted. The difference in inheritance of these two callosities is very difficult to explain satisfactorily on any basis except that of functional inlueritance.

Brief reference must also be made to two important papers by Guyer and Smith ${ }^{2}$ recently received. A fowl serum was prepared sensitized to (i.e., containing a cytolysin which dissolved) the lens of the eye of the rabbit. This serum injected into pregnant rabbits produced inherited defects in the eyes of many of the young. Experiments with mice gave similar results. In rabbits the defects were transmitted for six generations, through the male as well as the female, and were gradually intensified witlout any further injections. The defect behaved in general as a Mendelian recessive. Here is clearly a specific modification produced by extrinsic factors.

In concluding this chapter, it is evident that conceptions of functional inheritance in various forms are again making themselves felt in much of the constructive thinking of the present time.

1 Duerden, J. E. Amer. Nat. Vol. 54, 1920.

? Journ. Exptl, Zool. Vols, 26, 31. 


\section{CHAP'TER XI.}

\section{Graneral Comparison of Recapitulatoly and}

\section{Karyogenetic Characters.}

The Biogenetic Law.

It is only necessary to refer to two recent discussions of the biogenetic law in addition to those already cited. In his excellent book on form and function, Russell (1916) has written a history of animal morphology, including numerous references to the biogenetic law. Those who have opposed the law appear to have based their beliefs largely on (1) the dissimilarities found in related embryos and eggs, (2) the fact that specific characters often make their appearance very early in the ontogeny. Now both these situations are to be anticipated if mutations have taken place in organisms which already display recapitulatory characters. One of the most striking cases of the appearance of specific characters very early in the ontogeny, is cited by Russell (l.c., p. 352), who quotes Louis Agassiz. The latter wrote in 1859 that the snapping turtle " exhibits its small cross-like sternum, its long tail, its ferocious habits, even before it leaves the egg, before it breathes through lungs." It snaps at everything brought near, even when still surrounded by its amnion and allantois. This is to be expected if the specific characters in question have originated through mutations, for it is now well-proven, in plants at least that mutational characters begin to express themselves very early in the ontogeny. And this is a natural result of the circumstance that they are present in every nucleus. On the other hand, there is a certain amount of embryological evidence in animals that characters borne in the nuclei (in contrast to morphogenetic substances in the egg cytoplasm) frequently became actuated only after the earlier cleavage stages are passed. That such characters make their first appearance earlier than some of the recapitulatory characters which they traverse, is also to be expected; but it only limits and does not nullify the biogenetic law, since that law applies only to recapitulatory characters but not to ordinary mutational characters.

Sedgwick's (1894) criticisms of von Baer's law are based on the same objections as those considered above. He compared the embryos of the fowl and dogfish, admitting that they agree in many important points, as the presence in the chick of pharyngeal clefts, a tubular piscine heart, a similar arrangement of the cardiac 
arterial system, a cartilaginous endo-skeleton, oro-nasal grooves and a notochord. But he finds "equally important differences." Nevertheless, he admits the essential point for recapitulationthat embryos pass through "stages of structure permanent in lower members of the same group." He also says (p. 43), "The evidence seems to indicate that in a number of cases adult variations of any part are accompanied by precedent similar alteration of the same part in the embryo." We have already seen that this is accounted for on a mutational basis.

It is well-known that Hyatt showed with fossil Ammonites that there is recapitulation in successive coils of the shell, the first coils often reproducing characters belonging to types known from the palæontological record to be ancestral. His law of acceleration in development, deduced from purely palæontological observations is simply another expression of the more recent embryological law of tachygenesis.

Morgan (1916, p. 19) has recently expressed the view that the new mutationist ideas have played havoc with the biogenetic law. He says, for example, that the chick, the fish, and man all possess gill-slits at an early stage of their development merely because they have not lost them. But this merely glosses over a difficulty without explaining it. The fallacy in such an explanation is evident enough if one applies it to such a recent recapitulation as that of the parasitic Copepod, Achtheres (see page 91). In such a case the larval stage of this copepod corresponds obviously to the adult stage of free-living copepods. Achtheres, however, passes through and beyond this stage, and its adult stage has lost practically all its copepod features. We venture to think this is a recapitulatory phenomenon, involving a lengthening of the life-cycle and probably also the inheritance of acquired characters.

\section{Relation to Geographic Distribution.}

Brief allusion only will be made to this subject. We have already seen that recapitulatory characters appear to involve a gradual adaptation to a new habitat, while mutations do not. In this connection we have pointed out (Gates, 1917c) another relationship between variation and geographic distribution. With reference particularly to North American owls (Otus asio), it was shown that in Eastern North America the red colour phase, which occurs usually in the same regions as the gray with which it inter. breeds, probably originated as a mutation and behaves as a dominant Mendelian character, In Western America, on the other hand, a 
series of geographic sub-species succeed each other down the Pacific coast, the most northern form being largest and with dark brown markings, while further south they become progressively smaller and lighter in colour, i.e., with less brown and more gray. These various sub-species are co-terminous with each other in their distribution and they form a very close, practically continuous series. The conclusion was reached that while such discontinuous variations as the red colour phase are independent of environmental or functional influence, the continuous type occupying distinct and adjacent geographic areas, represents the results of the stress of environment on the species in its dispersal, leading to the gradual differentiation of local races or sub-species.

Sumner (1918), in his studies of the deer mice, Peromyscus maniculatus, has arrived at similar conclusions regarding the occurrence of both mutations and gradual differentiations, and their geographic relationships. This subject is one which requires much further investigation, but it is at least possible that this continuous type of geographic variety in its origin involves the neoLamarckian factor.

The neo-Lamarckian principle.

Experiments have shown that impressed modifications may affect the offspring for at least two generations, and to this extent the neo-Lamarckian principle has already been justified. The mechanism of transmission in such a case is apparently different from that of a mutation or a Mendelian character in a cross. The latter appears to be determined in the nuclei, and therefore transmitted as a stable and permanent feature. The acquired character is temporary, cytoplasmic in origin, and will not be permanently retained unless re-impressed generation aftergeneration until the nuclei of the germ cells are ultimately altered in their constitution.

The fixation of such an organismal character may require a longer or shorter number of generations. What determines the number of generations required is quite unknown at the present time, nor is the modus operandi understood. But we may assume that in the process, altered metabolic products in the cytoplasm ultimately produce a modification of a chromatin element which is permanent in character. It may be expected that such a transformation will occur much more rapidly in some cases than others. 
The views here set forth regarding the occurrence of hoth mutational and adaptational characters in organisms are entirely in harmony with Dendy's $(1913,1916)$ conclusions from investigations of the sponges. He concludes that the specific characters of sponges are generally non-adaptive, and that a great many of the spicule differences so characteristic of the group must have originated by mutations. He also points out what we would now regard as parallel mutations, as in the appearance of trichodragmata, and in the polyphyletic family Epipolasidæ, which is an assemblage of stelletid sponges which have independently lost their triæne spicules. Usually the most minute differences, both in megascleres and microscleres, remain constant throughout the species, though millions of spicules may occur in each individual, to whom these microscopic differences cannot be of the slightest use. Such differences point to chemical or physical alterations in the constitution of the germplasm.

On the other hand, adaptive modifications of spicules for various purposes have taken place, as in the modification of triænes into grapnels for anchoring the sponge to a muddy bottom, or into discotriænes which serve as a dermal protection. Some of these adaptive conditions may have come about through selection among a series of mutations, but it is difficult to see that any of them involve the principle of inheritance of acquired characters. 


\section{CHAPTER XII.}

\section{Orthogentic Characters.}

In previous chapters we have drawn a contrast between (a) karyogenetic characters originating as mutations in the germplasm and affecting every nucleus, and (b) organismal characters which belong to the organism as a whole, show recapitulation, and probably originate as environmentally impressed modifications of the cytoplasm. In this chapter we wish to consider briefly orthogenetic characters, which appear to stand midway between these two categories. Like the former they are germinal in origin, and like the latter they show recapitulation. But they differ from the recapitulatory characters previously considered, in that their origin is apparently not adaptational but on the contrary independent of environment. We will refer only to three cases from the recent experimental work with animals.

It is a well-known fact that in many birds the juvenile plumage differs from that of the adult, and usually at least represents a less specialized and presumably ancestral type of plumage. One of the most striking cases, recently studied by Beebe (1914), is in the white ibis, Guara alba. In the young chick the head and neck are covered with black down, becoming smoky gray over the greater part of the body except the under parts, which are white. In the juvenile and post-juvenile stages this is gradually replaced by white feathers, until late in the second year the birds are pure white with scarlet legs and bill. It seems clear that such a white bird has not originated through a mutation, and that the ontogeny represents a gradual transition from a dark-coloured ancestor. It is an interesting fact that the white loral spots in the young chick, which quickly disappear, apparently represent the permanent facial marking of a related ibis, Plegadis autumnalis. This would appear to be one of the few cases in which a specific (generic) difference is at the same time a recapitulatory character.

Whitman's (1919) recent posthumous volumes on orthogenetic evolution in pigeons cite a number of cases of juvenile plumage as recapitulatory stages furnishing evidence of orthogenetic development. Whitman's study of the wing patterns of pigeons is perhaps the most prolonged and intimate investigation which has ever been made of a single character. Reading the series in the opposite direction from Darwin, he concluded that the primitive condition was a uniform chequered pattern covering the whole wing, as in 
the Japanese turtle dove. Then he shows how in different groups of wild species of pigeons from all over the world, various stages of the reduction of this pattern are found, beginning always at the anterior end of the wing and wiping off the rows of spots until, in unrelated species belonging to different groups, patterns with $4,3,2,1$ or no bars of spots may be found. The rock pigeon (Columba livia) with usually two wing-bars thus represents a relatively reduced condition, while the white-winged pigeon (Melopelia leucoptera), in which the chequers have entirely disappeared, is a still more advanced stage. In these cases, moreover, the juvenile plumage generally represents the more extensively chequered and primitive type, recapitulation thus strongly supporting the author's interpretation. Whitman further claims that this orthogenetic trend in the colour patterns of pigeons is not a mere result of selection, but may even run counter to it and gradually eliminate a pattern of spots which sexual selection tended to strengthen and beautify. His monumental work places in a new light the claims of orthogenesis as an evolutionary factor, but space forbids a more extensive discussion of his results.

The claims of orthogenesis have also been taken up recently by Duerden (1919) for the ostriches. He believes that the reduction in the plumage, in the toes and their scutellation, and in other features, is proceeding progressively and independently in the North and South African ostrich. He believes the evidence is clear that the progress is entirely independent of adaptational considerations. On the other hand, there seems no doubt of the germinal origin of many of the variations. The case of reduction in toes and specialization of the middle toe for running is in many respects similar to that of the horse. If that is so, adaptation would appear to have taken place by the progressive selection of germinal variations. It does not necessarily follow, as Duerden believes, that the reduction of the ostrich's toes will continue until the extinction of the species results.

The last five chapters have been devoted to an attempt to bring into relation with each other such diverse things as the mutation theory, the cell theory, the facts of recapitulation and the evidence for the inheritance of acquired characters. We found that new features of the organism may originate internally through chromatin changes and express themselves centrifugally in the ontogeny of the crganism; or they may originate externally as organismal characters and ultimately become inherited, through a 
centripetal effect on tbe nuclei. We also concluded that karyogenetic characters were not as a rule recapitulatory, because they imply a change in the nuclear unit which is transmitted by mitosis to every cell, while organismal characters may become so by adding on certain stages to the life-cycle of the organism. The existence of these two types of characters accounts for many anomalies in the biogenetic law. The existence of two such classes of characters makes it possible to understand better many features of organic structure and inheritance.

But it is obvious that the relationship between these two types of characters cannot be fully understood in all their aspects at the present time, nor can a sharp line always be drawn between karyogenetic, cytogenetic and orthogenetic characters-in some aspects they shade into each other. As a constructive attempt to harmonize two bodies of evidence which are obviously in conflict and have long been considered irreconcilable, we make no apology for its tentative character and incompleteness.

\section{LITERATURE CITED.}

Agar, W. E., 1913. Transmission of environmental effects from parent to offspring in Simocephalus vetulus.

Phil. Trans. Roy. Soc., B. 203 : 319-350.

Allen, Charles E., 1919. The basis of sex inheritance in Sphærocarpos.

Proc. Amer. Phil. Soc., 58 : 289-316, figs. 27.

Balfour, Bayley, 1917. Observations on Rhododendron seedlings.

Trans. and Proc., Bot. Soc., Edin. 27 : 221-227.

Bartlett, H. H., 1914a. An account of the cruciate flowered CEnotheras of the sub-genus Onagra.

Amer. Journ. Bot. 1: 226-243, figs. 2, pls. 19-21.

" = 1914b. Twelve elementary species of Onagra.

Cybele Columbiana 1: 37-56, pls. 5 .

, 1915a. Mutation "en masse."

Amer. Nat. 49 : 129-139, figs. 9.

" $\quad$ " 1915c. The mutations of Enothera stenomeres.

Amer. Journ. Bot. 2 : 100-109, figs. 4.

" $\quad$ 1915e. Systematic studies on Enothera, 5.

Rhodora 17: 41.44, pl. 3.

Bateson, W., 1909. Mendel's principles of heredity.

Cambridge University Press, pp. 396, figs. 37, pls. 6.

" 1913. Problems of Genetics.

Oxford University Press, pp. 258, figs. 13, pis. 2.

, 1919. Dr. Kammerer's testimony to the inheritance of acquired characters. Nature $103: 344-5$.

, and E. R. Saunders, 1902. Experimental studies in the physiology of heredity. Reports of Evolution Committee, Royal Society, Report I. pp. 160.

, and Ida Sutton, 1919. Double fowers and sex linkage in Begonia. Journ. Genetics, 8 : 199-207, pl. 8. 
Baur, E., 1911. Einführung in die experimentelle Vererbungslehre. Berlin : Borntræger, pp. 293, figs. 80 , pls. 9 .

Beebe, C. William, 1914. Notes on the ontogeny of the white ibis, Guara alba. Zoologica 1 : 241-248, fig. 97.

Blackman, V. H, 1909. Alternation of generations and ontogeny. New Phytol. 8 : 207-218.

Bonavia, E., 1895 . Studies in the evolution of animals.

London: Constable, pp. 362, figs. 128.

Boulenger, G. A., 1897-98. The tailless Batrachians of Europe. London, Ray Society, pp. 376, pls. 24, figs. 124.

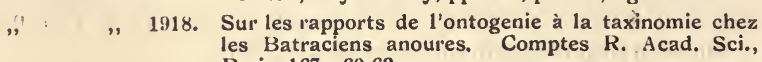
Paris, $167: 60.63$.

, " and N. Annandale, 1918. Further observations on Rana tigrina. Rec. 1nd. Mus. 15 ; 51-67, figs. 3.

Bower, F. O., 1908. The Origin of a Land Flora. London: Macmillan, pp. 727, figs. 361.

Braun, Hermann, 1909. Die spezifischen Chromosomenzahlen der einheimischen Arten der Gattung Cyclops.

Arch. f. Zellforsch. 3: 449-482, pls. 24-5, figs. 2.

Bridges, Calvin B., 1916. Non-disjunction as proof of the chromosome theory of heredity.

Genetics 1: 1-52, 107.163, figs. 9, pl. 1, tables 86.

, 1917: Deficiency. Genetics 2: 445-465.

Cockayne, L. A., 1907. On the sudden appearance of a new character in an individual of Leptospermum scoparium.

NeW PHYTOL. 6 : 43-46.

Cockerell, T. D. A., 1912. The red sunflower. Pop. Sci. Monthly: 373-382.

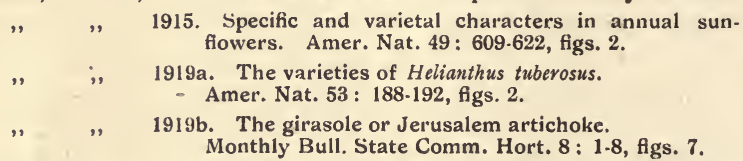

Conklin, E. G., 1916. Heredity and environment in the development of men. Princeton Univ. Press, 2nd Ed., pp. 550, figs. 96.

Coulter, John M., 1915. Orthogenesis in plants. Science N.S. $42: 683$.

, $\quad$, and C. J. Chamberlain, 1910. Morphology of Gymnosperms.

University of Chicago Press, pp. 458, figs. 462.

Crampton, H. E., 1917. Studies on the variation, distribution and evolution of the genus Partula. The species inhabiting Tahiti. Publ. Carnegie Inst. Wash., No. 228 . pp. 313, pls. 34, figs. 7.

Cunningham, J. T., 1908. The heredity of secondary sexual characters in relation to hormones, a theory of the heredity of somatogenic characters.

Arch. f. Entw.-Mech. $26: 372-428$.

Davenport, C. B., 1914. The bare necks. Journ. of Heredity $5: 374$, flg. 1 . Davis, B. M., 1909. Pollen development of Enothera grandiflora. Ann. of Botany 23 : 551-571, pls. 2.
, ,
1913. The behaviour of hybrids between $C E n o t h e r a b i e n n i s$ and
$C E$. grandiflora in the second and third generations. E. grandiflora in the second and third gen
Amer. Nat. 47: 449.476, 547-571, figs. 17 .
, " 1914. Parallel mutations in Enothera biennis L. Amer. Nat. 48 : 498.501.
" 1916. Life histories in the red algæ. Amer. Naturalist 50 ; 502.512 . 
Davis, B. M., 1918. The segregation of Enothera brevistylis from crosses with Enothera Lamarckiana.

Genetics 3 : 501-533, figs. 7 .

Delaunay, L., 1915. Etude comparée caryologique de quelques espèces du genre Muscari Mill. [Russian].

Mém. Soc. Nat. de Kiev 25 : 33-61, pl. 1, figs. 2.

Dendy, Arthur, 1911. Momentum in evolution. Report Brit. Assoc., Portsmouth Meeting.

", 1913. By-products of organic evolution. Journ. Quekett Micro. Club 12 : 65-82, pl. 1.

, " 1916. Some factors of evolution in sponges. Journ. Quekett Micro. Club 13: 27-46.

De Vries, Hugo, 1909. The mutation theory. Vol. I. English Trans., Chicago : Open Court Publ. Co., pp. 582, figs. 119, pls. 6.

" , 1913. Gruppenweise Artbildung, unter spezieller Berücksichtigung der Gattung Enothera.

Berlin: Gebruder Borntraeger, pp. 365, figs. 121, pls. 22 .

" " 1915a. Enothera gigas nanella, a Mendelian mutant.

Bot. Gazette 60 : 337-345.

" , 1915b. The coefficient of mutation in Enothera biennis L.

Bot. Gazette 59 : 169-196.

" , 1916. New dimorphic mutants of the CEnotheras.

Bot. Gazette 62 : 249-280, figs. 5.

, 1918. Mutations of Enothera suaveolens Desf. Genetics 3 : 1-26, figs. 4.

" 1919. Enothera Lamarckiana ervthrina einè neue Halbmutante. Zeits. f. Abst. u. Vererb. : 21 : 91-118.

Domin, Karl, 1908. Studien zur Entstehung der Arten dureh Mutation 1. Beih. z. Bot. Centralbl. 23 : 15-25, pls. 2, figs. 2.

Doncaster, L., 1920. An introduction to the study of Cytology. Cambridge University Press, pp. 280, pls. 24, figs. 31.

Duerden, J. E., 1919. Crossing the North African and South African ostrich. Journ. of Genetics, 8: 155-198, pl. 7, figs. 2.

Eames, A.J., 1913. The morphology of Agathis australis. Ann. of Botany, 27: 1-38, pls. 4, figs. 92.

East, E. M. and D. F. Jones, 1919. Inbreeding and outbreeding: their genetic and sociological significance. Philadelphia and London : Lippincott. pp. 285, figs. 46.

Farmer, J. Bretland and L. Digby, 1907. Studies in apospory and apogamy in ferns. Ann. of Botany, $21: 161-199$, pls. 5.

Fernald, M. L., 1917. A remarkable colony of Bidens in Connecticut. Rhodora, 19 : 257-259.

Fraser, H. C. 1. and J. Snell, 1911. The vegetative divisions in Vicia Faba. Ann. of Botany, 25: 845-855, pls. 2.

Fritch, F. E., 1916. The algal ancestry of the higher plants. New PHYTOL., 15 : 233-250, figs. 2.

Frost, H. B., 1912. The origin of an early variety of Matthiola by mutation. Proc. Amer. Breeders' Assoc. 7 : 536-545.

" 1915. The inheritance of doubleness in Matthiola and Petunia. Amer. Nat. 49 : 623-636, fig. 1.

Gates, R. P., 1909a. The stature and chromosomes of Enothera gigas de Vries. Arch. f. Zellforsch. 3 ; 525-552.

1909b. Further studies of Enotheran cytology. Science N.S. $29: 269$.

1911. Studies on the variability and heritability of pigmentation in CEnothera. Zeitschr. f. Abst. u. Vererb. 4: 337 . 372 , pl. 6 , figs. 5 . 
Gates, R. R., 1912a. Parallel mutations in Enothera biennis. Nature, 89 : 659-660.

1912b. Somatic mitoses in Enothera.
Ann. of Botany, 26: 993-1010, pl. 1.

. 1913. A contribution to a knowledge of the mutating Enotheras. Trans. Linn. Soc., 2nd Ser, Botany, Vol. 8, Part I., pp. 67, pls. 6.

" 1914a. Breeding experiments which show that hybridization and mutation are independent phenomena. Zeitschr. f. Abst. u. Vererb. 11: 209-279, figs. 25.

„1914b. Some CEnotheras from Cheshire and Lancashire. Ann. Mo. Bot. Gardens 1: $383-400$, pls. 3 .

" and Nesta Thomas, 1914. A cytological study of CEnothera mut. lata and $C E$. mut. semilata in relation to mutation. Quart. Journ. Micro. Sci. 59 : 523-571, pls. 3, figs. 4.

" 1915a. The Mutation Factor in Evolution, with particular reference to Enothera.

London: Macmillan, pp. 353, figs. 114.

" 1915b. On successive duplicate mutations. Biol. Bull. : 29 : 204220.

191ăc. Heredity and mutation as cell phenomena. Amer. Journ. Bot. 2 : 519-528.

1915d. On the nature of mutations. Journ. of Heredity $6: 99-108$, figs. 7 .

1915e. On the origin and behaviour of Enothera vubricalyx. Journ. of Genetics 4 : 353-360.

1915f. On the modification of characters by crossing. Amer. Nat. $49: 562-569$.

1916. On pairs of species. Bot. Gazette $61: 177-212$, figs. 12 .

1917a. Vegetative segregation in a hybrid race. Journ.of Genetics $6: 237-253$, pl. 1.

1917b. A systematic study of the North American genus Trillium, its variability, and its relation to Paris and Medeola Ann. Mo. Bot. Garden 4: 43-92, pls. 3 .

1917c. The mutation theory and the species concept. Amer. Nat. 51 : 577.595, fig. 1.

1918a. A systematic study of the North American Melanthacex from the genetic standpoint. Journ. Linn. Soc., Botany 44 : 131-172, pl. 1.

" 1918b. A systematic analytical study of certain North American Convallariaceæ, considered in regard to their origin through discontinuous variation. Ann. of Botany 32: 253-257.

Geerts, J. M., 1907. Über die Zahl der Chromosomen von QEnothera Lamarckiana. Ber. deut. bot. Gesells. 25: 191-195, pl. 1.

Glen, Edith H., 1918. A revision of certain points in the early development of Peripatus capensis. Quart. Journ. Micro. Sci. 63 : 283-292, pl. 1.

Gudernatsch, J. F., 1914. Feeding experiments on tadpoles, II. A further contribution to the knowledge of organs with internal secretion. Amer. Journ. Anat. 15: 431-480, pls. 2.

Gulick, J. T., 1905. Evolution, racial and habitudinal. Carnegie Inst. of Wash., Publ. No. 25, pp. 269, pls. 3.

Hance, Robert T., 1918. Variations in the number of somatic chromosomes in Enothera scintillans, De Vries. Genetics $3: 225$ 275 , pls. 7, figs. 5 .

Harper, R. A., 1918. Organization, reproduction and inheritance in Pediastrum. Proc. Amer. Phil. Soc. 57: 375-439, pls. 2, figs. 35.

Harrison, J. W. Heslop, 1920a. Genetical studies in the moths of the Geometrid genus Operabia (Oporinia) with a special consideration of melanism in the Lepidoptera. Journ. of Genetics 9: 195-280, figs. 13. 
Harrison, J. WV. Heslop, 1920b. The inheritance of melanism in the genus Tephrosia (Ectropis) with some consideration of the inconstancy of unit characters under crossing. Journ. of Genetics 10: 61-8v, figs. 3.

Heribert-Nilsson, N, 1912. Die Variabilität der Enothera Lamurckiana und das Problem der Mutation. Zeits. f. Abst. u. Vererb. 8: 89.231, pls. 3, figs. 36 .

Hilbert, R., 1913. Hepatica triloba Gil. mit gefüllter Blüte. Allgem. Bot. Zeitschr. f. Syst. Floristik, etc. 19 : 140-142.

Hooper, J. J., 1916. A peculiar breed of goats. Science N.S. $43: 571$.

Howard, A. and G. L. C. Howard, 1912. On the inheritance of some characters in wheat. Mem. Dept. Agr., India (Botany), 5 : 1.46, pls. 3.

Hus, Henri, 1911. The origin of species in nature. Amer. Nat. 45: 641-667,figs. 7.

Hutchinson, A. H., 1915. On the male gametophyte of Picea canadensis. Bot. Gazette 59: 287-300, pls. 5.

Hyde, R. R., 1915a. The origin of a new eye-color in Drosophila repleta, and its behavior in heredity. Amer. Nat. 49 : 183-185.

" 1915b. A wing mutation in a new species of Drosophila. Amer. Nat. 49 : 185-187.

Jeffrey, E. C., 1917. The anatomy of woody plants. University of Chicago Press. Pp. 478, figs. 306.

Kammerer, P., 1909. Vererbung erzwungener Fortpflanzungsanpassungen. III. Die Nachkommen der nicht brutpfiegenden Alytes obstetricans.

Arch f. Entw. Mech. 28 : 447-545, pls. 2.

$\therefore \quad$ 1919. Vererbung erzwungener Formveränderungen. I. Die Brunftschwiele des Alytes Männchen aus "Wassereiern." Arch. f. Entw. Mech, 45: 323-370.

Keeble, F., C. Pellew, and Jones, W. N., 1910. The inheritance of peloria and flower-colour in foxgloves (Digitalis purburea). New Phytol. 9 : 68.76 .

Lang, Aınold, 1912. Vererbungswissenschaftliche Miszellen. Zeits. f. Abst. u. Vererb. 8 : 233-283, figs. 6.

Lang, W. H., 1898. On apogamy and the development of sporangia upon fern prothalli. Phil. Trans. Roy. Soc., London B. 190 : 1s7-238, pls. 5.

" 1901. On apospory in Anthoceros lavis. Ann. of Botany 15: 503-510, pl. 1.

. 1909. A theory of alternation of generations in Archegoniate plants based on ontogeny. New PHYTOL. $8: 1-12$.

Lewis, I. F., 1909. The life history of Griffithsia Bornetiana. Ann. of Botany 23: 641-690, pls. 5, figs. 2.

Lodewijks, J. A., 1911. Erblichkeitsversuche mit Tabak. Zeitsch. f. Abst. u. Vererb. 5 : 139-172, figs. 9.

Loeb, Jacques, 1916. The Organism as a whole. Putnams : New York and London, pp. 379, figs. 51.

Lutz, Anne M., 1908. Chromosomes of the somatic cells of the Enotheras. Science N.S. 27; 335.

, 1909. Notes on the first generation hybrid of Enothera lata $\times$ E. gigas. Science N.S. $29: 263-267$.

1916. Enothera mutants with diminutive chromosomes. Amer. Journ. Bot. 3 : 502.526, pl. 1, figs. 7.

1917a. Characters indicative of the number of somatic chromosomes present in Enothera mutants and hybrids. Amer. Nat, 51 : 375-377.

1917b. Fifteen- and sixteen-chromosome En
Amer. Journ. Bot. 4:53.111, figs. 9. 
MacBride, E. W., 1914. Text-book of Embryology, Vol. 1. Invertebrata, London : Macmillan, pp. 692, figs. 468.

1917. Recapitulation as a proof of the inheritance of acquired characters. Scientia $22: 425.434$.

1919. The inheritance of acquired characters. Nature 103: 225-6.

May, H. G., 1917a. The appearance of reverse mutations in the bar-eyed race of Drosophila under experimental control. Proc. Nat. Acad. Sci. 3 : 544-545.

„1917b. Selection for higher and lower facet numbers in the bar-eyed race of Drosophila and the appearance of reverse mutations. Biol. Bull. 33 : 361-395, figs. 8.

Metz, C. W., 1914. A preliminary survey of five different types of chromosome groups in the genus Drosophila. Journ. Exptl. Zool. 17 : 45-59, pl. 1.

" and Metz, B. S., 1915. Mutations in two species of Drosophila. Amer. Nat, 49: 187-189.

" 1916a. Linked Mendelian characters in a new species of Drosophila. Science N.S. 44 : 431-2.

" 1916b. Mutations in three species of Drosophila. Genetics 1: 591-607, fig. 1 .

" 1916c. The paired association of chromosomes in the Diptera, and its significance. Journ. Exptl. Zool. $21: 213$. 262 , pls. 8 .

" 1916d. Additional types of chromosome groups in the Drosophilidæ. Amer. Nat. 50: 587-599, pl. 1.

1918. The linkage of eight sex-linked characters in Drosophila virilis. Genetics 3 : 107-134, pl. 1.

1920. Correspondence between chromosome number and linkage groups in Drosophila virilis.

Science N. S. 51 : 417-418.

Miyoshi, M., 1910. Ueber das Vorkommen gefüllter Blüten bei einem wildwachsenden japanischen Rhododendron, nebst Angabe über die Variabilität von Menziesia multiflora Maxim. Journ. Coll. Sci., Tokyo, Vol. 27, Art. 11, pp. 13, pls. 3.

" "1916. Die Japanische Bergkirschen, ihre wildformen und Kulturrassen. Journ. Coll. Sci. Imp. Univ., Tokyo $34: 1-175$, pls. 23 , fig. 1 .

Morgan, T. H., Sturtevant, Muller and Bridges, 1915. The mechanism of Mendelian heredity.

London, Constable, pp. 262, figs. 64.

" 1916. A critique of the theory of evolution.

Princeton University Press, pp. 197, figs. 95.

" 1919. The physical basis of heredity.

London: Lippincott, pp. 305, figs. 117.

Morse, Withrow, 1918. Factors involved in the atrophy of the organs of the larval frog. 13iol. Bull. 34 : 149-166, figs. 2.

Müller, H. A. Clemens, 1912. Kernstudien an Pflanzen.

Arch. f. Zellforsch. 8 : 1-51, pls. 2.

Muller, H. J., 1917. An CEnothera-like case in Drosophila. Proc. Nat. Acad. Sci. 8 : 619.626.

" 1918. Genetic variability, twin hybrids and hybrids, in a case of balanced lethal factors. Genetics 3: $422-499$, fig. 1.

Nawaschin, S., 1911. Über eine Art der Chromatindiminution bei Tradescantia virginica. Ber. deut. bot. Gesells. 29 : 437.449, pl. 1.

Nilsson-Ehle, H., 1909. Kreuzungsuntersuchungen an Hafer und Weizen. Dissertation; Lund., pp. 122. 
Nilsson-Ehle, H., 1911. Kreuzungsuntersuchungen an Hafer und Weizen, II. Lunds. Univ. Arsskrift, N.F. Afd. 2, Bd. 7, No. 6, pp. 82.

Onslow, H., 1920. The inheritance of wing colour in Lepidoptera. III. Melanism in Boarmia consortaria (var. consobrinaria BKH.) Journ. of Genetics $9: 339-346$, pl. I.

Osborn, H. F., 1918. The origin and evolution of life, on the theory of action, reaction and interaction of energy.

London: Bell, pp. 322, figs. 135.

Perrier, E. and Gravier, C., 1902. La tachygénèse ou accélération embryogénique, son importance dans les modifications des phénomènes embiryogeniques; son rôle dans la transformation des organismes.

Ann. des Sci. Nat. Zool. 16: 133-371, figs. 119.

Plough, H. H., 1917. The effect of temperature on crossing over. Journ. ExptI. Zool. 24.

Punnett, R. C., 1919. Note on the origin of a mutation in the sweet pea. Journ. of Genetics 8 : 27-31, fig. 1.

Raciborski, M., 1908. Coreopsis tinctoria var. prolıfica: eine ungweckmässige Mutation. Weisner-Festschrift, pp. 417-420.

Rehder, Alfred, 1907. Rhododendron albiflorum with double flowers. Bot. Gazette 43: 281-2.

Renner, O., 1919. Zur Biologie and Morphologie der männlichen Haplonten einiges Önotheren.

Zeits. f. Bot. 11: 305-380, figs. 32.

Ritter, W. E., 1919. The Unity of the Organism.

Boston: Gorham Press, 2 Vols, pp. 398, 408, figs. 35,61 .

Roberts, Norley, 1919. The function of pathological states in evolution. Proc. Zool. Soc., London, 1918 : 237.254.

Rosenberg, O., 1918. Chromosomenzahlen und Chromosomendimensionen in der Gattung Crepis.

Arkiv för Botanik 15: No. 11, pp. 16, figs. 36.

Russell, E. S., 1916. Form and function. London : Murray, pp. 383, figs. 15. Sakamura, Tetsu, 1915. Ueber die Einschnürung der Chromosomen bei Vicia Faba, L. Bot. Mag. Tokyo 29: 287.300, pl. 1, figs. 12.

Saunders, E. R., 1910. Studies in the inheritance of doubleness in flowers. I. Petunia. Journ. of Genetics 1: 57-69, figs. 5.

1911a. On inheritance of a mutation in the common foxglove (Digitalis purpurea).

New Phytol. 10 : 47-63, pl. 1, figs. 11.

1911b. Further experiments on the inheritance of "doubleness" and other characters in stocks. Journ. of Genetics 1 : 303-376, figs 2.

1912. On the relation of Linaria alpina type to its varieties concolor and rosea. NEW Phytol. 11 : 167.169.

1913. The breeding of double flowers. IVe. Conf. Internat. de Génétique, 1911, pp. 397-405.

1915a. A suggested explanation of the abnormally high records of doubles quoted by growers of stocks (Matthiola). Journ. of Genetics 5 : 137-143.

1915b. The double stock, its history and behaviour. Journ. Roy. Hort. Soc. $40: 450-472$.

1916a. On selective partial sterility as an explanation of the behaviour of the double-throwing stock and the Petunia. Amer. Nat. 50 : 486-498.

1916b. The results of further breeding experiments with Petunia.' Amer. Nat. 50 : 548-553.

1916c. On an early mention of the double wallfiower (Cheiranthus Cheiri).

Journ. Roy, Hort. Soc. 42 : 27-34. 
Saunders, E. R., 1917. Studies in the inheritance of doubleness in flowers II. Meconopsis, Altbaea and Dianthus.

Journ. of Genetics 6 : 165-184.

" 1918. On the occurrence, behaviour and origin of a smooth. stemmed form of the common foxglove (Digitalis purpurea). Journ. of Genetics 7 : 215-228.

Sax. Karl, 1918. The inheritance of doubleness in Chelidonium majus, Linn. Genetics 3 : $300-307$.

Sedgwick, A., 1894. On the inadequacy of the cel! theory of development and on the early development of nerves, particularly of the third nerve and of the sympathetic in Elasmobranchii.

Quart. Journ. Micro. Sci. 37 : 87-101.

" " 1894. On the law of development known as von Baer's Law; and on the significance of ancestral rudiments in embryonic development.

Quart. Journ. Micro. Sci. 36 : 35-52.

Shull, G. H., 1912. Inheritance of the heptandra-form of Digitalis purpurea L. Zeitschr. f. Abst. u. Vererb. 6: 257-267, pls. 2.

" . 1914a. A peculiar negative correlation in Enothera hybrids. Journ of Genetics 4 : 83-102, pls. 2.

" $\quad$ "1914b. Duplicate genes for capsule-form in Bursa bursa-pastoris. Zeitschr. f. Abst. u. Vererb. 12 : 97.149, flgs. 7.

Small, James, 1917-19. The origin and development of the Compositæ. New Рнутог. Vols. 16-18.

Sollas, I. B. J., 1914. Note on the offspring of a dwarf bearing strain of guinea pigs. Journ. of Genetics 3 : 201-204.

stomps, Theo. J., 1912. Mutation bei Enothera biennis L.

Biolog. Centlbl. 32 : 521-535, pl. 1, fig. 1.

1914. Parallele Mutationen bei Enothera biennis L. Ber. deut. bot. Gesells. 32 : 179-188.

Sturtevant, A. H., 1915. A sex linked character in Drosophila repleta.

Amer. Nat. 49 : 190-191.

Sumner, F. B., 1915. Genetic Studies of several geographic races of California deer-mice. Amer. Nat. 49 : 688.701, fig. 1.

" 1917. Several color "mutations" in mice of the genus Peromyscus. Genetics 2: 291-300.

" 1918. Continuous and discontinuous variations and their inheritance in Peromyscus. Amer. Nat. 52 : 117-208, 290-301, 439-454, figs. 13.

Thistleton-Dyer, W. T., 1901. Morphological notes.

Ann. of Botany $15: 423-425,547-8, \mathrm{pl} .1$.

Tupper, W. W. and Bartlett, H. H., 1916. A comparison of the wood structure of Enothera stenomeres and its tetraploid mutation gigas. Genetics 1: 177-184.

Whitman, C. O., 1894. The inadequacy of the cell-theory of development. Biol. Lectures, Woods Holl, 1893 : 105-124.

. " 1919. Vol. I. Orthogenetic evolution in pigeons. Carnegie Inst. Wash. Publ., No. 257, pp. 194, pls. 88, figs. 36.

Wilson, E. B., 1909. Studies on Chromosomes V. The chromosomes of Metapodius. A contribution to the hypothesis of the genetic continuity of chromosomes.

Journ. Exptl. Zool, 6 : 147-205, pl. 1, flgs. 13.

" 1910. Studies on chromosomes VI. A new type of chromosome combination in Metapodius.

Journ. Exptl. Zool. 8 : 53-78, figs. 5.

Yamanouchi, S., 1906. The life history of Polysiphonia violacea, Bot, Gazette 42: 401-449, pls. 10. 


\section{N D E X.}

Achatinellidx

Achtheres ambloplitis, recapitulation in 91,100

Acquired characters, inheritance of, 76,77 , $89,93,94,104$

Actæa

Adaptation, $\quad 77,86,91,102$ in the ostrich $\quad . . \quad 104$ in Pediastrum $\quad . . .98$ in tadpoles $\quad \ldots \quad 91$ rate of $\quad \ldots \quad$... 96 to terrestrial conditions 84 $\begin{array}{lllll}\text { Agar } \quad . . & \ldots & . & & \end{array}$ Agassiz L. $\quad \ldots . \quad \ldots . \quad 99$ Alahama $\quad \ldots \quad \ldots .50$ Allen, C. E. ... … 9 Alternation of generations,

Alternation of generations

Althæa, double Alytes obstetricans, reproduction of, 95 Ammonites $\quad . . \quad \ldots \quad 100$ Anemone, clouble, ... 62 Angiosperms, embryo-sac of, 80 Annandale $\quad$... $\quad . .992$ Antedon, recapitulation in, 90 Antirrhinum $\quad . . \quad \quad \ldots 64,66$ Apogamy $\quad \ldots \quad$... 82 Apospory $\quad$... $\quad \ldots \quad 82$ Aquilegia, mutation, ... 64 Araucaria, archegonium $\quad 84$ " recapitulation in 87 Archegonium, reduction of,

Aristotle

Ascidians, recapitulation in, 90 Avena stricta, variation in, 68

Balfour 87,88 Barfurth 92 Bareneck fowls Bartlett, 15, 30, 49, 50, 52, 68, 78
Batchelor ... ... 5 Pages Bateson, 55, 56, 59, 66, 75, 96 Baur ... ... ... 65 Beebe $\quad . . \quad \quad \ldots \quad \ldots \quad 103$ Begonia, double $\quad$... 59 Betula, variation in ... 70 Bidens, variation in ... 68 Biogenetic law $\quad 99,100$ Birds, featherless $\quad . . \quad 75$ Blackman, V. H. $\quad$... $\quad 82$ Blastoderm, of insect egg, 79 Bonavia $\quad$... $\quad . . \quad 74$ "Book of Agriculture" 59 Boulenger $\quad \ldots \quad 91,92$ Bower, F. O. ... 81, 83, 93 Brachyoxylon, leaf traces of, 87 Braun, Al. $\quad \ldots \quad \ldots . \quad 69$ Bridges $\quad 8,15,38,41,88$

Callitriche verna $\quad$... 33 Capsella, mutation in $\quad 14$ Castle, W. E. $\quad$... $\quad 75$ Cell lineage $\quad \ldots \quad 80$ Cell theory, limitations of, 76 $\begin{array}{llll}\text { Chamisso } & \text {... } & \text {... } & 67\end{array}$ Characters, Cell 77 Cytogenetic $\quad \ldots . .77,105$ Karyogenetic, 77, 91, $94,99,103,105$ organismal, 77, 91, 93, 103 recapitulatory, 90 , $91,92,93,94,99,105$ two types ... ... 76 Cheiranthus, double ... 59 inheritance of doubles, $\mathbf{5 7}$ Chelidonium, double ... 56 Cherries, variation in Japanese, 63

Chromosomes, and mutation $\quad \ldots \quad 6$ duplication $8,20,23$ extra $\quad \ldots \quad 10,24,42$ in Drosera $\quad . . \quad 11$ in Drosophila, 8, 9, $15,35,38,52,53$ 
in Enothera, 6, 10,

$24,27,33,42,47$

in ontogeny

segmentation of, 31,32

Sex, $\quad 9,35,38,40,53$

Supernumerary ... 17

Chromosome numbers,

in Angiosperms ...

85

in Callitriche verua

33

in Coruus glabrata

33

in Crepis ... ... 88

in Drosophila... $\quad 36,53$

in Gymnosperms

in Enothera, 6, 7,

$10,11,24,33,42,43,78$

in Staphylea primatı 33

in Tradescantia

virginica

33

Church ... ...

71

Clintonia, pairs of species in, 55

Cockayne $\quad$.. $\quad \ldots \quad 69$

Cockerell $\quad$... $\quad$... 71

Colaptes, origin of species in, 55

Columba livia, wing-hars of 104

Colombia

64

Compositæ, evolution in $\quad 55$

$\begin{array}{llll}\text { Conklin } & \ldots & \ldots & 78\end{array}$

$\begin{array}{llll}\text { Connecticut } & \ldots & \ldots & 68\end{array}$

Convallariacex... $\quad \ldots \quad 55$

Convolvulus, double $\quad . .6 \quad 62$

Copepod larva ... ... 91

Coreopsis tinctoria, variation in, 69

Cornus glabrata $\quad$.. $\quad 33$

Coulter ... $\quad . . \quad$... 85

Crampton $\quad \ldots \quad \ldots 72,73$

Cratægus multiformity 64

Crepidula, reversal of symmetry in, ...

Crepis, chromosomes of,

Cretin, sweet pea,

Crossing-over

... 18

Cruciate varieties,

$17,18,37$

pollen formation in 47,48

Crustacea, ancestor of,

Cuha

... 52

$\begin{array}{llll}\text { Cunningham } & \ldots & \ldots & 97\end{array}$

Cycads, male prothallialcells, 86

Cypripedium caudatum

Dahlia, double

Darwin, 1, 2, 4, 66, 81, 96, 103
Davis $\quad \ldots \quad \ldots \quad 16,45,82$

Dendy ... $\quad \ldots \quad 97,102$

Deutzia, double $\quad$... $\quad 62$

Dianthus, double $\quad$... 56

Dichromatism in birds $\quad 73$

Dighy ... ... ... 82

Digitalis, mutation in, 64,67

Digitalis purpurea montrosa 65 heptandra $\quad$... 67 mudicaulis $\quad . . .67$

pubescens $\quad$... 67

Dioscoides $\quad \ldots . \quad \ldots \quad 58$

Distribution $\quad 1,55,77,100$ of Partula $\quad$... 72

of Otus asio $\quad \ldots \quad 100$

of Peromyscus .... 101

Dodoens $\quad \ldots \quad \ldots \quad 58$

Dogs, hairless variety, $\quad \mathbf{7 4}$

Don $\quad \ldots \quad \ldots \quad \quad \ldots \quad 49$

Doncaster $\quad \ldots \quad \ldots . \quad 36$

Dorippe dorsipes $\quad$... $\quad 75$

Doubleness, inlseritance

of, 47,56

Doubling in flowers ... 47, 56

Draba verna $\quad . . \quad \ldots \quad 64$

Drosera, natural hybrid 11 dwarf variety $\quad 68$

Drosophila, chromosomes

lethal factors in of, $8,15,53,88$ mutations in, 14, 15 , $19,20,47,52,67$ non-disjunction in,

$8,9,17,35$

Duerden $\quad \ldots \quad 98,104$

Duplicate factors,

mutations, 12

Dwarfs, Drosera $\quad$... 68

Guirea-pigs $\quad$... 75

$\begin{array}{lll}\text { Matthiola } & \text {... } & 58\end{array}$

$\begin{array}{lll}\text { Partula } & \text {... } & 73\end{array}$

Eames $\quad \ldots \quad \ldots \quad 84$

Elasmobranch embryos, $\quad 79$

Empedocles $\quad . . \quad \ldots \quad 77$

Epharmosis ... $\quad . . \quad 3$

Ephemeridæ, modification

for aquatic life, 89

Epigaea, double $\quad$... 61

Epilobium $\quad \ldots . \quad \ldots 47,48$

Epipolasidæ ... $\quad \ldots \quad 1(12$ 
Erigeron ramosus, Pages variation in, 70

Farmer $\quad \ldots \quad \ldots 82,83$

Fasciation $\quad \ldots \quad \ldots .63$

Fernald $\quad \ldots \quad 67,68,70$

Fragaria Virginiana, variation in, 70

Fraser ... $\quad$... 32

Fritsch $\quad \ldots . \quad \ldots .82$

Frog, recapitulation in, 91 metamorphosis,

Frost, H. B. ... ... 57, 58

Fuchs $\quad \ldots \quad \ldots . \quad 58$

Fuchsia, double $\quad \ldots \quad 56$

Garrett

72

Gaylussacia resinosı,

variation in, 68

Geographical distribution,

of Otus asio, 100 of Peromyscus, 101

Gigantism $\quad 47,63,73,75$

Ginkgo, prothallial cells 86

Glen, Miss $\quad$... $\quad \ldots \quad 79$

Gnetales $\quad \ldots . \quad \ldots \quad 84$

Goats, variation in, ... 73

Gray, Asa, $\quad \ldots \quad 59,61,67$

Griffithsia, alternation

of generations in, 82,83

Guara alba, juvenile plumage, ... 103

Gudernatsch $\ldots, \quad \ldots, 92$

Gulick ... $\quad . . . \quad \ldots .72$

Guyer and Smith $\quad$... 98

Gymnosperms,

chromosomes of, ... 85

gametophyte of, $79,84,90$

orthogenesis in, ... 85

recapitulation in,

$84,86,87,88$

Hance, $24,26,30,31,32,33$

Harper,

Harrison $\quad \ldots .60 \%$

Hawaii ... $\quad \ldots . \quad \ldots \quad \quad 72$

Helianthus, variation in, 71

Helix, variation in, ... 73

Helminthophila $\quad \ldots \quad 55$
Hemiramphius ... Pages

Hepatica, double, $\quad$... 75

Heribert-Nilsson $\quad \ldots . \quad 14$

Hermannus $\quad \ldots \quad \ldots . \quad 45$

Herodotus $\quad \ldots .6 \quad \ldots . \quad 74$

Heterochrony ... $\quad \ldots .91$

Histophorus gladius $\quad . . \quad 74$

Hooper ... ... ... 73

Hormones $\quad \ldots \quad \ldots . \quad 5$

Hornlessness, in cattle, 74

Howard... ... ... 13

Hus $\quad \ldots \quad \ldots 6 \quad \ldots 68,70$

Hutchinson $\quad \ldots \quad \ldots \quad 86$

Hyatt $\ldots . \quad \ldots \quad \ldots \quad 100$

Hybridisation ... ... 4, 22

Hyde $\quad . . \quad \ldots \quad \ldots \quad 52$

Inleritance, functional, 98 of acquired characters, 76,94

$\begin{array}{lllll}\text { Jeffrey } & \ldots & \ldots & \ldots & 87\end{array}$

Jerusalem Artichoke ... 71

Jones ... $\quad \ldots . \quad \ldots \quad 65$

Juvenile plumage of birds, 103

Kalmia, variation in, ... 67

Kammerer $\quad \ldots \quad$... 95

Karyogenetic

characters $77,91,103$

Keeble ... $\quad . . \quad \ldots \quad 65$

Kerner ... $\quad . . \quad \ldots \quad 62$

Laciniation $\quad . . \quad \ldots \quad \mathbf{7 0}$

Lamarckian factor, 1, 2, 96, 97

Lancashire $\quad . . \quad \ldots \quad 52$

Lang, A. $\quad \ldots \quad \ldots \quad 73$

Lang, W. H. ... ... 78, 82

Lankester $\quad \ldots . \quad \ldots \quad 91$

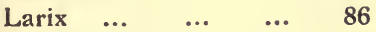

$\begin{array}{llll}\text { Lemberg } & \ldots & \ldots & 69\end{array}$

Lepidoptera,

melanism in, $\quad 75,97$

Leptospermum Scoparius, variation in,

Lethal factors, $\quad 20,45,57$

Lewis ... ... ... 82, 83

Linaria alpina, variation in, 66

Linaria vnlgaris $\quad \ldots 64,66$

Linnæus $\quad \ldots \quad \ldots 45,64$

Lodewijks $\quad \ldots \quad \ldots \quad 63$ 
Loeb $\quad \ldots \quad \ldots \quad \ldots \quad \ldots \quad \begin{array}{r}\text { Pages } \\ 78\end{array}$

Lutz, Miss, 11, 24, 27, 28,

$30,32,33$

MacBride $\quad \ldots \quad 89,90,96$

MacDougal $\quad \ldots \quad 11,49,50$

Maianthemum species $\quad 55$

Maize, origin of, $\quad$... 71

$\begin{array}{llll}\text { Makino } & \ldots & \ldots & 62\end{array}$

Maryland $\quad \ldots \quad \ldots \quad 50$

Massachusetts $\quad \ldots 49,50$

Matthiola $\quad . . \quad \ldots \quad 67$

inheritance of doubles, 57, 68

plastid colour $\quad$... 57

dwarfs $\quad \ldots . \quad \ldots . \quad 58$

May, H. G. $\quad$.. $\quad \ldots \quad 21$

Meconopsis, double $\quad$... 56

Meehan, Thomas $\quad \ldots 60,61$

Melanism in Lepidoptera

75,97

Melanthaceæ $\quad$... 55

Melica sativa, variations in 68

Melopelia leucoptera, wing

pattern of, 104

Mendelian factor mutations 15

Mentha aquatic: $\quad$... 64

Metapodius $8,17,39,42,88$

Metschnikoft $\quad . . \quad \ldots \quad 92$

Metz $\quad \ldots \quad 36,52,53$

Mexico $\quad$... $\quad . . \quad 59$

Microtus, mutation in, $\quad 75$

Missouri $\quad$... $\quad$... 50

Miyoshi $\quad \ldots \quad 62,63,64$

Monstrosities ... $\ldots 74,75$

Moore, А. H. ... ... 68

Morgan, 14, 15, 19, 20,

$$
21,36,37,52,100
$$

Morphogenesis in plants

$\begin{array}{ccrr}\text { Morse } & \ldots & \ldots & 92,93 \\ \text { Muller } & \ldots & \ldots & 18,45 \\ \text { Mutations } & . . & \ldots & 43 \\ \text { and chromosomes, } & 53 \\ \text { arising at fertilisation, } & 17 \\ \text { in animals } & \ldots & 72 \\ \text { in Drosophila, } & 19 & 20,\end{array}$

in Drosophila, 19 20,

in instinct $\quad \ldots \quad 74$

in wild plants $\ldots .55$

parallel, $43,52,60,66,67$

presumptive $\quad . . \quad 55$

tetraploid $\quad \ldots 17,47$

triploid $\ldots . \quad \ldots \quad 17$

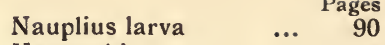

Nawaschin $\quad \ldots \quad \ldots . \quad 33$

Neo-Lamarckian factor 96,101

Newfoundland , ... 70

New Zealand $\quad$... 65

Nilsson-Ehle $\quad$... 13

Non-disjunction in

Drosophila $8,9,35$

in Staphylea pinnata 33

$\begin{array}{llll}\text { Norton } & \ldots & \ldots & 56\end{array}$

Nova Scotia $\quad \ldots \quad \ldots \quad 50$

Nuclei in beredity '... 80

Nuttall $\quad$... $\quad \ldots \quad 49$

Enothera $\quad \ldots \quad 5,86,88$

aberrans $\quad \ldots \quad \ldots 30,33$

albida $\quad \ldots \quad \ldots 29,30$

atrovirens $\quad . . \quad$... 50

biennis, 6, 22,

$28,43,44,45,46,49$

biennis leptomeres,

$43,44,49,51$

biennis sulphurea, 44, 45, 46

bipartita $\quad \ldots . \quad \ldots \quad 29$

brevistylis $\quad \ldots . \quad \ldots . \quad 16$

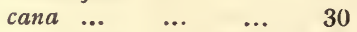

cleistantha $\quad . . \quad-\ldots .50$

columbiana ... $\quad$... 52

cruciatı $\quad 47,48,49,50$

var. varia ... $\quad . . \quad 49$

$\begin{array}{llll}\text { elliptica } & \ldots & \ldots & 29\end{array}$

erythrina $\quad . . \quad \ldots . \quad 29$

exilis ... $\quad \ldots \quad 24,26,29$

exundans $\quad \ldots \quad 24,26,29$

gigas, $10,15,18,42,43,46,78$

nanella $\quad$... ... 11, 15

grandiflora $\quad . . \quad \ldots 13,97$

incurvata $\quad . . \quad$... 24, 28

lactuca $\quad$... $\quad$... 30

lavifolia $\quad \ldots . \quad \ldots 43,44$

Lamarckiana 6, 14, 16, 18, $24,26,27,28,29,30,33,43$ var. cruciata $\quad \ldots 48,49$ lata, $6,7,8,9,10,20,24,25$, $27,28,29,30,31,33,34$, $35,43,44,46$.

liquida $\quad$... $\quad . . \quad 30$ nanella $\quad \ldots 18,26,43,44$

Oakesiana $\quad . . \quad \ldots \quad 51$

oblonga $\quad \ldots . \quad \ldots 27,29$

pallescens $\quad . . \quad \quad \ldots \quad 30$

practincola $\quad . . \quad \quad \ldots . \quad 43$

Robinsonii $\quad . . \quad \ldots \quad 51$ 


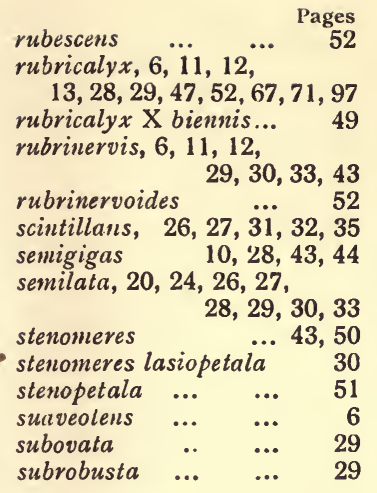

Pædogenesis $\quad \ldots \quad$... 93

Parallel induction ...99, 97

Partula, mutations in,... 72, 73

Pediastrum colonies ... 98

Pellew, Miss ... $\quad . .65$

Peloria, origin of, $\quad \ldots 64,74$ inheritance of, 65

$\begin{array}{llll}\text { Pentacrinus } \quad \ldots & \ldots & 90\end{array}$

Peripatus capensis $\quad$... 79

Peromyscus, mutations in, 75, 101

Perrier and Gravier ... 91

Petunia, double $\quad$... 57

Phyllocladus, recapitulation

in, 86

Picea, prothallial cells, $\quad 86$

Pigeons, evolution in, ... 103

Pinus, prothallial cells, $\quad 86$

Plegadis autumnnlis ... 103

$\begin{array}{llll}\text { Plough } & \ldots & \ldots & 17\end{array}$

Polymorphism $\quad$... 66

Polysiphonia, alteruation

Poulton of generations in, 82

$\begin{array}{llll}\text { Primula } & \ldots & \ldots & \ldots \\ & & & \end{array}$

Prince Edward Island $\quad 68$

Prunus, double $\quad$... 63

Punnett $\quad \ldots \quad 18,19,74$

Quebec ... ... ... 68, 70

Raciborski $\quad \ldots \quad \ldots 69$

Rana $\quad \ldots \quad \ldots 92,95$

Ranunculus $\quad \ldots . \quad \ldots \quad 55$ doubles $\quad \ldots \quad \ldots 61$

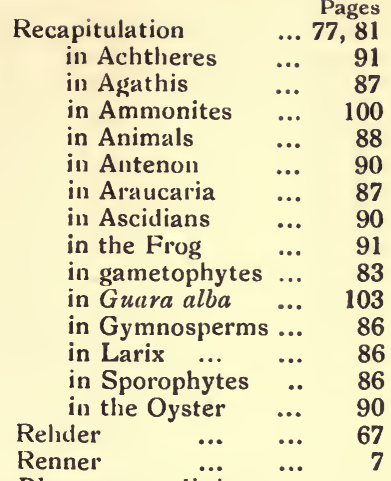

Rhamnus caroliniana, variation in, 70

Rhododendron, recapitulation in, 87 double $\quad \ldots \quad \ldots \quad 62$ white $\quad \ldots . \quad \ldots .62$

Rhus toxicodendron,

variation in, 68

$\begin{array}{llll}\text { Ritter } & \ldots & \ldots & \mathbf{7 8}\end{array}$

Roherts $\quad \ldots . \quad \ldots \quad 96$

Rosenberg $\quad \ldots . \quad \ldots \quad 88$

$\begin{array}{llll}\text { Ruellius } & \ldots & \ldots & 58\end{array}$

Russell, E. S. ... $\quad \ldots \quad 99$

Sagittaria, double $\quad$... 62

$\begin{array}{llll}\text { Sakamura } & \ldots & \ldots & 32\end{array}$

Sargent, C. S. ... $\quad \ldots \quad 67$

Saunders, Miss, 50, 57,

Saxifraga Virginiensis, $58,59,66,67$
S. chlorantha $\quad \ldots \quad 60$
S. crassifolia $\quad \ldots \quad 60$
S. granulata $\quad \ldots \quad 60$
S. pentadecandra ... 60

Schleiden and Schwann $\quad 79$

$\begin{array}{llll}\text { Schouten } & \ldots & \ldots & 15\end{array}$

Sedgwick $\quad \ldots \quad \ldots 797$

Sensberg $\quad \ldots \quad \ldots \quad 61$

$\begin{array}{lll}\text { Sequoia gigantea } & \ldots & 86\end{array}$

Sexual selection $\quad \ldots \quad 104$

Shull

$13,14,50,67$

Significance of larval stages, 89

Silene antirrhina, variation in, 70 
Simocephalus vetulus ... $\quad \begin{array}{r}\text { Pages } \\ 94\end{array}$

Singleness, inheritance of, 57

Siphonogamy ... $\quad \ldots \quad 84$

$\begin{array}{lllll}\text { Small } & . . & \ldots & \ldots & 55\end{array}$

Snapping turtles $\quad \ldots \quad 99$

$\begin{array}{lllll}\text { Snell } & \ldots & \ldots & \ldots & 32\end{array}$

Society Islands... $\quad \ldots . \quad 72$

Sollas, Miss ... $\quad \ldots .75$

Sowerby $\quad \ldots . \quad \ldots .58$

Species and varieties ... 55

Species cell $\quad \ldots \quad \quad \ldots . \quad 78$

Spiræa ... $\quad \ldots . \quad \ldots . \quad 55$

Spiranthes, pair of species, 55

Sponges, evolution in, 102

Sporogenesis,

relation to sporophyte, 93

Staphylea pinnata,

$\begin{array}{lccc}\text { Stebbing } & \ldots & \ldots & 75 \\ \text { Sterns } & \ldots & \ldots & 60\end{array}$

Stocks, see Matthiola.

Stomps $\quad \ldots \quad 7,43,44$

Stone $\quad . . \quad \ldots . \quad \ldots .67$

Streptopus, pairs of species, 55

Sturtevant $\quad . . \quad$... 52

Sumner $\quad \ldots .77,101$

Sunflower, see Helianthus.

Sutton, Miss ... ... 59

Tachygenesis ... $\quad \ldots \quad 91$

Tadpoles, adaptation in, 91

Tahiti.... ... ... 72

Tennessee $\quad . . \quad \ldots .73$

Tephrosia, melanism in, 97

Tetraploidy $\quad . . . \quad \ldots . \quad 47$

Thalictrum, double $\quad . .6 \quad 60$

Thistleton-Dyer $\quad$... 87
Tiarella cordifolia,

Pages variation in, 68

Tobacco, double flowers 63

Trichodragmata $\quad$... 102

Trillium, species $\quad$... 55 double $\quad \ldots .62$

Trochophore larva $\quad \ldots \quad 90$

Tupper... $\quad . . \quad \ldots \quad 78$

Uropedium Lendenii: ... $\quad 64$

Variations, Weismann's conception, ... 94

Vegetative segregation $\quad 49$

Veliger larva ... ... 90

Vicia Faba $\quad$... $\quad$... 32

Viola tricolor, variation in, 64

Violets, double $\quad . . . \quad 58$

de Vries, 2, 6, 11, 15, 16, 17, 27,

$28,29,43,45,46,49,64,86$

Wallflower, see Cheiranthus.

Weismann _.. .. 78,94

Weiss, F. E. ... ‥ 77

Whitman $\quad 4,80,103,104$

Wilson $\quad 8,17,39,42,88$

Winge $\quad$... $\quad . . \quad 33$

Yamanouchi $\quad \ldots \quad \ldots 82,83$

Yosemite $\quad . . \quad \ldots 6 \quad 86$

$\begin{array}{llll}\text { Zioberg } & \ldots & \ldots & 64\end{array}$

Zoaea larva $\quad$.. $\quad \ldots \quad 90$

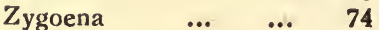






\section{Published by WILLIAM WESLEY \& SON, London.}

\section{The New Phytologist,}

A British Botanical Journal.

Edited by A. G. TANSLEY, M.A., F.R.S.,

University Lecturer in Botany, Cambridge.

In consultation with the Staff of the Cambridge Botany Sichool.

THE NEW PHYTOLOGIST was founded in 1902 to afford a medium for the publication of original papers, critical articles and reviews, summaries of recent advances in botanical lnowledge, and occasional notes and correspondence on botanical topics. Preference is given to those contributions dealing with matters of general interest to botanists and to those branches of science undergoing rapid current development. The journal is well illustrated, and is issued each year in five numbers. The minimum size of the annual volume is 240 pages $8 \mathrm{vo}$. Annual subscription price, as from the beginning of of 1921,615 s. post free. Separate numbers $7 s .6 d$. each.

Vols. $1,3,6,7,10,11$ and 12 are out of print. Vols. $2,4,5,8,9,13-19, £ 15$ s.

\section{New Phytologist Reprints.}

No. 6. The vegetation OF JAP.N. By H. Takbda. Pp. 21. Price 2s. net.

No. 7. THE INTER-RELATIONSHIPS OF THE FLAGELLATA AND PRIMITIVB ALGA. By F. CAvbrs. Pp. vi and 52, with Literature List and Phylogenetic Tables, and numerous Figures in the Text. Price 4s. net.

No. 8. THE Classification OF CONIfERS. By W. T. Saxton. Pp. 2l, with Bibliography and a Phylogenetic Table. Price 2s. net.

No. 9. A REVIEW OF LITERATURE CONCERNING THE EVOLUTION OF MONO. COTYLEDONS. By N. Bancropt. Pp. 24, with Bibliography and 4 Diagrams. Price 2s. net.

WILLIAM WESLEY \& SON, 28, Essex Street, Strand, London, W C.2. 


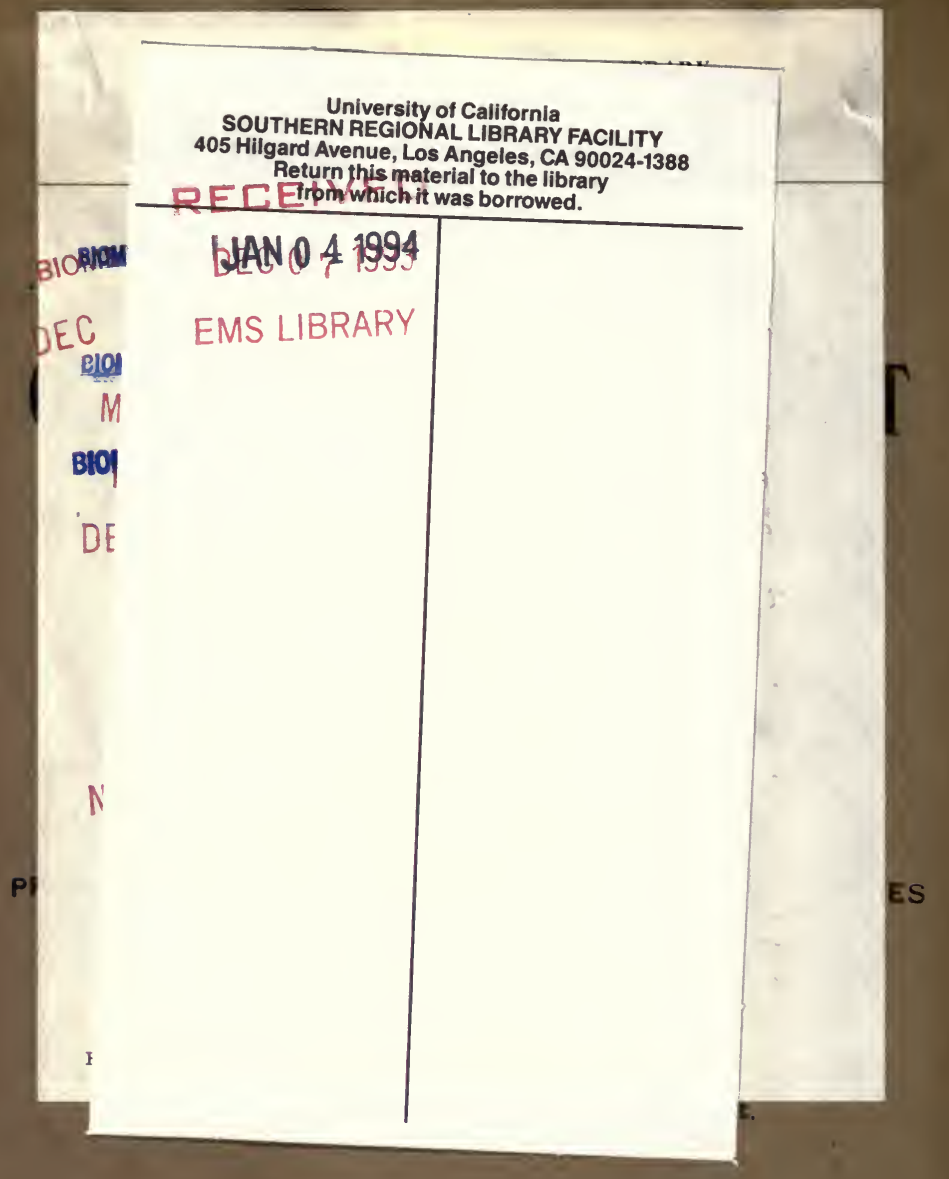

Naturc, (10th June, 1920) says:

"His contribution to the investigation of the origin and deyelopment of the family is by far the most important that has appeared for many years.

Conclusions are drawn to the effect that the Senecionex are the most primitive type of the famly and that from them directly or indirectly, and ultimately from Senecio itself, as the basal genus from which the Senecionea arose there sprang all the other tribes and genera of the family. This is very strikingly confirmed by a study of the geographical distrubution."

WILLIAM WESLEY \& SON, 28, Essex Street, Strand, LONDON, W.C.2. 
1

Universit

Southe

Libra 